\title{
A domestication history of dynamic adaptation and genomic deterioration in sorghum.
}

Oliver Smith ${ }^{1,2}$, William V Nicholson ${ }^{1,3}$, Logan Kistler ${ }^{1,4}$, Emma Mace $^{5}$, Alan Clapham ${ }^{1}$, Pamela Rose ${ }^{6}$, Chris Stevens ${ }^{7}$, Roselyn Ware ${ }^{1}$, Siva Samavedam ${ }^{1}$, Guy Barker ${ }^{1}$, David Jordan ${ }^{8}$, Dorian Q Fuller ${ }^{7}$, Robin G Allaby ${ }^{1 *}$.

1. School of Life Sciences, University of Warwick, Coventry, CV4 7AL, United Kingdom.

2. Natural History Museum of Denmark, Øster Voldgade 5-7, 1350 København K, Denmark.

3. Warwick Medical School, University of Warwick, Coventry, CV4 7AL, United Kingdom.

4. Department of Anthropology,4. Smithsonian Institution, National Museum of Natural History, Washington, D.C. 20506, USA.

5. Department of Agriculture, Fisheries and Forestry Queensland (DAFFQ), Warwick, Queensland 4370, Australia.

6. The Austrian Archaeological Institute, Cairo Branch, Zamalek, Cairo, Egypt 7. Institute of Archaeology, UCL, London, United Kingdom

8. Queensland Alliance for Agriculture and Food Innovation, The University of Queensland, Warwick, Queensland 4370, Australia.

* Corresponding author 


\begin{abstract}
The evolution of domesticated cereals was a complex interaction of shifting selection pressures and repeated introgressions. Genomes of archaeological crops have the potential to reveal these dynamics without being obscured by recent breeding or introgression. We report a temporal series of archaeogenomes of the crop sorghum (Sorghum bicolor) from a single locality in Egyptian Nubia. These data indicate no evidence for the effects of a domestication bottleneck but instead suggest a steady decline in genetic diversity over time coupled with an accumulating mutation load. Dynamic selection pressures acted sequentially on architectural and nutritional domestication traits, and adaptation to the local environment. Later introgression between sorghum races allowed exchange of adaptive traits and achieved mutual genomic rescue through an ameliorated mutation load. These results reveal a model of domestication in which genomic adaptation and deterioration was not focused on the initial stages of domestication but occurred throughout the history of cultivation.
\end{abstract}

\title{
Keywords
}

Ancient DNA, archaeobotany, bottleneck, introgression, genomic rescue 
The evolution of domesticated plant forms represents a major transition in human history that facilitated the rise of modern civilization. In recent years our understanding of the domestication process has become revised considerably (1). In the case of cereals it has been recognized that the selective forces that give rise to domestication syndrome traits such as the loss of seed shattering were generally weak and comparable to natural selection $(2,3)$ and that the intensity of selection pressures changed over the course of time as human technology evolved (4). Furthermore, domesticated lineages have often been subjected to repeated introgressions from local wild populations that endowed adaptive traits and obscured historical signals in the genome (5). Such complexity obfuscates attempts to reconstruct the evolutionary history of domesticated species from modern plants. To counter these confounding factors in this study we directly tracked the evolutionary trajectory of a domesticated species, sorghum (Sorghum bicolor ssp. bicolor (L.) Moench.), through the archaeological record. This approach enabled the identification of selection pressures not clear today, and the tracking of the introgression process, revealing a domestication history which runs counter to the expectations of the current conventional model of domestication.

Sorghum is the world's fifth most important cereal crop and the most important crop of arid zones (6) used for food, animal feed, fibre and fuel. The evolution of sorghum has seen its transition from being a wild pluvial plant in north-eastern Africa (S. bicolor ssp. verticilliflorum (Steud.) De Wet ex Wiersema \& Dahlberg, hereafter referred to as $S$. verticilliflorum for clarity) to the ancestral domesticated 
form Sorghum bicolor type bicolor in Central Eastern Sudan by around 5000 years ago, while cultivation is inferred to have begun by 6000 yrs BP (7)., Ultimately, four specialized agroclimatic adapted types evolved after domestication—durra, caudatum, guinea, and kafir (8-10). The derived types were likely founded on introgressions of the wild progenitor complex Sorghum verticilliflorum or closely related species into the ancestral bicolor type, endowing traits such as drought tolerance in the case of type durra $(8,11)$. The evolutionary history of sorghum, replete with introgression, is difficult to reconstruct from modern datasets. However, a temporal series of archaeobotanical domesticated sorghums spanning back to 2100 before present (yrs BP) at the archaeological site of Qasr Ibrim, situated on the Nubian frontier of northern Africa, affords the opportunity to track this complex crop directly through time removing the obscuring effects of introgression (12). Prior to this wild sorghum is present at Qasr Ibrim from at least ca. 2800 yrs BP. Domesticated sorghum (race bicolor) appears at the site ca. 2100 yrs BP. After this time period phenotypically domesticated sorghum of the ancestral type bicolor occurs throughout all cultural periods until the site was abandoned 200 years ago. During the early Christian period at 1470 yrs BP, the oldest known drought-adapted, free-threshing durra type appears at the site and occurs there for the rest of the site's occupancy. The origins of the durra type are unclear. Current distributions in northern and eastern Africa and its dominance in the Near East and South Asia led to the proposal that durra originated on the Indian subcontinent (13) and returned to Africa at some point after 2000 yrs BP (14). 


\section{Results}

\section{Genetic diversity of sorghum over time}

To gain a longitudinal insight into the evolutionary history of sorghum, we sequenced 9 archaeological genomes from different time points at Qasr Ibrim, including a wild phenotype from 1765 yrs BP and 8 domesticated phenotypes between 1805 and 450 yrs BP, a further 2 genomes from herbarium material, and 12 genomes of modern wild and cultivated sorghum types representing the varietal range (Table S1, S2).

We investigated how genetic diversity has changed through time by measuring within genome heterozygosity of $100 \mathrm{kbp}$ genomic blocks that revealed a pattern of broad variation in heterozygosity in the wild progenitor $S$. verticilliflorum that became progressively narrower over time in the ancestral bicolor type, Figure S1. Interestingly, the wild phenotype of sorghum at Qasr Ibrim (sample A3) has a narrower variation in heterozygosity than the wild progenitor (represented by modern wild diversity), suggesting that it had been already been subject to genetic erosion. Conversely, the durra types all showed similar low levels of genomic variation in heterozygosity suggestive of genetic erosion prior to their appearance at Qasr Ibrim. Total genomic heterozygosity of bicolor over time confirmed that the 'wild' sorghum had already undergone considerable genetic erosion relative to the wild progenitor. To our surprise, the decreasing trend in heterozygosity over time fits a linear model ( $p$ values 0.0041 and $9.2 \times 10^{-6}$ for parameters $a$ and $b$ respectively) better than an exponential model ( $p$ values 0.042 and $\left.9.3 \times 10^{-5}\right)$ as would be expected from an early initial 
loss of diversity through a domestication bottleneck (15), Figure 1, Table S3 suggesting that there was no measurable effect on genetic diversity attributable to a domestication bottleneck.

\section{Mutation load over time in Sorghum}

The apparent lack of a domestication bottleneck runs contrary to expectations for a domesticated crop. To investigate the apparent lack of a domestication bottleneck further, we considered the mutation load. An expected consequence of the bottleneck is a rise in mutation load as small populations incorporate deleterious mutations through strong-acting drift. High mutation loads have generally been observed in domesticated crops (16-18), which have been taken as a confirmation of the effects of the domestication bottleneck. We measured the mutation load over time in the archaeological sorghum using a genome evolutionary rate profiling (GERP) analysis considering the total number of potentially deleterious alleles (19) (see methods), Figure 2. As with other domesticated crops, modern sorghum has a higher mutation load than its wild progenitor under both recessive and additive models. In contrast to the expectations of a domestication bottleneck we did not observe an initial large increase in mutation load associated with domestication, but rather an overall increasing trend in mutation load over time to the present day suggesting a process of load accumulation combined with selective purging episodes. In this case the trend line is best described by a positive exponential model rather than a linear model, Table S3, indicating mutation load has become increasingly 
problematic in recent times. However, the p-values suggest that the coefficient for the time in each model is only weakly significant, which could be the result of multiple processes on going, such as a strong increase in the rate of mutation load accumulation in recent times. When we considered the number of sites containing deleterious alleles (dominant model) rather than total number of deleterious alleles we observe a decreasing trend over time (Figure S3). This pattern suggests that part of the rising mutation load in the bicolor type was due to the increased homozygosity over time causing fixation of deleterious alleles originating from the wild progenitor pool. There is variation over time in mutation load, most notably in 1805 year-old sorghum (sample A5) that shows a sharp increase due to the incorporation of strongly deleterious alleles, both in the total number of alleles and number of sites. Interestingly, we found that the durra types show a pattern that contrasts to the bicolor type with relatively little change in heterozygosity and a significant fall in mutation load over time, suggesting the purging of deleterious mutations either through selection or genomic rescue through hybridization (Figure S2, S3). The contrasting patterns in mutation load over time are also reflected in methylation state profiles, which can reflect the state of genome-wide stress (20), Figure S4.

\section{Signals of selection in sorghum}

We considered that episodes of selection could have contributed in part to the variation in mutation load observed over time, either through reducing population size due to the substitution load or through hitchhiking effects. Three approaches 
were used to identify candidate regions under selection. Firstly, we surveyed for wild/domestication heterozygosity to look for significant reduction in heterozygosity in domesticates, which revealed 30 peaks of genome-wide significance (denoted by prefix pk), Figure 3, Table S4, S5. We also specifically surveyed 38 known domestication loci and also found a significant reduction of heterozygosity in 15 of the 38 associated regions, Table S6. Secondly, we used a SweeD analysis to detect selective sweeps (21), which identified 11 peaks (denoted by prefix s), Figure 3, Table S7. In the third approach we utilized the temporal sequence of archaeogenomes to investigate episodes of selection intensification by considering the gradient of heterozygosity change over time (see methods). In this latter approach we tracked the gradient of change in the heterozygosity of regions identified in the first two approaches and assigned significance based on the gradient deviation from the genome average for each type. We considered multiple time sequences representing alternative possible routes through contemporaneous genomes over time within type bicolor and type durra respectively. This revealed a period of selection intensification associated with domestication loci prior to 1805 yrs BP, followed by oscillations in diversity, Table S8, Figures S5-S7.

Together, the selection identification approaches exploit a range of different types of signature left by selection, and reveal a complex and dynamic history of selection over time summarized in Figure 5. We generally found more evidence for selection in the bicolor type sorghum than the durra type. Despite its apparent wild phenotype, the wild sorghum (A3) at Qasr Ibrim from 1765 yrs BP shows 
evidence of selection at domestication loci concerned with architecture (int1, tb1), suggesting possible introgression with contemporaneous domesticated forms (represented by sample A5) that could have contributed to reduced heterozygosity. Interestingly, the intensification signals show some overlap between samples A3 and A5 (int1 and ae1), with A5 showing further evidence for selection at shattering, dwarfing and sugar metabolism loci (Sh3/Bt1, dw2 and SPS5) that would contribute to the domesticated phenotype of A5 relative to A3. Subsequent to this a period of intensification in selection is apparent both for dwarfing and sugar metabolism traits (710-715 years BP) in the bicolor type, with ten domestication loci showing significantly low levels of heterozygosity in this lineage by 710 yrs BP in A7. In the bicolor type, two of the sugar metabolism associated gene families show evidence of early selection controlling photosynthetic sucrose production first (SPS) and then an intensification of selection for breakdown (SUS). A third gene family (SUT) associated with sucrose transport appears to come under later selection in bicolor. In contrast, fewer domestication loci were found to show evidence of intensifying selection in the durra type, and none showed evidence of low heterozygosity. In this case we detected signals for an intensification of selection on tillering and maturity associated loci (gt1, ma3, the latter also being detected using SweeD s1 in the bicolor lineage). Significant heterozygosity reduction was identified in windows containing a large number of disease resistance loci (pk4, pk11, pk15, pk20, pk24, pk25) as well as sugar metabolism loci (pk14, pk18, pk19, pk22) in the bicolor type. One of SweeD peak (s2) was closely matched to pk5 on 
chromosome 2 in the 54.0 - 54.2 Mbp interval, possibly indicating signatures for the same selection process. This region shows a consistently low heterozygosity over time in the bicolor type with the notable exception of the 1805 year old sorghum (A5). The region contains the far-red impaired response genes (FAR1), as well as anther indehiscence $1(A / 1)$. The FAR1 gene is associated with phytochrome A signal transduction (22), so is important in responses to far red light that divert resources away from tall growth to increase root and grain growth. The Al1 gene regulates anther development (23), allowing earlier development. Either of these genes may be locally adapted to the Qasr Ibrim environment since they already appear to be under intense selection in the wild sorghum at this site (sample A3), but not apparently under as much constraint in modern sorghum type bicolor.

The dynamic selection over time detected with most intensification of selection occurring before 1805 years BP, appears to correlate with a sharp increase in mutation load in the bicolor type. In contrast, the durra type shows much less evidence of selection and on arrival at Qasr Ibrim shows initially similar levels of mutation load to the bicolor type that then decreased over time (Figure S3). To investigate whether loci of selection are associated with higher regions of mutation load we measured the maximum deviations between genomes in GERP load scores across the genome and compared those to the locations of selection peak candidates (Figure 3, Table S9). Selection signatures were highly significantly associated with regions of maximum deviation in mutation load with $30 \%$ of low heterozygosity peaks ( $\left.p 8.04 \times 10^{-9}\right), 45 \%$ SweeD 
peaks $\left(p 2.55 \times 10^{-7}\right)$ and $26 \%$ domestication loci $\left(p 5.03 \times 10^{-5}\right)$ occurring in such regions. The intensification of selection is associated with increased mutation load and could explain the spike in mutation load observed in the 1805 year old sorghum (sample A5).

\section{Genome rescue through hybridization}

We considered that the decreasing mutation load observed in the durra type could be due to a genomic rescue caused by hybridization with the local bicolor type. To investigate for evidence of hybridization we first constructed a maximum likelihood phylogenetic tree of wild and cultivated total genomes (Figure S8), and individual trees for 970 sections across the genome (Supplementary data set 1). After accounting for biases introduced by ancient DNA modification, both the durra and bicolor type from Qasr Ibrim form a single clade to the exclusion of modern bicolor and durra types, suggesting they have indeed hybridized over time. D-statistic analysis for introgression (24) shows over time the durra type became increasingly similar to the local bicolor type, suggesting progressive introgression between the two types (Figure S9). We then compared the archaeological genomes against a global sorghum diversity panel $(25,26)$ (Figure 4). The archaeological genomes are distributed along an axis of spread that has Asian durra types at the extremity. The oldest archaeological durra type (A11) sits between East African durra types and Asian durra types, whilst the wild phenotype sorghum, most closely aligned to the subsequent type bicolor, sits close to the center of the PCA, suggesting East African durras may have arisen 
from a hybridization between Asian durra and African bicolor. The oldest archaeological durra type in this study (sample A11) may represent one of the earliest of the east African durras. The younger archaeological genomes of the two types become progressively closer on the PCA supporting a process of ongoing hybridization between the two types over time.

Finally, we investigated whether the hybridization between the bicolor and durra types led to adaptive introgression or genomic rescue. Phylogenetic incongruence between the bicolor and durra type clades suggests that hybridization was frequent at loci under selection (Table S10). In agreement with previous studies (10) there is clear evidence for a donation of the dwarfing $d w 1$ allele from durra to bicolor with a single durra type sample sitting within the bicolor type clade in this region, but in most cases although the clades of bicolor and durra have become mixed, it is not sufficiently clear which is the more likely donor. Interestingly, seven of the nine sugar-metabolism associated loci potentially under selection in the bicolor type are also areas of introgression with durra. In all cases where identified was possible (su, SUS1 and SPS3), durra was identified as the donor. However, in the case of SPS5 in which we identified early intensification of selection in the bicolor type, no phylogenetic incongruence occurred. Conversely, at the maturity locus ma3 containing region, the durra type A11 that was identified as potentially under selection sits within the bicolor clade suggesting a donation from bicolor to durra. The FAR1/Al1 loci region, which appears to have been under strong selection in bicolor throughout, appears to have been donated from bicolor to durra. 
Assuming that prior to the introduction of the durra type to Qasr Ibrim the two types, bicolor and durra, had accrued mutation loads independently, then hybridization would have afforded the opportunity for genomic rescue between the two types. We therefore considered all ancestor/descendent pairs of genomes within the bicolor and durra type lineages in the context of a third potential donor genome, and scanned all sites for comparative GERP load scores under the additive model. We calculated firstly the difference in GERP load scores between the ancestor and potential donor to give a 'total rescue value' that reflects a donor's potential to reduce mutation load across the entire genome, Figure 5. We secondly assessed the donor's potential to effect mutation load reduction specifically at only those sites in which there had been a reduction in GERP load score between the ancestor and descendent to give an 'on target rescue value'.

In the case of durra sample A11 (1470 yrs BP) as ancestor and A9 as descendent, bicolor samples A6 (715 yrs BP) and A7 (710 yrs BP) are intermediate in age and therefore potential donor genome types from the bicolor lineage. The analysis predicts that either A6 or A7 would have reduced load in the regions that were observed to be reduced in the descendent $A 9$ (505 yrs BP), but an overall detrimental effect to genome wide load, which is in fact observed (Figure S3). However, had earlier bicolor types been available for introgression, such as A5 (1805 yrs BP), then hybridization would have been more beneficial for the durra types. Generally, there is strong rescue potential of bicolor types by durra on the sites that were observed to improve, however in most cases there is 
an expectation that the over all load would be increased from the transfer of durra specific load to bicolor. Notably, durra types in general are predicted to reduce the on target load and genome wide load in $A 7$, which is observed (Figure S3).

\section{Discussion}

This study demonstrates that sorghum represents an alternative domestication history narrative in which the effects of a domestication bottleneck are not apparent, mutation load has accrued over time probably as a consequence of dynamic selection pressures rather than a domesticationassociated collapse of diversity, and that genomic rescue from load occurred when two different agroclimatic types met.

The linear nature of the decreasing trend in diversity over time observed in sorghum in this study is surprising. An extreme bottleneck early in the history of would be expected to lead to a negative exponential trend as diversity is rapidly lost in the early stages of domestication. An alternative explanation for the trend could be that diversity has been lost steadily through drift over time. However, a simple drift model shows that such a ten-fold loss in diversity would also be associated with a negative exponential trend, Figure S11. It is possible that diversity loss could have been supplemented by gains through introgression from the wild over time, counteracting the trend made by drift. Sample A3 could be the result of a wild introgression event since there are older domesticate phenotypes in the archaeobotanical record, such as sample A5. Sorghum is known for its 
extensive introgression leading to a strong regional structure within cultivars (10), making continuous introgression seem like a plausible scenario for sorghum at Qasr Ibrim. Incorporation of three systems of introgression into the simple drift model in which introgression is either constant, diminishing or increasing over time still results in a non-linear trend, which become parabolic when introgression becomes very high over time (not shown), Figure S11. We therefore think it unlikely that a model of constant drift and introgression is causative of the apparent linear decrease in diversity over time observed in this study.

Such linear decreases in diversity have been observed in human populations with increasing geographic distance from Africa and are most robustly explained by sequential founder models (27). The annual cycle of crop sowing and harvesting also represents a serial founding event scenario. A simple model of founding events in which $25 \%$ of the harvest is set aside for sowing based on field experiments (28) demonstrates that loss of genetic diversity approximates a linear process as populations become large, Figure S12A, and that the gradient of diversity loss is highly correlated with the populations size, Figure S12B. On the basis of the gradient of diversity loss observed in sorghum, this model predicts a long-term population size of 289,407 for the sorghum in this study. This estimate is in excess of the effective population size estimated from the heterozygosity of wild sorghum, 135,823 . It therefore seems plausible that in the case of sorghum diversity has likely been lost through a series of sequential founding episodes based on the cropping regime in a process that likely 
incorporated all the available wild genetic diversity at the outset rather than a substantial initial domestication bottleneck.

The deleterious effects of mutation load are becoming increasingly apparent and a major problem in modern crops such as the dysregulation of expression in maize (29). The study here demonstrates the potential immediacy of the problem in that mutation load may generally be a consequence of recent selection pressures leading to an exponentially rising trend rather than a legacy of the domestication process. While the general trend of the archaeogenomes is for the increase in the number of sites homozygous for deleterious variants (recessive model), the overall trend for the number of sites holding deleterious variants decreases (dominant model), which suggests a process of general purging of variants from the standing variation of the wild progenitor combined with the rise of homozygosity with decreasing diversity of the variant sites that remain.

However, this is sharply contrasted by modern sorghum in which there is a leap in the number of sites holding deleterious mutations (dominant model). This process contributes to the accompanying jump in load under both the recessive and additive models in modern sorghum. This indicates a large influx of new deleterious variants within the last century giving the trend of mutation load accumulation an exponential shape. It is likely that this influx of mutation load is the product of recent breeding programs and the genetic bottlenecks associated with the Green Revolution. The accumulation of load has previously been associated with mutation meltdown and extinction of past populations (30) but it remains unclear whether crops could follow the same fate in the absence of 
rescue processes, or whether such episodes could have been involved with previous agricultural collapses when crops experienced extensive adaptive challenges $(31,32)$. In the case of sorghum wild genetic resources may be valuable not only as a source of improved and environmentally adaptive traits, but also as a source for reparation of genome wide mutation load that may affect housekeeping and economic traits alike.

This represents the first plant archaeogenomic study that tracks multiple genomes to gain insight into changes in diversity over time directly. The trends revealed, based on a relatively low number of archaeological genomes, suggest a domestication history contrary to that typically expected for a cereal crop. Further archaeogenomes may establish whether this is a general trend for sorghum and other crops.

\section{Methods}

1. Sample Acquisition. Archaeological samples were sourced from A. Clapham from the archaeological site Qasr Ibrim, outlined in Table S1. For details on dating see section 1.3 below. Historical samples from the Snowden collection were sourced from Kew Gardens, Kew1: Tsang Wai Fak, collection no. 16366 Kew2: Tenayac, Mexico, collection assignation 's.n.'. Modern samples of $S$. bicolor ssp. bicolor type bicolor, durra, kafir, caudatum, drumondii and guinea were supplied through the USDA [accession numbers PI659985, PI562734, PI655976, PI509071, PI653734 and PI562938 respectively]. Wild sorghum samples S. vertilliciliflorum, S. arundinaeum, and S. aethiopicum were also 
obtained from the USDA [accession numbers PI520777, PI532564, PI535995], and wild S. virgatum was donated by D. Fuller. The outgroups S. propinquum and S. halapense were obtained from the USDA [accession numbers PI653737 and Grif 16307] respectively.

The genomes generated in this study were also compared to 1023 resequenced genomes taken from Thurber et al 2013 (26).

1.2 A note on taxonomy. The sorghum genus is complex with numerous taxonomic systems. After Morris et al.'s findings (10), we have elected not to describe the principal cultivar types as subspecies or races but rather simply 'types' to reflect the reality that there is evidence of considerable introgression between each of these forms. The wild progenitor of domesticated sorghum is a complex made up of four 'races' verticilliflorum, arundinaceum, aethiopicum and virgatum. However, the integrity of these races is also questioned, and the currently more accepted designation is one species, verticilliflorum, of which the other races are subtypes. For clarity and simplicity in this study we have used the race type as a variety designation.

1.3 A note on Qasr Ibrim and archaeological context of samples. Qasr Ibrim was a fortified hilltop site in the desert of Lower Nubia on the east bank of the Nile, about 200 km, south of Aswan in modern Egypt. It has been excavated over numerous field seasons, since 1963 by the Egyptian Exploration Society (UK). In recent years with higher Lake Nasser levels only upper parts of the site are 
preserved as an island $(33,34)$. The desert conditions provided exceptional organic preservation by desiccation with exceptional preservation of a wide range of biomolecules (e.g. 35-37). Systematic sampling for plant remains was initiated in 1984 (38) and the first studies of these remains were carried out in the 1980s by Rowley-Conwy (39) and had continued by Alan Clapham $(40,41)$. The exceptional plant preservation has previously allowed successful ancient genomic studies of barley (35) and cotton (36).

Qasr Ibrim was founded sometime before 3000 years BP. It had occupations associated the Napatan kings (Egyptian Dynasty 25: 747-656 BC), possible Hellenistic and Roman Egypt ( $3^{\text {rd }}$ century $B C$ to $1^{\text {st }}$ c. AD), the Meroitic Kingdom $\left(1^{\text {st }}\right.$ century to $4^{\text {th }}$ century AD), and local post-Meroitic (AD 350-550) and Nubian Christian Kingdoms (AD 550-1300). Earlier periods are associated temples to Egyptian and Meroitic deities. After Christianity was introduced the site had a Cathedral. Later Islamic occupations finished with use as an Ottoman fortress. The site was abandoned in AD1812. The Sorghum material studied here comes from a range of different contexts from excavation seasons between 1984 and 2000. While the chronology of the site is well established by artefactual material, including texts in various scripts, several sorghum remains or associated crops, were submitted for direct AMS radiocarbon dating, as listed below in Table S2. For directly dated find the median of the 2-sigma calibrated age range has been used. Note that Radiocarbon calibration defines "the present" as AD 1950, and we have recalculated the median as before AD 2000, and assigned Snowden historical collections form the start of the $20^{\text {th }}$ century as ca. $100 \mathrm{BP}$. For material 
not directly dated, sample A12 could be assigned based on associated pottery and finds, which have a well-established chronology through the Christian periods (42), A12 is associated with Islamic/Ottoman material (1500-1800 AD, ca. $400 \mathrm{BP})$

2. DNA extraction. DNA was extracted from archaeological and historical samples in a dedicated ancient DNA facility physically isolated from other laboratories. All standard clean-lab procedures for working with ancient DNA were followed. Single seeds from each accession were ground to powder using a pestle \& mortar and incubated in CTAB buffer (2\% CTAB, 1\%PVP, $0.1 \mathrm{M}$ Tris- $\mathrm{HCl}$ $\mathrm{pH} 8,20 \mathrm{mM}$ EDTA, $1.4 \mathrm{M} \mathrm{NaCl}$ ) for 5 days at $37^{\circ} \mathrm{C}$. The supernatant was then extracted once with an equal volume of $24: 1$ chloroform:isoamyl alcohol. DNA was then purified using a Qiagen plant Mini Kit with the following modifications: a) $5 x$ binding buffer was used instead of $1.5 x$ and incubated at room temperature for 2 hours before proceeding. b) After washing with AW2, columns were washed once with acetone and air-dried in a fume hood to prevent excessive G-forces associated with centrifugal drying. c) DNA was eluted twice in a total of $100 \mu \mathrm{l}$ elution buffer and quantified using a Qubit high sensitivity assay.

DNA from modern samples was extracted using a CTAB precipitation method due to excessive polysaccharide levels precluding column-based extractions. Briefly, seeds were ground to powder and incubated at $60^{\circ} \mathrm{C}$ for 1 hour in $750 \mathrm{ul}$ CTAB buffer as previously described, with the addition of $1 \mathrm{ul} \beta$-mercaptoethanol. Debris was centrifuged down and the supernatant was extracted once with an 
equal volume of $24: 1$ chloroform:isoamyl alcohol. The supernatant was then collected and mixed with $2 x$ volumes precipitation buffer (1\% CTAB, 50mM Tris$\mathrm{HCl}, 20 \mathrm{nM}$ EDTA) and incubated at $4^{\circ} \mathrm{C}$ for 1 hour. DNA was precipitated at $6^{\circ} \mathrm{C}$ by centrifugation at $14,000 \mathrm{~g}$ for 15 minutes. The pellet was washed once with precipitation buffer and incubated at room temperature for 15 minutes before being centrifuged again under the same conditions. The pellet was dried and resuspended in $100 \mu$ l high-salt TE buffer $(10 \mathrm{mM}$ Tris- $\mathrm{HCl}, 1 \mathrm{M} \mathrm{NaCl})$ and incubated at $60^{\circ} \mathrm{C}$ for 30 minutes with $0.5 \mu$ l RNase $A$. The DNA was then purified using Ampure XP SPRI beads.

3. Library construction and genome sequencing. Libraries for all samples were constructed using an Illumina TruSeq Nano kit, according to manufacturers' protocol. A uracil-intolerant polymerase (Phusion) was used to amplify the libraries, in order to eliminate the $\mathrm{C}$ to $\mathrm{U}$ deamination signal often observed in ancient DNA in favour of the 5 ' $5 \mathrm{mC}$ to $\mathrm{T}$ deamination signal. The purpose of this was to obtain epigenomic information after analysis using epiPaleomix (43). Consequently the data set was reduced for non-methylated cytosine deamination signals in the 5' end, but showed expected levels of $G$ to $A$ mismatches for ancient DNA (5-10\%) in the 3' end and high levels of endogenous DNA content typical for samples from this site (Table S1). While this approach is thought to reduce library complexity by reducing the number of successfully amplified molecules, we considered this to be a worthwhile trade-off considering the exceptional preservation and endogenous DNA content of the Qasr Ibrim 
samples. We found no evidence to suggest insufficient library complexity after amplification. A minor modification was made to the protocol for ancient and historical samples: a column-based cleanup after end repair was used, in order to retain small fragments that would otherwise be lost under SPRI purifications as per the standard protocol. Genomes were sequenced on the Illumina HiSeq 2500 platform. Ancient and historical samples were sequenced on one lane each using SR100 chemistry and modern samples on 0.5 lanes each using PE100 chemistry.

4. Preliminary Bioinformatics processing. Illumina adapters were trimmed using cutadapt v1.11 using 10\% mismatch parameters. Resulting FastQ files were mapped to the BTX623 genome (44) using bowtie2 v2.2.9 (46) under --sensitive parameters. SAM files containing mapped reads with a minimum mapping score of 20 were then converted to BAM files using samtools v1.14 (47). Variant calls format (VCF) files were then made from pileups constructed using samtools mpileup, and variant calls were made using bcftools v1.4 (47).

5. Methylation analysis. Since a uracil-intolerant polymerase was used for library generation, we analysed BAM files using epipaleomix (43) on the ancient samples. We then collated the number of identifiable $5 \mathrm{mC}$ sites globally for each sample. Epipaleomix is designed to characterise $\mathrm{CpG}$ islands typical to animal genomes and, is not suited to gene-specific analysis of plant genomes to due to their wider methylation states ( $\mathrm{CHH}$ and $\mathrm{CHG})$ (45). However when assessing 
relative overall genome methylation between individuals of the same species, CpG islands measured in this way provide a perfectly adequate proxy. We opted for global and windowed-measurements to determine relative methylation states between samples.

6. Evolutionary and population analyses. Two archaeological genomes (A8 and A12) were from phenotypes intermediate between bicolor and durra types. We found that sample A8 was predominantly of bicolor type and A12 predominantly of durra type. Given the uncertainty of these samples and their likely hybrid origins, we elected to leave them out of most analyses.

6.1 Heterozygosity analysis The number of heterozygous sites was measured for each $100 \mathrm{kbp}$ window of genome aligned to the BTX_623 reference sequence (44). The frequency distribution of heterozygosity was then calculated by binning the windows in 1 heterozygous base site intervals. Ratios of wild:cultivated heterozygosity were calculated for each window using S. verticilliflorum as the wild progenitor. Ratios closely approximate a negative exponential distribution. Probabilities of observed heterozygosity ratios for each window were obtained from a negative exponential distribution with $\lambda$ equal to $1 / \mu$ for all ratios for each chromosome. A Bonferroni correction was applied by multiplying probability values by the number of windows on a chromosome in Figure 4 . Locations of 38 known domestication syndrome loci (shown in Tables S5 and S7) were obtained by reference to the BTX_623 genome. Candidate domestication loci were 
obtained from the scans of Mace et al (25). In the genome-wide scan peaks were considered significant if $1 / p>100$ after Bonferroni correction.

We considered the possibility that the observed heterozygosity levels may be influenced by postmortem DNA damage. To explore this, we characterized the relationships between time, heterozygosity and postmortem deamination. As we previously described, $\mathrm{C}$ to $\mathrm{U}$ damage signals are eliminated at the 5 ' ends of sequence reads because of our choice of polymerase, so we therefore characterized damage profiles at the 3 ' ends only, using mapDamage output statistic '3pGtoA_freq' and taking a mean of the 25 reported positions for each ancient or historical sample. Unsurprisingly, we found that the accumulation of damage patterns is a function of time in a logistic growth model, assuming a zero-point intercept for both factors $\left(R^{2}=0.9\right) .80 \%$ of damage capacity under this model is reached reasonable quickly, in 331.0 years. All the Qasr Ibrim samples are at least 400 years old, and so we re-fitted a linear regression model to these samples only so characterize these relationships in a true time-series. We found a negligible correlation between time and damage accumulation after 400 years $\left(R^{2}=0.15, p=0.34\right)$. Next, we characterized the relationship between age and heterozygosity under the same model (although without the assumption of a zero-point intercept, since even modern domesticate lines in this study show non-zero levels) and found a weak fit $\left(R^{2}=0.64, p=0.14\right)$. This relationship is however likely influenced by our central hypothesis, with 'less domesticated' samples being earlier in the archaeological record, and so a counter-argument should not be inferred from this analysis. Finally, we assessed the relationship 
between damage and heterozygosity by linear regression, assuming inappropriateness of a logistic model since both damage and heterozygosity factors are functions of time. We found a weak correlation when considering all samples $\left(R^{2}=0.2, p=0.2\right)$, and virtually no correlation when considering the Qasr Ibrim time series only $\left(R^{2}=0.04, p=0.61\right)$. Considering that the two historical Kew samples are ostensibly domesticates, and historical and geographic outliers to the rest of the dataset, we conclude that the observed levels of heterozygosity in the ancient samples are not influenced by postmortem damage patterns.

6.2 Differential Temporal Heterozygosity Gradient Analysis. Our rationale was to utilize the temporal sequence of genomes to identify time intervals associated with intensification of selection. To this end we designed an analysis to identify outliers in changing heterozygosity over time to the general genomic trend. We considered all possible historical paths between genomes given three pairs of samples were almost contemporaneous (A3/A5, A6/A7 and A9/A10), with wild S. verticilliflorum representative of the wild progenitor in the case of the bicolor lineages.

For each $100 \mathrm{kbp}$ window we calculated the gradient of change in heterozygosity between temporally sequential genome pairs by subtracting younger heterozygosity values from older and dividing through by the time interval between samples. Genome-wide gradient values for all 100kbp windows were used to construct a non-parametric distribution to obtain probability values 
of change over each time interval for a $100 \mathrm{kbp}$ window between a particular pair of samples. Peak regions identified by heterozygosity ratio, SweeD analysis and known domestication syndrome genes were then measured for gradient probability.

6.3 SweeD analysis. VCF files from our 23 ancient, historical and modern samples and also 9 samples from Mace et al (25) were combined using the GATK (52) program CombineVariants. Subsequently, the combined VCF file was filtered - using bcftools v1.4 (47) - to only include sites with 2 or more distinct alleles and at sites where samples have depth less than 5 or a variant calling quality score less than 20 to exclude those samples. Then a further filter was applied - using bcftools v1.4 - to exclude variant calls due to C->T and G->A transitions relative to the reference, which potentially represent post-mortem deamination which has a high rate in aDNA samples (48). SweeD (21) was run with options for multi-threading (to run with 64 threads) and to compute the likelihood on a grid with 500 positions for each chromosome.

\subsection{Genome Evolutionary Rate Profiling (GERP) analysis. This analysis was} carried out broadly following the methodology of Cooper et al. (19). We aligned the repeat-masked genomes of 27 plant taxa to the BTX_623 sorghum reference genome using last, and processed resulting maf files to form netted pairwise alignment fastas using kentUtils modules maf-convert, axtChain, chainPreNet, chainNet, netToAxt, axtToMaf, mafSplit, and maf2fasta. We forced all alignments 
into the frame of the sorghum reference using an expedient perl script, and built a 27-way fasta alignment excluding sorghum for GERP estimation. We created a fasta file of fourfold degenerate sites from chromosome 1 (347394 sites; NC_012870) with a perl script, and calculated a neutral rate model using phyloFit, assuming the HKY85 substitution model and the following tree:

((((()((Trifolium_pratense,Medicago_truncatula), Glycine_max),Prunus_persica),( Populus_trichocarpa,Manihot_esculenta)),(((Arabidopsis_thaliana,_Arabidopsis_ly rata),(Brassica_napus,Brassica_rapa)), Theobroma_cacao)), Vitis_vinifera),((Sola num_tuberosum,Solanum_lycopersicum),(Chenopodium_quinoa,Beta_vulgaris))) ,(((Zea_mays,Setaria_italica),(((Oryza_rufipogon,Oryza_longistaminata),Leersia_ perrieri),(((Triticum_urartu,Aegilops_tauschii),Hordeum_vulgare),Brachypodium_ distachyon))),Musa_acuminata)),Amborella_trichopoda)

We then calculated GERP rejected subsitutions (RS) scores using gerpcol with the default minimum three taxa represented for estimation. The mutation load for each genome was then assessed by scanning through their VCF files generated by alignment to BTX_623. Maize was used as an outgroup to judge the ancestral state, and only sites at which there was information from maize were incorporated into the analysis. Sites which differed to the ancestral state were scored based on the associated RS score for that site following the scheme of Wang et al. (18): 0, neutral, 0-2 slightly deleterious, 2-4, moderately deleterious, $>4$ seriously deleterious. We collected scores under three models, recessive, 
additive and dominant. Under the dominant model we counted each site once regardless of whether it had one or two alternative bases to the ancestor, so giving the total number of base sites containing at least one potentially deleterious allele. Under the additive model we counted the total number of alleles that were alternative to the ancestor such that each homozygous alternative site scored 2, but heterozygous sites scored 1. Under the recessive model only sites that were homozygous for potentially deleterious variants were counted.

To investigate the significance of overlap between regions significant GERP regions of difference (GROD) between taxa and signatures of selection we used a binomial test in which the null probability of selecting a GROD was equal to the total number of GRODS (193) divided by the total number of $100 \mathrm{kbp}$ regions studied (6598), and $\mathrm{N}$ and $x$ were the total number of selection signals and the number of selection signals occurring in a GROD respectively.

We used the GERP profiles to explore potential genomic rescue from mutation load accrued independently in the bicolor and durra lineages prior to hybridization between the two types. For the purposes of this analysis we used the wild sorghum genome A3 as a possible wild ancestor genome to the domesticated bicolor form A5 even though this wild sample is contemporaneous to that domesticated form. All possible ancestor descendent pairs were assembled within bicolor or durra types, and all $100 \mathrm{kbp}$ windows were scanned for the relative additive model GERP load scores for ancestor, descendent and a third potential donor genome. The total potential for the donor genome to rescue 
the ancestral genome was scored summing the difference in GERP scores across all windows between the ancestor and donor. To better fit a scenario in which the donor genome was the causative agent of reduction GERP load score we identified windows that satisfied the condition ancestor GERP load score > descendent GERP load score, and summed up the difference in ancestor and potential donor scores to give an 'on target rescue' value.

6.5 Phylogenetics Maximum likelihood tress were constructed using exaML (49) firstly using whole genome sequences (Figure S7), and for 970 consecutive blocks across the genome (supplementary data set). Prior to computing phylogenetic trees, the VCF files were processed as described in section 6.3 (on the SweeD analysis) albeit with our 23 ancient, historical and modern samples only.

The maximum likelihood tree using the whole genome sequences was constructed as follows. Our own script created a multiple sequence alignment file by concatenating the variant calls in the VCF file and outputting the results in PHYLIP (50) format. The program parse-examl from the ExaML package (version 3.0.15) was run in order to convert the PHYLIP format file into ExaML's own binary format. Also, ExaML requires an initial starting tree which was obtained by running (on multiple threads) Parsimonator v1.0.2, a program available as part of the RaxML package (51) - developed by the same research group - for computing maximum parsimony trees. An ExaML executable 
(compiled to run using MPI) was run on multiple CPUs in order to compute the maximum likelihood tree.

The trees for 970 consecutive blocks across the genome were computed by essentially the same approach as described above for a single tree, after a script obtained the blocks from the input VCF file (for the combined samples) and output them in PHYLIP format.

To assess potential donation between genomes at candidate loci we examined trees spanning the corresponding100kbp windows. The tree topology was examined for congruence in the maintenance of bicolor and durra type groups within the Qasr Ibrim group of genomes. Instances of phylogenetic incongruence were interpreted as candidate regions of recombination between the two genome types, although identification of the donor and recipient genomes was not always clear. Simple cases in which a single genome from one sorghum type was found within the group of the other type were interpreted as possible genome donations from that group to the single genome. In the case of regions that scored highly in the SweeD analysis no phylogenetic congruence was attempted because the taxon in which selection has operated is not identified.

\subsection{Principal Component Analysis of global diversity set. A subset of 1894 SNPs} were used to find the principal axes of genetic variation for the 23 samples and an unpublished set of 1046 diverse sorghum lines spanning the racial and geographic diversity of the primary gene pool of cultivated sorghum. 580 of these 
diverse lines were described in Thurber et al (26). These lines were produced within the Sorghum Conversion Program which introgressed key height and phenology genes into exotic lines to enable them to be produced in sub-tropical environments. The introgressed regions spanned approximately $10 \%$ of the genome which were masked for the purposes of this analysis. Principal component analysis of the centered data matrix was performed in $R$ ( $R$ core team, 2017) using the prcomp function in the base "stats" package.

6.7 D statistics. Patterson's D-Statistic and modified F-statistic on Genome wide SNP data was used to infer patterns of introgression (24). D-statistic and fdstatistic for each of the 10 chromosomes was calculated using the R-package PopGenome. Variant Call Format (VCF) file, which is generated after mapping reads of an individual sample to the reference genome, was given as input to the readVCF() function of the package (52).

We used four R-language based S4 class methods from PopGenome package to carry out the introgression tests for every chromosome. First, we used the method set.population by providing 3 populations ( 2 sister taxa and an archaic group) viz., P1=BTX_623, P2=varying samples, P3=Most ancient S.bicolor A3. Second, using set.outgroup function, we set an outgroup (P4= S.halapense). Third, the method introgression.stats was employed to calculate the introgession tests. Finally, we used jack.knife.transform method (53) which transforms an existing object belonging to GENOME class into another object of the GENOME class with regions that corresponding to a Jackknife window. 
Standard error was then calculated by eliminating one such window i.e., a single chromosome under study and calculation was applied to the union of all the other chromosomes.

We tested for admixture from the most ancient $S$. bicolor type bicolor sample (A3), assuming this represents a genome prior to the appearance of the durra type on the African continent. The BTX_623 sorghum reference genome was taken as $P_{1}$, sample $A 3$ was taken as $P_{3}$ and $S$. halapense was taken as the out group $\mathrm{P}_{4}$. S. halapense is native to southern Eurasia to east India and does not readily cross with $S$. bicolor. Samples were then tested at the $P_{2}$ position across all 100kbp windows, each chromosome tested separately. Negative values (indicating an excess of $\mathrm{P}_{1} / \mathrm{P}_{3}$ combinations) are expected when the BTX_623 genome is more similar to sample $A 3$ than $P_{2}$. This is observed as expected for the durra types, although the value of $D$ decreases over time consistent with either an increase in instances of $P_{2} / P_{3}$ or instances of $P_{1} / P_{2}$, both suggesting progressive introgression between the durra and bicolor types over time. Positive values (indicating an excess of $\mathrm{P}_{2} / \mathrm{P}_{3}$ combinations) suggest a close relationship between sample $A 3$ and $P_{2}$, which is observed the Qasr Ibrim bicolor types (A5, A6 and A7).

6.8 Linear and exponential line fitting to heterozygosity and GERP score data. A straight line was fit to the heterozygosity data in Figure 2 using the glm function (for generalized linear models) in $\mathrm{R}$ and also an exponential function was fit to the same data using the gnm package (for generalized non-linear models) in $\mathrm{R}$ 
obtaining the values for the parameters, standard errors, $\mathrm{p}$ and AIC shown in Table S3. (It was confirmed similar values were obtained for the parameters, standard errors, $p$ and AIC by fitting the straight line model using the gnm package in R.)

6.9 Basic simulation of diversity loss through drift, introgression and serial founding events

To explore the effect on general trend line shape of introgression over time we used a basic simulation of drift loss using the standard equation:

$$
\frac{H_{t}}{H_{0}}=\left(1-\frac{1}{2 N_{f o}}\right)\left(1-\frac{1}{2 N\left(\frac{N_{e}}{N}\right)}\right)^{t-1}
$$

where $N_{f o}, N$ and $N_{e}$ are the founding population size, census population size and effective population size respectively. For simplicity, we assumed in the case of our crop that all three population sizes were equal. To incorporate introgression we used a simulation to calculate and modify each generation by using the above equation to modify the diversity from the previous generation, and then adding a diversity value representative of gene flow. Gene flow was altered each generation by a power factor $f$, which was 1 in the case of constant introgression, 1.0001 in the case of diminishing introgression over time and 0.99995 in the case of increasing introgression over time, with an initial value for introgression as 0.000015 , equating to the value of genetic diversity added to the population each generation. We used a founder population of 2000 for 6000 generations to 
recapitulate the observed 10 -fold loss of diversity over this time frame in sorghum.

The serial founder event simulation was executed using the following model: To initialize, allele frequencies were randomly assigned for a defined number of alleles using a uniform distribution. We also applied a skewed distribution in which the first allele frequency generated as above was amplified to become a dominating allele frequency by a defined value. We found this made no difference to the simulation outcomes. $\mathrm{N}$ individuals were then randomly drawn using the allele frequencies, and the resultant frequency distribution calculated. Homozygosity was calculated as the sum of the squares of allele frequencies and subtracted from 1 for the heterozygosity. To convert these allele values to a per base site heterozygosity comparable to the sorghum data we divided by $1 / \mathrm{He}$ of the wild progenitor. A founder event was then generated by drawing $\mathrm{Nb}$ individuals from the allele frequency distribution, the new resultant allele frequency distribution calculated. $\mathrm{N}$ individuals were then drawn from this distribution, new frequencies calculated and the resultant heterozygosity calculated as above. The process was repeated for a defined number of cycles. We explored a scenario in which the founder population was based on setting aside $25 \%$ of the (seed) population each year, following classic experimental archaeology field trials (28). We explored several orders of magnitude of $N(100$, $1000,10000,100000)$, and assumed 5 alleles per gene, for 1000 founding events, equating to 1000 years of agriculture. Each trial was repeated 100 times, equating to 100 genes being simulated independently. While the overall 
distribution of diversity loss over time is exponential, seen more clearly at smaller population sizes, the trend approximates linear more closely with increasing population size (Figure 12A). We calculated the gradient of descent from the first 60 founding events and found the logs of the gradient and population size to be directly proportional (Figure 12B). We used linear regression of this relationship to predict the log of the population size associated with the log of the observed gradient of descent of diversity in sorghum. We independently calculated the effective population size associated with wild sorghum using the heterozygosity as an estimate of $\theta$ (using the relationship $\theta=4 \mathrm{Ne} \mu$ ), and an estimate of $5 \times 10^{-9}$ subs/site/year for the neutral mutation rate (54).

\section{Acknowledgements}

The authors would like to thank M. Nesbitt for permitting the use of herbaria material from Kew. OS, WN, GB and RGA were supported by the NERC (NE/L006847/1) and LK was supported by NERC (NE/L012030/1). CJS and DQF work with archaeobotanical materials was supported by a European Research Council grant (no. 323842). Sequence data were deposited in the European Molecular Biology Laboratory European Bioinformatics Institute [project code PRJEB24962.]. 
(1) Larson G, Piperno D, Allaby RG et al. Current perspectives and the future of domestication studies. Proc. Natl. Acad. Sci. U.S.A. 111, 6139-6146 (2014).

(2) Purugganan MD, Fuller DQ. The nature of selection during plant domestication. Nature 457, 843-848 (2009).

(3) Fuller DQ, Denham T, Arroyo-Kalin M, Lucas L, Stephens C, Qin L, Allaby RG, Purugganan MD Convergent evolution and parallelism in plant domestication revealed by an expanding archaeological record. Proc. Natl. Acad. Sci. U.S.A. 111, 6147-6152 (2014).

(4) Allaby RG, Stevens S, Lucas L, Maeda O, Fuller DQ. Geographic mosaics and changing rates of cereal domestication. Philosophical Transactions of the Royal Society B. 372, 20160429 (2017).

(5) Poets AM, Fang Z, Clegg MT, Morell PL. Barley landraces are characterized by geographically heterogeneous genomic origins. Genome Biology 16, 173 (2015).

(6) Food and Agriculture Organization of the United Nations. [http://www. fao.org/index_en.htm].

(7) Winchell F, Stevens CJ, Murphy C, Champion L, Fuller DQ. Evidence for Sorghum Domestication in Fourth Millennium BC Eastern Sudan: Spikelet Morphology from Ceramic Impressions of the Butana Group. Current Anthropology 58, 673-683 (2017).

(8) Doggett H Sorghum $2^{\text {nd }}$ Ed, Longman, Harlow (1988). 
(9) Brown PJ, Myles S, Kresowich S. Genetic support for a phenotype-based racial classification in sorghum. Crop Sci. 51, 224-230 (2011).

(10) Morris G, et al. Population genomic and genome-wide association studies of agroclimatic traits in sorghum. Proc. Natl. Acad. Sci. U.S.A. 110, 453-458 (2013).

(11) Fuller, Dorian Q and Chris J. Stevens (n.d.) Sorghum Domestication and Diversification: A current archaeobotanical perspective. In: Anna Maria Mercuri, A. Catherine D’Andrea, Rita Fornaciari, Alexa Höhn (eds.) Plants and People in Africa's Past. Progress in African Archaeobotany. Springer (2017).

(12) Clapham AJ, Rowley-Conwy PA In Fields of Change-Progress in African Archaeobotany, Cappers R, ed. Groningen Archaeological Studies. Groningen, 5, 157-164 (2007).

(13) de Wet JML, Harlan JR, Price EG Variability in Sorghum bicolor. In: Harlan JR, de Wet JMJ, Stemler ABL (eds) Origins of African plant domestication. Mouton Press, The Hague, p 453-463 (1976).

(14) Harlan JR, Stemler ABL The races of Sorghum in Africa. In: Harlan JR, de Wet J, Stemler ABL (eds) Origins of African plant domestication. Mouton Press, The Hague, p 465-478 (1976).

(15) Meyer R, Purugganan M. Evolution of crop species: genetics of domestication and diversification. Nature Reviews Genetics 14, 840-852 (2013). 
(16) Liu Q, Zhou Y, Morrell PL, Gaut BS Deleterious variants in Asian rice and the potential cost of domestication. Mol. Biol. Evol. 34(4), 908-924 (2017).

(17) Renault S, Rieseberg L. The accumulation of deleterious mutations as a consequence of domestication and improvement in sunflower and other Compositae crops. Mol. Biol. Evol. 32(9), 2273-2283 (2015).

(18) Wang L, Beissinger TM, Lorant A, Ross-Ibarra C, Ross-lbarra J, Hufford MB The interplay of demography and selection during maize domestication and expansion. Genome Biol. 18, 215 (2017).

(19) Cooper GM et al. Distribution and intensity of constraint in mammalian genomic sequence. Genome Res. 15, 901-913 (2005).

(20) Smith O, Clapham A, Rose P, Liu Y, Wang J, Allaby RG. Genomic methylation patterns in archaeological barley show de-methylation as a time-dependent diagenetic process. Scientific Reports 4, 5559 (2014).

(21) Pavlidis P, Živkovic D, Stamatakis A, Alachiotis N SweeD: Likelihood-based detection of selective sweeps in thousands of genomes. Mol Biol Evol 30, 2224-2234 (2013).

(22) Hudson M, Ringli C, Boylan MT, Quail PH The FAR1 locus encodes a novel nuclear protein specific to phytochrome A signaling. Genes Devel. 13, 2017-2027 (1999).

(23) Zhu QH, Ramm K, Shivakkumar R, Dennis ES, Upadhyahya NM The ANTHER INDEHISCENCE1 gene encoding a single MYB domain protein is involved in anther development in rice. Plant Physiol. 135, 1514-1525 (2004). 
(24) Martin, S, Davey, J, Jiggins, C. Evaluating the Use of ABBA-BABA

Statistics to Locate Introgressed Loci. Mol. Biol. Evol. 32(1), 244-257 (2014).

(25) Mace ES et al. Whole genome sequencing reveals untapped genetic potential in Africa's indigenous cereal crop sorghum. Nature Communications 4, 2320 (2013).

(26) Thurber CS, Ma JM, Higgins RH, Brown PJ Retrospective genomic analysis of sorghum adaptation to temperate-zone grain production. Genome Biol. 14, R68 (2013).

(27) DeGiorgio M, Jakobsson M, Rosenberg N. Explaining worldwide patterns of human genetic variation using a coalescent-based serial founder model of migration outward from Africa. Proc. Natl. Acad. Sci. U.S.A. 106: 1605716062 (2009).

(28) Hillman GC, Davies MS. Domestication rates in wild type wheats and barley under primitive cultivation. B. J. Linn. Soc. 39:39-78 (1990).

(29) Kremling KA et al. Dysregulation of expression correlates with rare-allele burden and fitness loss in maize. Nature 555:520-523 (2018).

(30) Rogers \& Slatkin Excess defects in a woolly mammoth on Wrangel Island PloS Genetics 13(3): e1006601 (2017).

(31) Shennan S, Downey SS, Timpson A, et al. Regional population collapse followed initial agricultural booms in mid -Holocene Europe. Nat Commun. 4:2486 (2013) 
(32) Allaby RG, Kitchen JL, Fuller DQ (2016) Surprisingly low limits of selection in plant domestication. Evolutionary Bioinformatics 11:(S2) 41-51.

(33) Alexander, J The Saharan divide in the Nile Valley: the evidence from Qasr Ibrim. The African Archaeological Review 6, 73-90 (1988).

(34) Rose P (2013) Qasr Ibrim In: Bagnall RS, Brodersen K, Champion CB, Erskine A, Huebner SR (eds.) The Encyclopedia of Ancient History. Oxford: Wiley. Pp. 5695-5697 DOI: 10.1002/9781444338386.wbeah15340.

(35) Palmer SA, Moore JD, Clapham AJ, Rose P, Allaby RG. Archaeogenetic evidence of ancient Nubian barley evolution from six to two-row indicates local adaptation. PLoS One, 4(7), e6301 (2009).

(36) Palmer SA, Clapham AJ, Rose P, Freitas F, Owen BD, Beresford-Jones D, Moore JD, Kitchen JL, Allaby RG. Archaeogenomic evidence of punctuated genome evolution in Gossypium. Molecular biology and evolution, 29(8), 2031-2038 (2012).

(37) O’Donoghue K, Clapham A, Evershed RP, Brown TA. Remarkable preservation of biomolecules in ancient radish seeds. Proc R Soc B Biol Sci. 263, 541-547 1996.

(38) Alexander, J , Driskell B. Qasr Ibrim 1984. Journal of Egyptian Archaeology 71, $12-26$ (1985).

(39) Rowley-Conwy P Nubia AD 0-550 and the 'Islamic' agricultural revolution: Preliminary botanical evidence from Qasr Ibrim, Egyptian Nubia. Archeologie du Nil Moyen 3, 131-138 (1989). 
(40) Clapham AJ, Rowley-Conwy PA (2007). New discoveries at Qasr Ibrim, Lower Nubia. Fields of change: progress in African archaeobotany. Barkhuis \& Groningen University Library, Groningen, The Netherlands, 157-164.

(41) Clapham, A., \& Rowley-Conwy, P. (2009). The archaeobotany of cotton (Gossypium sp. L.) in Egypt and Nubia with special reference to Qasr Ibrim, Egyptian Nubia. From foragers to farmers. Papers in honour of Gordon C. Hillman. Oxbow Books, Oxford, 244-253.

(42) Adams, WY (1986) Ceramic Industries of Medieval Nubia. University of Kentucky Press

(43) Hanghøj K, Seguin-Orlando A, Schubert M, Madsen T, Pedersen JS, Willerslev E, Orlando L. Fast, Accurate and Automatic Ancient Nucleosome and Methylation Maps with epiPALEOMIX. Mol. Biol. Evol. 33, 3248-3298 (2016).

(44) Paterson AH et al. The Sorghum bicolor genome and the diversification of grasses. Nature 457, 551-556 (2009).

(45) Bouyer et al. DNA methylation dynamics during early plant life. Genome Biology 18:179 (2017)

(46) Langmead B, Salzberg SL. Fast gapped-read alignment with Bowtie 2. Nature Methods. 9(4), 357-359 (2012).

(47) Li H, Handsaker B, Wysoker A, Fennell T, Ruan J, Homer N, Marth G., Abecasis G., Durbin R. and 1000 Genome Project Data Processing Subgroup The Sequence alignment/map (SAM) format and SAMtools. Bioinformatics 25, 2078-2079 (2009). 
(48) da Fonseca RR, Smith BD, Wales N, Cappellini E, Skoglund P, Fumagalli M, Samaniego JA, Carøe C, Ávila-Arcos MC, Hufnagel DE, Korneliussen

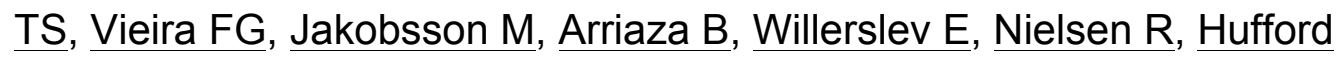
MB, Albrechtsen A, Ross-lbarra J, Gilbert MT The origin and evolution of maize in the Southwestern United States. Nature Plants 1, 14003 (2015).

(49) Koslov AM, Aberer A, Alexandros S. ExaML version 3: a tool for phylogenomic analysis on supercomputers. Bioinformatics 31, 2577-2579 (2015).

(50) Felsenstein J Evolutionary trees from DNA sequences: A maximum likelihood approach. J Mol Evol 17(6), 368-376 (1981).

(51) Stamatakis A RAxML-VI-HPC: maximum likelihood-based phylogenetic analyses with thousands of taxa and mixed models. Bioinformatics 22(21), 2688-2690 (2006).

(52) Van der Auwera GA, Carneiro M, Hartl C, Poplin R, del Angel G, LevyMoonshine A, Jordan T, Shakir K, Roazen D, Thibault J, Banks E, Garimella K, Altshuler D, Gabriel S, DePristo M. From FastQ Data to High-Confidence Variant Calls: The Genome Analysis Toolkit Best Practices Pipeline.

Current Protocols In Bioinformatics 43,11.10.1-11.10.33 (2013).

(53) Pfeifer B, Wittelsbürger U, Ramos-Onsins S, Lercher M. PopGenome: An Efficient Swiss Army Knife for Population Genomic Analyses in R. Mol. Biol. Evol. 31(7):1929-1936 (2014).

(54) Wolfe KH, Sharpe PM, Li WH. Rates of synonymous substitution in plant nuclear genes. J. Mol. Evol. 29:208-211 (1989). 
bioRxiv preprint doi: https://doi.org/10.1101/336503; this version posted June 3, 2018. The copyright holder for this preprint (which was not certified by peer review) is the author/funder, who has granted bioRxiv a license to display the preprint in perpetuity. It is made available under aCC-BY-ND 4.0 International license. 
Figure 1. Genomic heterozygosity over time in S. bicolor type bicolor.

Figure 2. Total recessive GERP load over time in S. bicolor type bicolor.

Figure 3. Selection signals across S. bicolor chromosomes 1 to 10.

Heterozygosity ratio (wild/cultivated) inverted probabilities (Bonferroni corrected) shown in colours as described in key. Grey dashed line indicates $1 \%$ significance threshold after Bonferroni correction. SweeD values shown in red. Above: Locations of 38 known domestication genes shown in black. Locations of candidate domestication loci identified by Mace et al (24) shown in brown. Locations of GERP score regions of difference (grod) between genomes shown in green.

Figure 4. Principal Coordinate Analysis of 1894 SNPs from 23 genomes in this study and 1046 sorghum lines described in Thurber et al (25). Arrows indicate temporal movement of bicolor and durra type archaeogenomes in PCA.

Figure 5. Summary of selection signals over time in archaeogenomes. Red indicates selection intensification episodes, green indicates selection signals identified by low heterozygosity or SweeD analysis. 


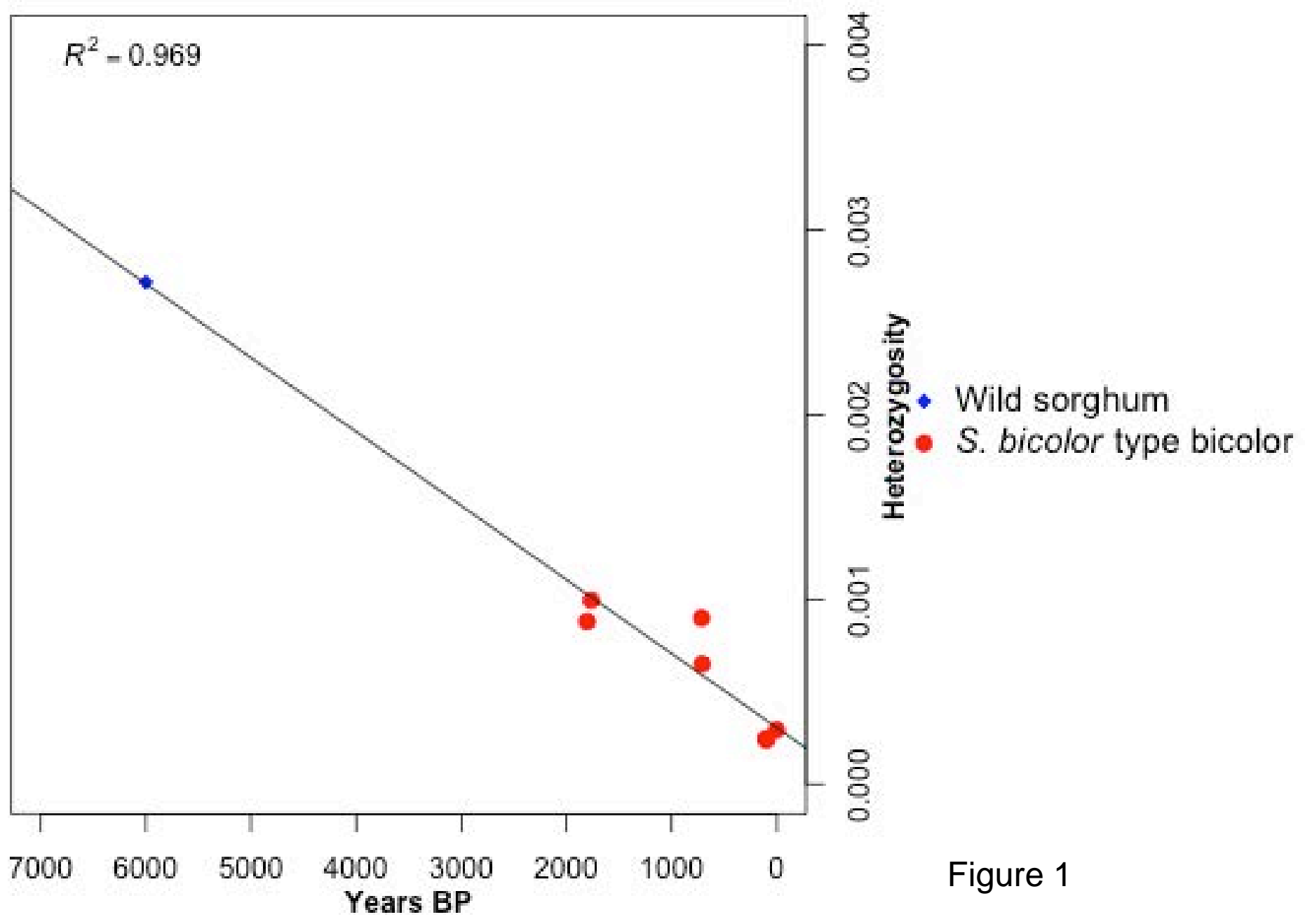




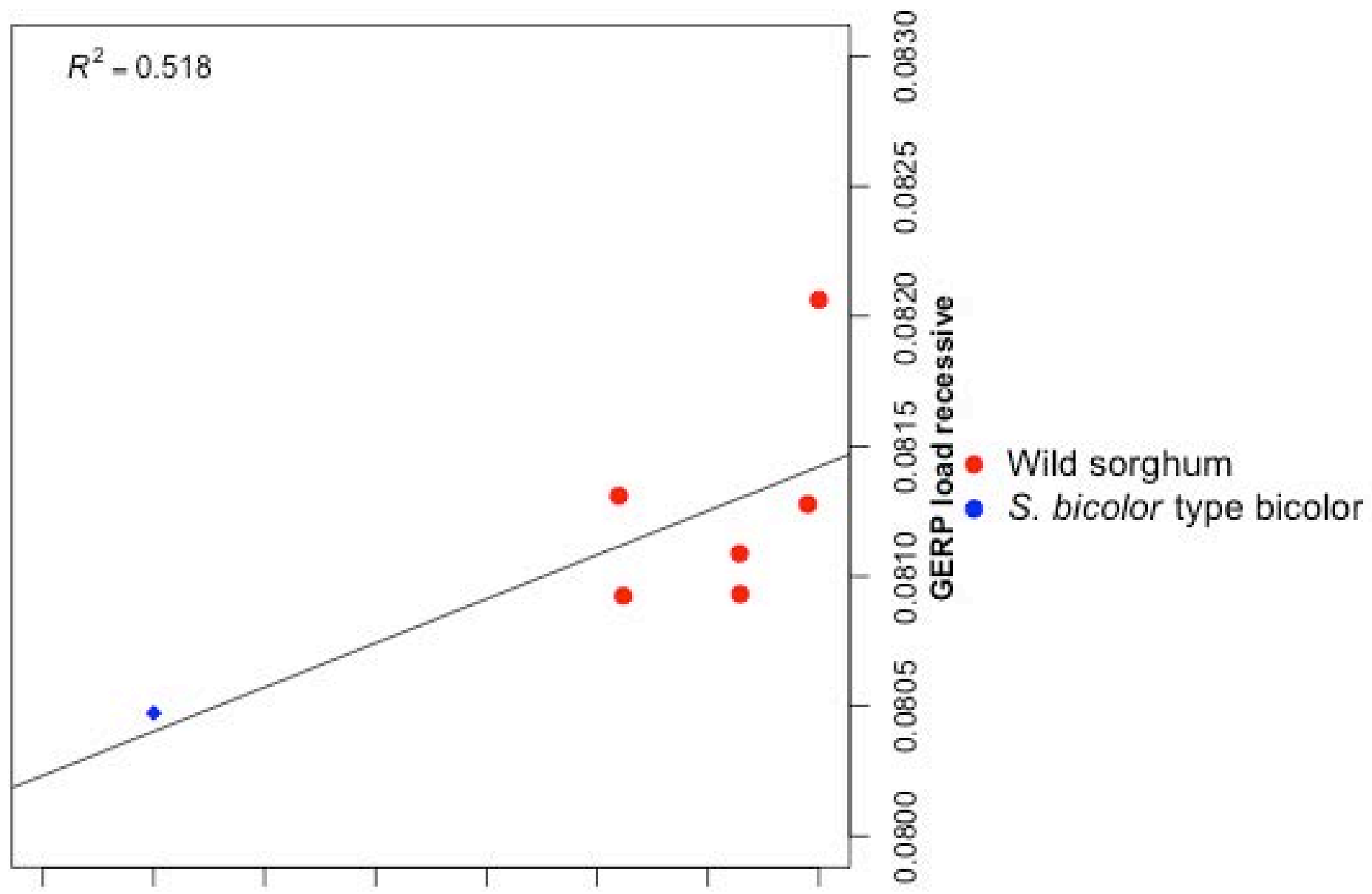

$\begin{array}{llllllll}7000 & 6000 & 5000 & 4000 & 3000 & 2000 & 1000 & 0\end{array}$ Years BP

Figure 2 


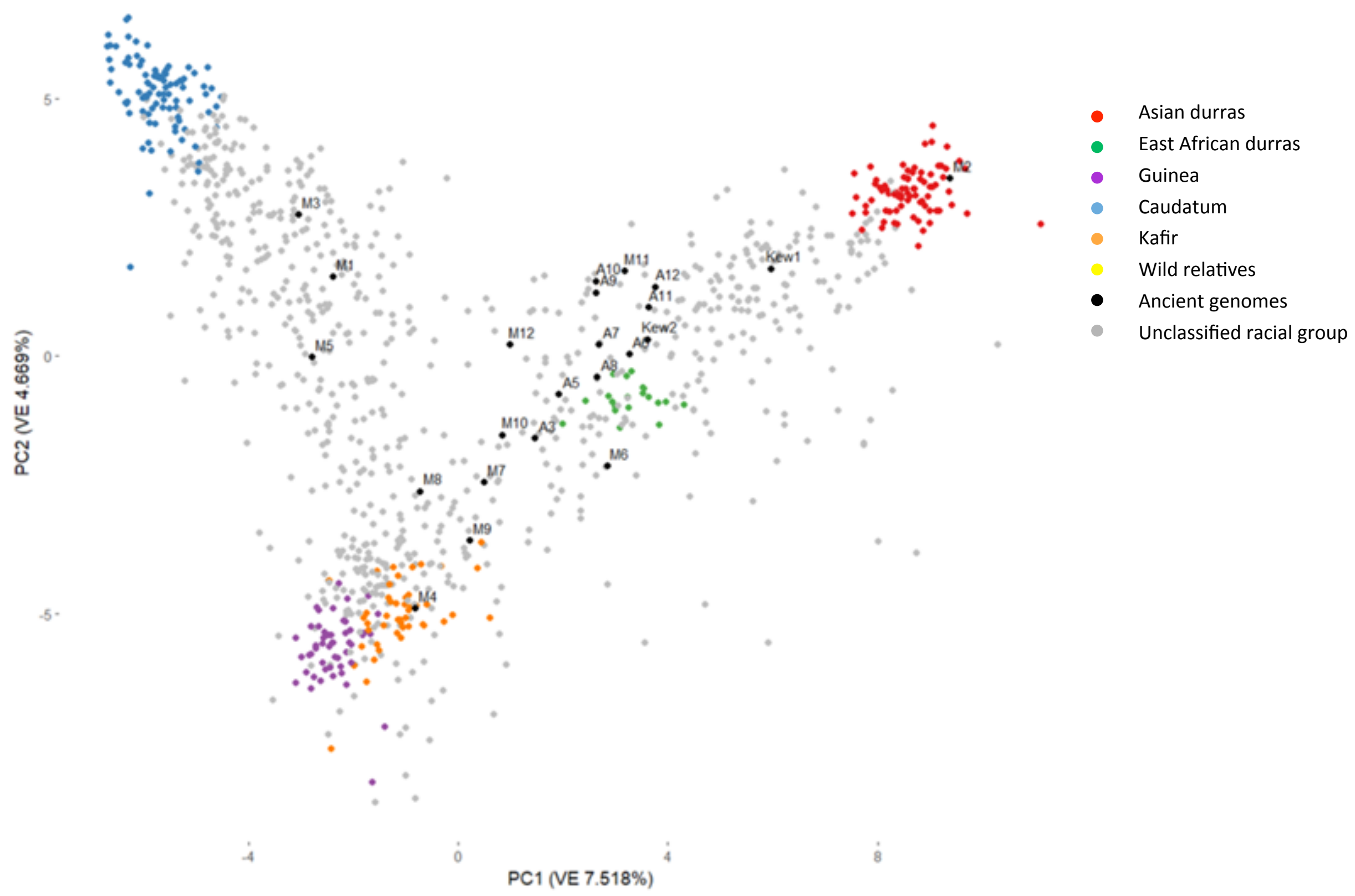

Figure 4 

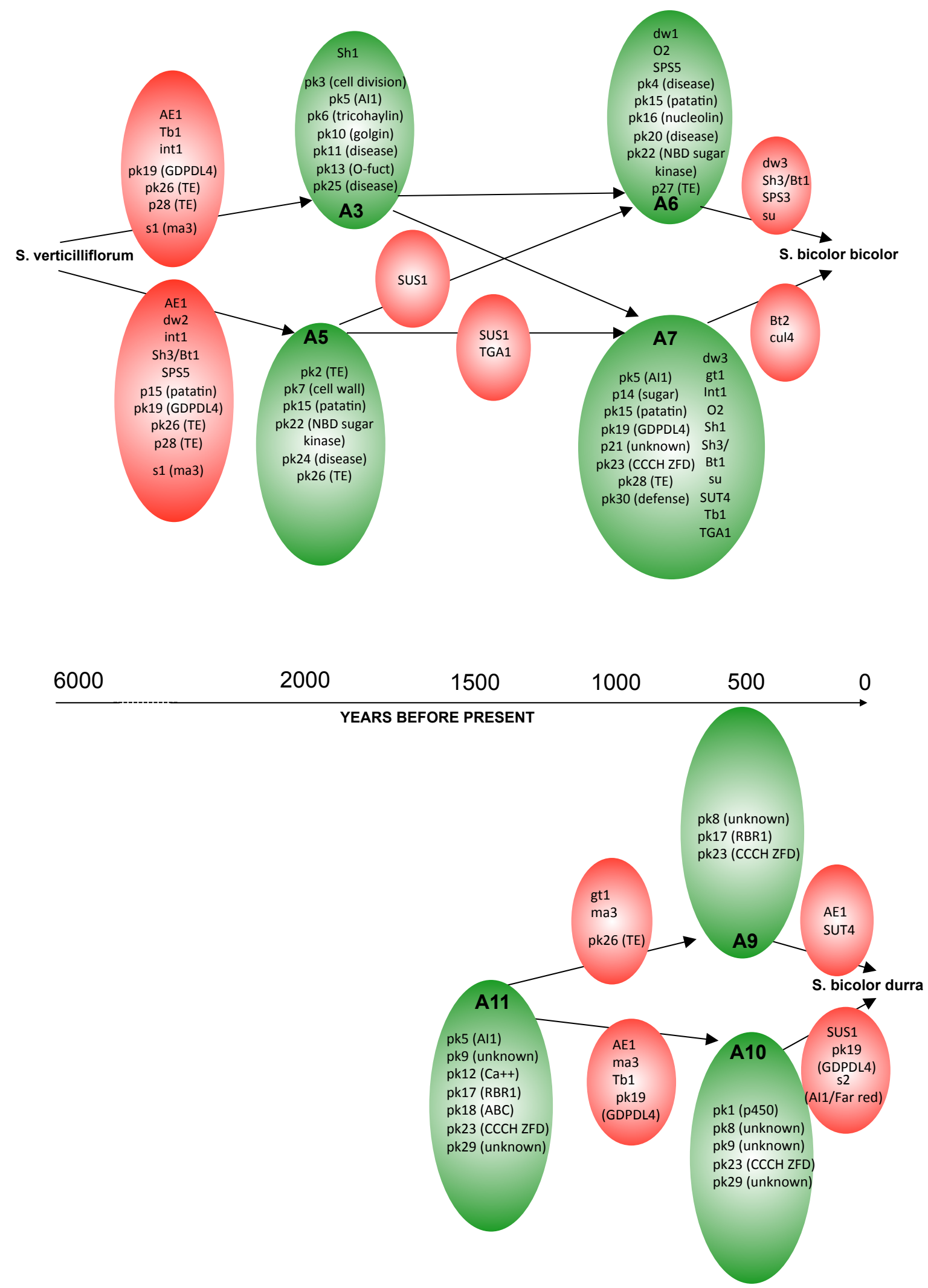
Table S1. Sample details of genomes sequenced in this study

Table S2. Radiocarbon dates on sorghum specimens or closely associated plant remains

Table S3 Summary statistics of fit to linear and exponential models of change in heterozygosity and GERP score in S. bicolor bicolor.

Table S4. Peaks of significant heterozygosity ratios (wild/cultivated) and associated annotated gene models. ${ }^{*}$ refers to genes also found in Mace et al (24) candidate domestication loci gene set.

Table S5. $P$ values of heterozygosity ratio peaks.

Table S6 $P$ values of heterozygosity ratio peaks for known domestication loci.

Table S7 Peaks of high signal found with SweeD analysis and associated annotated gene models. * refers to genes also found in Mace et al (24) candidate domestication loci gene set.

Table S8 $P$ values of gradient deviation in heterozygosity over time relative to genomic average. 
Table S9 Genomic locations for $100 \mathrm{kbp}$ windows that differ in gerp load between genomes by more than two standard deviations.

Table S10 Phylogenetic congruence between type bicolor and type durra clades in selection candidate regions.

Figure S1 Frequency distributions of heterozygosity in genomes for $100 \mathrm{Kbp}$ windows. A. Sorghum verticilliflorum. B. S. bicolor 'wild phenotype' (sample A3) 1765 yrs BP, C. S. bicolor type bicolor (sample A5) 1805 years BP, D. S. bicolor type bicolor (sample A6) 715 years BP, E. S. bicolor type bicolor (sample A7) 710 years BP, F. S. bicolor type bicolor BTX 623, G. S. bicolor type durra (sample A11) 1470 years BP, H S. bicolor type durra (sample A9) 505 years BP, I S. bicolor type durra (sample A10) 450 years BP, J S bicolor type durra modern.

Figure S2 Heterozygosity over time in S bicolor type durra

Figure S3 Additive, dominant and recessive model GERP load scores in S bicolor type bicolor and S bicolor type durra over time. Total GERP load calculated from variant sites with RS scores $>0$, strongly deleterious GERP load calculated from variant sites with RS scores $>4$. See methods for details on models. 
Figure S4 Methylated site number in S bicolor type bicolor and S bicolor type durra over time.

Figure S5 Heterozygosity over time of regions containing genome-wide significant wild/cultivated ratios. Significant deviations from the genomic gradient of change over time shown only.

Figure S6 Heterozygosity over time of regions containing high SweeD scores. Significant deviations from the genomic gradient of change over time shown only.

Figure S7 Heterozygosity over time of regions containing domestication loci that have significantly reduced in heterogygosity relative to wild. Significant deviations from the genomic gradient of change over time shown only.

Figure S8. Maximum likelihood tree of whole genome sequence built in EXaML

Figure S9. D statistic analysis: $P_{1}=S$. bicolor type bicolor $B T X 623, P_{2}=$ sample displayed on $\mathrm{X}$ axis, $\mathrm{P}_{3}=$ sample $\mathrm{A} 3, \mathrm{P}_{4}$ halapense.

Figure S10 Potential genome rescue of descendents from ancestors by donors based on GERP scores. Red indicates the resultant change from combined score of ancestors and donors in regions of observed GERP load reduction in 
descendents. Blue indicates the genome wide change in gerp score from combining ancestor and donor scores.

Figure S11. Standard model of loss of genetic diversity through drift combined with introgression over time. Arbitrary founding population of 2000 individuals simulated for 6000 generations to match the over all decrease observed in sorghum. Four models considered, no introgression (drift only), constant introgression (adding 0.000015 to the genetic diversity each generation). Dynamic introgression was defined where the gene flow (gf) contribution each generation is $g f^{f f}$, where $t$ is the generation number and $f$ the modification factor. Diminishing introgression, $f$ is 1.0001 , increasing introgression $f$ is 0.99995 . See methods for details of calculations.

Figure S12. Lost of heterozygosity through founder event model based on crop cycling. A. Sequential founding episodes based on $25 \%$ of harvest set aside for sowing (28) for various populations sizes (N). B. Gradients of diversity loss over time in the model and the observed gradient in sorghum with $\mathrm{N}$ obtained through linear regression of the model outputs. 
Age (median

ars cal. BP).

\begin{tabular}{|c|c|c|c|c|c|c|c|c|}
\hline Sample & Species & $B P=2000 A D$ & Source id & Total reads LINES & Total reads/pairs & Reads mapped & \% endogenous (genome) & Mean coverage at Q20 \\
\hline A3 & S. bicolor type bicolor wild phenotype & 1765 Qasr Ibrim & $00 / 22008$ & 896934328 & 224233582 & 200857980 & 89.57533399 & 9.56468 \\
\hline A5 & S. bicolor type bicolor & 1805 Qasr Ibrim & $96 / 18082$ & 932645300 & 233161325 & 204691251 & 87.78953842 & 6.62945 \\
\hline A6 & S. bicolor type bicolor & 715 Qasr Ibrim & $86 / 128$ & 889698924 & 222424731 & 182750309 & 82.16276498 & 8.13831 \\
\hline A7 & S. bicolor type bicolor & 710 Qasr Ibrim & $84 / 155$ & 839807884 & 209951971 & 188064725 & 89.57511763 & 7.7284 \\
\hline A8 & S. bicolor intermediate durra/bicolor & 890 Qasr Ibrim & $84 / 142$ & 1074259696 & 268564924 & 242003275 & 90.10978478 & 14.0648 \\
\hline A9 & S. bicolor type durra & 505 Qasr Ibrim & $84 / 162$ & 741640764 & 185410191 & 160463966 & 86.54538628 & 5.522 \\
\hline A10 & S. bicolor type durra & 450 Qasr Ibrim & $84 / 55$ & 486782488 & 121695622 & 108176150 & 88.89074909 & 4.02703 \\
\hline A11 & S. bicolor type durra & 1470 Qasr Ibrim & $86 / 82$ & 720632616 & 180158154 & 158338076 & 87.88837612 & 5.6919 \\
\hline A12 & S. bicolor intermediate durra/bicolor & 450 Qasr Ibrim & $84 / 112$ & 986445336 & 246611334 & 207934377 & 84.31663445 & 8.62576 \\
\hline Kew1 & S. bicolor type bicolor & 100 Kew Snowden Collection & Tsang Wai Fak 16366 & 1306192292 & 326548073 & 186573150 & 57.13497198 & 5.00975 \\
\hline Kew2 & S. bicolor type bicolor & 100 Kew Snowden Collection & Tenayac & 1247071228 & 311767807 & 191726861 & 61.49668333 & 5.22517 \\
\hline M1 & S. bicolor type caudatum & 0 USDA & PI509071 & 492898852 & 123224713 & 217257730 & 88.15509678 & 18.3405 \\
\hline M2 & S. bicolor type durra & 0 USDA & PI562734 & 384496108 & 96124027 & 177009252 & 92.07336476 & 14.368 \\
\hline M3 & S. bicolor type guinea & 0 USDA & PI562938 & 425911276 & 106477819 & 196350280 & 92.20243326 & 16.0876 \\
\hline M4 & S. bicolor type kafir & 0 USDA & PI655976 & 385197696 & 96299424 & 177636336 & 92.23125571 & 16.0181 \\
\hline M5 & S. bicolor type bicolor BTX623 & 0 USDA & PI659985 & 320880996 & 80220249 & 152004900 & 94.74222649 & 14.9171 \\
\hline M6 & S. verticilliflorum var. verticilliflorum & 0 USDA & PI520777 & 433237112 & 108309278 & 195610443 & 90.30179437 & 13.9573 \\
\hline M7 & S. verticilliflorum var. arundinaceum & 0 USDA & PI532564 & 403234860 & 100808715 & 167378436 & 83.01784027 & 12.0593 \\
\hline M8 & S. verticilliflorum var. aethiopicum & 0 USDA & PI535995 & 408447108 & 102111777 & 172471549 & 84.45232963 & 13.0077 \\
\hline M9 & S. propinquum & 0 USDA & PI653737 & 320834680 & 80208670 & 147017274 & 91.64674717 & 11.2134 \\
\hline M10 & S. verticilliflorum var. virgatum & 75 Vinall 11.7.1929 (UCL Archaeobotany) & S. virgatum & 321596756 & 80399189 & 94103477 & 58.52265313 & 6.75004 \\
\hline M11 & S. bicolor type drummondii & 0 USDA & Pl653734 & 674746364 & 168686591 & 293908369 & 87.1166959 & 23.2651 \\
\hline M12 & S. halapense & 0 USDA & Grif 16307 & 420386852 & 105096713 & 193426298 & 92.02300076 & 14.2121 \\
\hline
\end{tabular}

Table S1 Sample details 
Table S2. Radiocarbon dates on sorghum specimens or closely associated plant remains

\begin{tabular}{|c|c|c|c|c|c|c|c|c|c|}
\hline Sample & Notes on date & Lab Code & Date BP & error & $\begin{array}{l}\text { cal. BP } \\
\text { Start* }\end{array}$ & $\begin{array}{l}\text { cal. BP } \\
\text { Finish* }\end{array}$ & $\begin{array}{l}\text { Median } \\
\text { years } \\
\text { before AD } \\
2000 \\
\end{array}$ & Source id & Context \\
\hline A3 & $\begin{array}{l}\text { direct date on } \\
\text { sorghum }\end{array}$ & OxA-14892 & 1789 & 27 & 1780 & 1620 & 1765 & $00 / 22008$ & $00 / 22008$ \\
\hline A5 & $\begin{array}{l}\text { direct date on } \\
\text { sorghum }\end{array}$ & OxA-14818 & 1818 & 32 & 1820 & 1710 & 1805 & $96 / 18082$ & $96 / 18082$ \\
\hline A6 & $\begin{array}{l}\begin{array}{l}\text { direct date on } \\
\text { sorghum }\end{array} \\
\end{array}$ & $\begin{array}{l}\text { Beta- } \\
491610 \\
\end{array}$ & & & & & 715 & $86 / 128$ & $86 / 128$ \\
\hline A7 & $\begin{array}{l}\text { direct date on } \\
\text { sorghum }\end{array}$ & $\begin{array}{l}\text { Beta- } \\
491611\end{array}$ & & & & & 710 & $84 / 155$ & $84 / 155$ \\
\hline A8 & $\begin{array}{l}\text { date on Vigna } \\
\text { (Room } 8 \text { pit } \\
\text { 1028) }\end{array}$ & OxA-14757 & 906 & 27 & 910 & 780 & 890 & $84 / 142$ & $\begin{array}{l}\text { House 785; } \\
\text { Room 4; } \\
\text { Level 8; in } \\
\text { Floor } 7\end{array}$ \\
\hline A9 & $\begin{array}{l}\text { direct date on } \\
\text { sorghum }\end{array}$ & $\begin{array}{l}\text { Beta- } \\
491612 \\
\end{array}$ & & & & & 505 & $84 / 162$ & $84 / 162$ \\
\hline A10 & $\begin{array}{l}\text { direct date on } \\
\text { sorghum }\end{array}$ & Wk-21087 & 349 & 29 & 470 & 320 & 450 & $84 / 55$ & pit 932 \\
\hline A11 & $\begin{array}{l}\text { Direct date on } \\
\text { sorghum? }\end{array}$ & OxA-1023 & 1440 & 50 & 1530 & 1310 & 1470 & $86 / 82$ & $\begin{array}{l}\text { pit } \\
\text { associated } \\
\text { with X- } \\
\text { horizon }\end{array}$ \\
\hline
\end{tabular}

*= Before AD 1950 


\begin{tabular}{|c|c|c|c|c|c|c|c|}
\hline \multirow{2}{*}{$\begin{array}{l}\text { Function fit } \\
\text { Straight } \\
\text { line }\end{array}$} & \multirow[t]{2}{*}{ Parameter } & \multicolumn{3}{|l|}{ Heterozygosity } & \multicolumn{3}{|c|}{ GERP load recessive } \\
\hline & & value & $\begin{array}{l}\text { standard } \\
\text { error }\end{array}$ & $p$-value & value & $\begin{array}{l}\text { standard } \\
\text { error }\end{array}$ & $p$-value \\
\hline \multirow[t]{4}{*}{$y=b x+a$} & $a$ & 3.05E-04 & $6.80 \mathrm{E}-05$ & 0.0041 & 8.10E-02 & $1.80 \mathrm{E}-04$ & $1.07 \mathrm{E}-12$ \\
\hline & $b$ & 4.00E-07 & $2.90 \mathrm{E}-08$ & $9.20 \mathrm{E}-06$ & $-1.70 \mathrm{E}-07$ & 7.30E-08 & 0.0683 \\
\hline & AIC & & & -114 & & & -87.039 \\
\hline & MSE & & & 1.76E-08 & & & 9.89E-08 \\
\hline \multirow[t]{5}{*}{$\begin{array}{l}\text { Exponential } \\
y=a \cdot \exp (b)\end{array}$} & & value & $\begin{array}{l}\text { standard } \\
\text { error }\end{array}$ & p-value & value & $\begin{array}{l}\text { standard } \\
\text { error }\end{array}$ & $p$-value \\
\hline & $a$ & 0.00048 & $7.90 \mathrm{E}-05$ & 0.042 & 8.10E-02 & $1.80 \mathrm{E}-04$ & $1.08 \mathrm{E}-12$ \\
\hline & $b$ & 0.00029 & $3.15 E-05$ & $9.30 \mathrm{E}-05$ & $-2.10 \mathrm{E}-06$ & $9.10 \mathrm{E}-07$ & 0.0686 \\
\hline & AIC & & & -108 & & & -87.047 \\
\hline & MSE & & & 3.77E-08 & & & $9.88 \mathrm{E}-08$ \\
\hline
\end{tabular}

Table S3 - parameter values for curves fit to bicolor heterozygosity and GERP data (versus Years BP) 


\begin{tabular}{|c|c|c|c|c|c|c|c|c|}
\hline chromosome & window & a3 (bic 1765) & a5 (bic 1805) & a6 (bic 715) & a7 (bic 710) & a11 (du 1470) & a9 (du 505) & a10 (du 450) \\
\hline 1 & $44900000 \mathrm{pk} 1$ & 0.102805669 & 0.361722461 & 0.037909655 & 0.672815666 & 0.488542667 & 0.131199566 & 3.07E-06 \\
\hline 2 & 11000000 pk2 & 0.41358704 & 8.09E-06 & 0.572475817 & 0.441985835 & 0.154849864 & 0.234619463 & 0.344378095 \\
\hline 2 & $43900000 \mathrm{pk} 3$ & 4.94E-07 & 0.068120687 & 0.113563673 & 0.312212401 & 0.323721596 & 0.140345085 & 0.127117347 \\
\hline 2 & 53700000 pk4 & 0.344474996 & 0.401256338 & 1.52E-11 & 0.019124686 & 0.03962074 & 0.3485805 & 0.158021188 \\
\hline 2 & 54200000 pk5 & 2.91E-27 & 0.420599337 & 0.000105802 & 8.86E-06 & 7.54E-05 & 0.798886327 & 0.77234906 \\
\hline 3 & 32700000 pk6 & $3.58 \mathrm{E}-06$ & 0.122276411 & 0.007236644 & 0.511002154 & 0.250304643 & 0.566516074 & 0.279493597 \\
\hline 4 & $18100000 \mathrm{pk} 7$ & 0.11396104 & 1.58E-12 & 0.088156494 & 0.000195191 & 0.471447038 & 0.41702393 & 0.372331665 \\
\hline 4 & 27500000 pk8 & 0.261286593 & 0.205473343 & 0.14112128 & 0.46524292 & 0.003680721 & 1.14E-12 & 5.66E-06 \\
\hline 4 & 32800000 pk9 & 0.24931856 & 0.362688509 & 0.058495099 & 0.299449624 & $2.21 \mathrm{E}-06$ & 0.058438023 & $1.33 \mathrm{E}-05$ \\
\hline 4 & 37300000 pk10 & 2.31E-07 & 0.019809067 & 0.533628263 & 0.157409081 & 0.594011942 & 0.714415363 & 0.722213508 \\
\hline 5 & 14900000 pk11 & 1.35E-07 & 0.25271921 & 0.337898946 & 0.350962433 & 0.503030099 & 0.353336892 & 0.538949648 \\
\hline 5 & 27900000 pk12 & 0.713062847 & 0.225616734 & 0.073535584 & 0.137585802 & 9.34E-07 & 0.034101907 & 0.082247478 \\
\hline 5 & 43300000 pk13 & 7.16E-39 & 0.227277619 & 0.353860854 & 0.42828102 & 0.5041582 & 0.495277017 & 0.482806499 \\
\hline 5 & 59500000 pk14 & 0.51063073 & 0.361951397 & 0.624818174 & 1.73E-08 & 0.35261265 & 0.310154615 & 0.191120249 \\
\hline 5 & 61100000 pk15 & 0.060786667 & 5.66E-07 & 1.74E-09 & $1.21 \mathrm{E}-06$ & 0.106943639 & 0.083185043 & 0.216052513 \\
\hline 6 & 22600000 pk16 & 0.485480771 & 0.293894564 & 1.00E-05 & 0.366941418 & 0.218434017 & 0.107525029 & 0.02336006 \\
\hline 6 & 28600000 pk17 & 0.171185183 & 0.114355189 & 0.043428406 & 0.017284366 & 2.09E-05 & $1.38 \mathrm{E}-07$ & 0.001290742 \\
\hline 7 & 50700000 pk18 & 0.551471147 & 0.665910386 & 0.254773419 & 0.724932256 & 7.57E-06 & 0.800061835 & 0.36169038 \\
\hline 7 & 63100000 pk19 & 0.081917263 & 0.178246552 & 0.677009647 & $1.68 \mathrm{E}-07$ & 0.7213842 & 0.560745808 & 0.677619632 \\
\hline 8 & 12300000 pk20 & 0.003378476 & 0.389234972 & 3.59E-12 & 0.689368891 & 0.602756238 & 0.032440655 & 0.147217192 \\
\hline 8 & 29500000 pk21 & 0.464342822 & 0.268334064 & 0.550375439 & 7.12E-06 & 0.107161053 & 0.352865059 & 0.22445346 \\
\hline 8 & 31400000 pk22 & 0.320457043 & $2.11 \mathrm{E}-26$ & 1.23E-05 & 0.161024806 & 0.238387641 & 0.262500125 & 0.21551472 \\
\hline 8 & 32900000 pk23 & 0.452847218 & 0.422118402 & 0.360210465 & 1.18E-06 & 1.08E-05 & 5.16E-16 & 1.05E-06 \\
\hline 8 & 40600000 pk24 & 0.10546731 & 6.14E-09 & 0.004401777 & 0.286047016 & 0.234993339 & 0.293012606 & 0.454354348 \\
\hline 8 & 52900000 pk25 & 1.07E-13 & 0.522375209 & 0.308411152 & 0.15312801 & 0.372493801 & 0.382384948 & 0.480322344 \\
\hline 9 & 42000000 pk26 & 0.105550876 & $1.74 \mathrm{E}-08$ & 0.206695471 & 0.206278078 & 0.497667977 & 0.00371231 & 0.006383025 \\
\hline 10 & 17700000 pk27 & 0.47452556 & 0.248307926 & $1.82 \mathrm{E}-11$ & 0.028057542 & 0.356069589 & 0.372543624 & 0.381636121 \\
\hline 10 & 21500000 pk28 & 0.040683815 & 0.003257893 & 0.035047978 & 2.20E-09 & 0.049966079 & 0.055062808 & 0.033568321 \\
\hline 10 & 26500000 pk29 & 0.340520232 & 0.109276198 & 0.501928453 & 0.028309324 & 4.03E-05 & 0.001987998 & 1.95E-06 \\
\hline 10 & 27000000 pk30 & 0.459154643 & 0.23804888 & 0.069064252 & 7.95E-06 & 0.396138422 & 0.160478352 & 0.279727425 \\
\hline
\end{tabular}

Table S4 $p$ values for windows containing significant reduction in heterozygosity relative to S. verticilliflorum 


\begin{tabular}{|c|c|c|c|c|c|c|c|c|c|c|}
\hline chromosome & window & peak & start & stop & Uniparc code & Unparc code & Sb code & SORBI code & \multicolumn{2}{|l|}{ Gene description } \\
\hline 1 & \multirow{2}{*}{\multicolumn{2}{|c|}{$44900000 \mathrm{pk} 1$}} & 44830820 & \multirow{2}{*}{$\begin{array}{l}44831431 \\
44861635\end{array}$} & UPI0001A82246 & UPI0001A82246 & Sb01g026525 & C5WP69_SORBI & \multirow{2}{*}{\multicolumn{2}{|c|}{$\begin{array}{l}\text { unknown function (DUF1645) } \\
\text { cytochrome p450 }\end{array}$}} \\
\hline & & & 44860037 & & UPI0001A82247 & UPI0001A82247 & Sb01g026530 & C5WP70_SORBI & & \\
\hline 2 & \multirow{2}{*}{\multicolumn{2}{|c|}{$11000000 \mathrm{pk} 2$}} & 10974343 & \multicolumn{2}{|c|}{10978599 UPI0001A83EC8 } & UPI0001A83EC8 & Sb02g008271 & C5X2V0_SORBI & \multicolumn{2}{|l|}{ reverse transcriptase } \\
\hline & & & 10981018 & 10981874 & UPI0001A83EC9 & UPI0001A83EC9 & Sb02g008311 & C5X2V1_SORBI & transposase & \\
\hline 2 & 43900 & pk3 & 43786194 & 43787234 & UPI0001A842F4 & UPI0001A842F4 & Sb02g018043 & C5X843_SORBI & chromsome segregat & ATPase \\
\hline & & & 43788873 & 43789595 & UPI0001A842F5 & UPI0001A842F5 & Sb02g018110 & C5X844_SORBI & transposase & \\
\hline & 53700 & pk4 & 53484601 & 53494615 & *UPI0001A83D56 & UPI0001A83D56 & Sb02g021535 & C5X9S1_SORBI & RGA3 disease resista & protein (NB-ARC, LRR domain) \\
\hline & & & 53668339 & 53669764 & UPI0001A83D57 & UPI0001A83D57 & Sb02g021540 & C5X9S2_SORBI & transposase & \\
\hline & & & 53671197 & 53673521 & UPI0001A838F5 & UPI0001A838F5 & Sb02g021550 & C5X9S3_SORBI & RGA3 disease resista & protein (NB-ARC domain) \\
\hline & & & 53687315 & 53688481 & UPI0001A838F6 & UPI0001A838F6 & Sb02g021560 & C5X9S4_SORBI & RGA3 disease resista & protein (LRR domain) \\
\hline & & & 53693445 & 53694484 & UPI0001A838F7 & UPI0001A838F7 & Sb02g021570 & C5X9S5_SORBI & RGA3 disease resista & protein (PKc domain) \\
\hline & 54200 & pk5 & 54156595 & 54156834 & UPI0001A83D5D & UPI0001A83D5D & Sb02g021853 & C5X9T6_SORBI & unknown & \\
\hline & & & 54169579 & 54170586 & UPI0001A83D5E & UPI0001A83D5E & Sb02g021856 & C5X9T7_SORBI & Polynucleotidyl trans & ase ribonuclease \\
\hline & & & 54173272 & 54173781 & UPI0001A83D5F & UPI0001A83D5F & Sb02g021860 & C5X9T8_SORBI & unknown & \\
\hline & & & 54179475 & 54180150 & UPI0001A83D60 & UPI0001A83D60 & Sb02g021911 & C5X9T9_SORBI & Anther Indehiscence & \\
\hline 3 & 32700 & pk6 & $32649562 . .32$ & 2651401 & LOC110433684 & & & & trichohyalin-like & \\
\hline 4 & 18100 & pk7 & $17966716 . .17$ & 7967603 & LOC8155713 & & & & vegetative cell wall $\mathrm{p}$ & ein gp1 \\
\hline & & & $17982112 . .17$ & 7982948 & LOC110434760 & & & & serine/arginine repe & e matrix protein 1 -like \\
\hline & & & $18046591 . .18$ & 8047799 & LOC110434315 & & & & unknown function (D & 1668 domain) \\
\hline & 27500 & pk8 & 27402052 & 27402504 & UPI0001A86024 & UPI0001A86024 & Sb04g014271 & C5YON2_SORBI & unknown & \\
\hline 4 & 32800 & pk9 & 32660496 & 32661207 & UPI0001A8598F & UPI0001A8598F & Sb04g014491 & C5YON6_SORBI & unknown function & \\
\hline 4 & 37300 & pk10 & 37359135 & 37371246 & UPI0001C80D84;0 & Ontology_term=GO & (Sb04g016070 & & golgin a5 type protei & \\
\hline 5 & 14900 & pk11 & 14885427 & 14891094 & UPI0001A863DE & UPI0001A863DE & Sb05g008160 & C5Y116_SORBI & RPP-13 like disease $r$ & itance \\
\hline & 27900 & pk12 & 27791293 & 27795021 & UPI0001A865C1 & UPI0001A865C1 & Sb05g013400 & C5Y282_SORBI & GDT1 like protein & Ca transporter \\
\hline & & & 27797941 & 27798643 & UPI0001A865C2 & UPI0001A865C2 & Sb05g013410 & C5Y283_SORBI & Rho binding protein & Regulatory transcription inhibitor \\
\hline & 43300 & pk13 & $43,247,187$ & $43,269,799$ & LOC8075771 & & & & O-Fuct like & auxin independent growth promoter \\
\hline & 59500 & pk14 & 59411298 & 59414857 & UPI0001A8660D & UPI0001A8660D & Sb05g025890 & C5Y7E1_SORBI & lipase & \\
\hline & & & 59416966 & 59417283 & UPI0001A8660E & UPI0001A8660E & Sb05g025900 & C5Y7E2_SORBI & glutaredoxin C10 & \\
\hline & & & 59437739 & 59438068 & 3 UPI0001A8660F & UPI0001A8660F & Sb05g025910 & C5Y7E3_SORBI & glutaredoxin $\mathrm{C} 10$ & \\
\hline & & & 59452563 & 59457270 & UPI0001A86610 & UPI0001A86610 & Sb05g025915 & C5Y7E4_SORBI & galactose oxidase & \\
\hline & & & 59458058 & 59462321 & UPI0001A86611 & UPI0001A86611 & Sb05g025920 & C5Y7E5_SORBI & peptide chain releas & ctor APG3 \\
\hline & & & 59463266 & 59463718 & 3 UPI0001A86639 & UPI0001A86639 & Sb05g025930 & C5Y7E6_SORBI & RALF like protein & arrests root development \\
\hline & & & 59464960 & 59466737 & UPI0001A86C54 & UPI0001A86C54 & Sb05g025940 & C5Y7E7_SORBI & alkB & DNA repair \\
\hline & & & 59474035 & 59475117 & UPI0001A86C55 & UPI0001A86C55 & Sb05g025945 & C5Y7E8_SORBI & pollen extensin like & \\
\hline & & & 59475347 & 59477611 & UPI0001A86C56 & UPI0001A86C56 & Sb05g025950 & C5Y7E9_SORBI & pollen extensin like & \\
\hline 5 & 61100 & pk15 & 61009529 & 61010503 & UPI0001A86440 & UPI0001A86440 & Sb05g026965 & C5Y826_SORBI & RPP13 disease resist & e protein NBS-LRR \\
\hline & & & 61015798 & 61018316 & UPI0001A86441 & UPI0001A86441 & Sb05g026970 & C5Y827_SORBI & RPP13 disease resist & e protein NBS-LRR \\
\hline & & & 61028126 & 61029756 & UPI0001A8643F & UPI0001A8643F & Sb05g026950 & C5Y825_SORBI & dirigent protein & disease response involvig lignification \\
\hline & & & 61048282 & 61050689 & UPI0001A86A3A & UPI0001A86A3A & Sb05g026990 & C5Y829_SORBI & patatin & storage protein and fatty acid metabolism \\
\hline & & & 61057619 & 61058128 & 3 UPI0001A86A3B & UPI0001A86A3B & Sb05g026993 & C5Y830_SORBI & isopentenyl transfer & \\
\hline & & & 61061641 & 61062092 & UPI0001A86A3C & UPI0001A86A3C & Sb05g026996 & C5Y831_SORBI & patatin & \\
\hline & & & 61082967 & 61094282 & UPI0001A86442 & UPI0001A86442 & Sb05g027000 & C5Y832_SORBI & RPP13 disease resist & e protein NBS-LRR \\
\hline & & & 61097301 & 61098179 & UPI0001A86443 & UPI0001A86443 & Sb05g027005 & C5Y833_SORBI & transposable elemen & \\
\hline 6 & 22600 & pk16 & $22725443 . .22$ & 2735214 & LOC110436433 & & & & nucleolin & \\
\hline 6 & 28600 & pk17 & 28027121 & 28028229 & UPI0001A8715A & UPI0001A8715A & Sb06g010020 & C5YDW7_SORBI & RBR1,"similar to Reti & lastoma related protein RBR1" \\
\hline 7 & 50700 & pk18 & 50563493 & 50568895 & UPI0001A87F06 & UPI0001A87F06 & Sb07g019540 & C5YKN9_SORBI & $A B C$ transporter & \\
\hline & & & 50772772 & 50778650 & UPI0001A87F07 & UPI0001A87F07 & Sb07g019740 & C5YKPO_SORBI & $A B C$ transporter & \\
\hline & & & 50794332 & 50794661 & UPI0001A87F08 & UPI0001A87F08 & Sb07g019745 & C5YKP1_SORBI & transposable elemen & \\
\hline & & & 50896473 & 50902950 & *UPI0001A87F09 & UPI0001A87F09 & Sb07g019750 & C5YKP2_SORBI & $A B C$ transporter & \\
\hline 7 & 63100 & pk19 & 63002738 & 63004800 & UPI0001A87EBC & UPI0001A87EBC & Sb07g028040 & C5YJ45_SORBI & MFS, putative peptid & ransporter \\
\hline & & & 63007131 & 63012078 & 3 UPI0001A87A47 & UPI0001A87A47 & Sb07g028050 & C5YJ46_SORBI & glycerophosphodiest & phosphodiesterase GDPDL4 \\
\hline & & & 63019028 & 63020726 & UPI00022071D4;b & UPI00022071D4 & Sb07g028060 & & fibrous sheath CABY & inding protein \\
\hline & & & 63027930 & 63028675 & UPI0001A87EBD & UPI0001A87EBD & Sb07g028065 & C5YJ47_SORBI & unknown function & \\
\hline & & & 63029524 & 63033671 & UPI0001A87A48 & UPI0001A87A48 & Sb07g028070 & C5YJ48_SORBI & SWIB domain protair & 53 associated) \\
\hline & & & 63059608 & 63062274 & UPI0001A87EBE & UPI0001A87EBE & Sb07g028080 & C5YJ49_SORBI & serine--glyoxylate an & transferase \\
\hline & & & 63062573 & 63062995 & UPI0001A87A49 & UPI0001A87A49 & Sb07g028090 & C5YJ50_SORBI & PEF family (apoptosi & sociated) \\
\hline & & & 63073408 & 63073999 & UPI0001A87A4A & UPI0001A87A4A & Sb07g028095 & C5YJ51_SORBI & Peptidase M14 Succi & glutamate desuccinylase \\
\hline & & & 63088404 & 63095390 & UPI0001A87A4B & UPI0001A87A4B & Sb07g028100 & C5YJ52_SORBI & wall-associated rece & r kinase 5 \\
\hline 8 & 12300 & pk20 & 12228641 & 12230086 & UPI0001A881AC & UPI0001A881AC & Sb08g007200 & C5YTS4_SORBI & TNP1 like protein & \\
\hline & & & 12259170 & 12259505 & UPI0001A881AD & UPI0001A881AD & Sb08g007210 & C5YTS5_SORBI & TNP2 like protein & \\
\hline & & & 12279014 & 12286998 & 3 UPI0001A881AE & UPI0001A881AE & Sb08g007220 & C5YTS6_SORBI & la-related $6 \mathrm{~B}$ protein & \\
\hline & & & 12293716 & 12301627 & UPI0001A880E7 & UPI0001A880E7 & Sb08g007230 & C5YTS7_SORBI & outer envelope pore & tein 37 chloroplastic \\
\hline & & & 12351604 & 12355600 & UPI0001A880E8 & UPI0001A880E8 & Sb08g007240 & C5YTS8_SORBI & 2 alkenal reductase & defense \\
\hline & & & 12367068 & 12370954 & UPI0001A880E9 & UPI0001A880E9 & Sb08g007243 & C5YTS9_SORBI & 2 alkenal reductase & \\
\hline & & & 12372086 & 12372376 & UPI0001A880EA & UPI0001A880EA & Sb08g007246 & CSYTTO_SORBI & unknown & \\
\hline & & & 12385186 & 12386774 & UPI0001A881AF & UPI0001A881AF & Sb08g007250 & C5YTT1_SORBI & obtusifoliol 14 alpha & methylase \\
\hline & & & 12388327 & 12390954 & UPI0001A880EB & UPIO001A880EB & Sb08g007260 & C5YTT2_SORBI & transposase (transpo & \\
\hline
\end{tabular}


829500000 pk21 $29483080 \quad 28483220$ none

$831400000 \mathrm{pk} 22 \quad 31451800 \quad 31452274$ UPI0001A8836E $\quad$ UPIO001A8836E $\quad$ Sb08g012126

$8 \quad 32900000$ pk23 $32307877 \quad 32329902$ UPI0001A8824A UPI0001A8824A Sb08g012360

840600000 pk24 4041331140414000 UPI0001A8845B $\quad$ UPI0001A8845B $\quad$ Sb08g015335 $40414044 \quad 40416104$ UPI0001A8845C UPI0001A8845C Sb08g015337 4042625240430241 UPI0001A8845D UPI0001A8845D Sb08g015340 4060269540619018 UPI0001A8845E UPI0001A8845E Sb08g015350 4062508740634676 UPI0001A8845F UPI0001A8845F Sb08g015360 4063734140638570 UPI0001A882CF UPIO001A882CF Sb08g015370

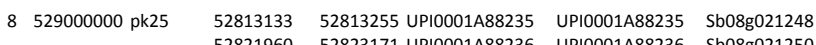

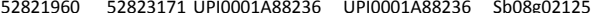
5283261852849272 UPI0001A88103 UPI0001A88103 Sb08g021260 $52877001 \quad 52880228$ UPI0001A88104 UPI0001A88104 Sb08g021270 5288616852889779 UPI0001A88105 UPI0001A88105 Sb08g021280 $52899503 \quad 52904524$ UPI0001A88106 UPI0001A88106 Sb08g021290

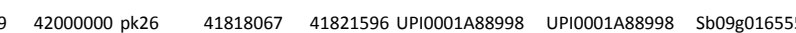
4183729041838894 UPI0001A88999 UPI0001A88999 Sb09g016560 $42022771 \quad 42023844$ UPI0001A88C3B UPI0001A88C3B Sb09g016570 4202648642027580 UPI0001A88C3C UPI0001A88C3C Sb09g016580 4209332242093834 UPI0001A88C3D UPI0001A88C3D Sb09g016590 $42094740 \quad 42097538$ UPI0001A8899A UPI0001A8899A Sb09g016595 4209801342101984 UPI0001A8899B $\quad$ UPI0001A8899B $\quad$ Sb09g016600

$10 \quad 17700000$ pk27 $\quad 17513261 \quad 17515058$ UPI0001A895DC $\quad$ UPI0001A895DC Sb10g011850 1758056917581168 UPI0001A895DD UPI0001A895DD Sb10g011916 1773160017734506 UPI0001A88F2F UPI0001A88F2F Sb10g012050

$10 \quad 21500000 \mathrm{pk} 28$

2135717521367692 UPI0001A8963D UPI0001A8963D Sb10g013495 2138510821386957 UPI0001A8963E UPIO001A8963E Sb10g013500

$10 \quad 26500000$ pk29 $26207429 \quad 26207653$ UPI0001A89698 $\quad$ UPI0001A89698 Sb10g015631

$10 \quad 27000000 \mathrm{pk} 30 \quad 27060330 \quad 27070160$ UPI0001A $8902 \mathrm{~A}$

27000000 pk30 $27060330 \quad 27070160$ UPI0001A8902A $\quad$ Sb10 015690 possible ncRNA

C5YNI7_SORBI NBD sugar kinase HSP70

C5YNJ3_SORBI zinc finger $\mathrm{CCCH}$ domain protein

C5YNU4_SORBI RGA2 LRR disease resistance C5YNU5_SORBI RGA2 NB-LRR disease resistance C5YNU6_SORBI RGA2 NB-LRR disease resistance C5YNU7_SORBI RGA2 NB-LRR disease resistance C5YNU8_SORBI RAD-51 DNA repair C5YNU9_SORBI methyl transferase

C5YRX2_SORBI unknown function C5YRX3_SORBI unknown function C5YRX4_SORBI achilleol B synthase C5YRX5_SORBI serine/threonine-protein kinase PBL13

C5YRX6_SORBI RGA2 NB-LRR disease resistance C5YRX7_SORBI RGA3 disease resistance protein (NB-ARC domain)

C5YWB8_SORBI unknown function

C5YWB9_SORBI transposase

C5YWCO SORBI myb-related protein 330

C5YWC1_SORBI unknown function

C5YWC2_SORBI GRF zinc finger protein

C5YWC3 SORBI MUDR transposase

C5YWC4_SORBI RanBP1 (chromosome condensation)

C5Z1L6_SORBI anthranilate O-methyltransferase 3

C5Z1L7_SORBI transposon protein

C5Z1L9_SORBI LRR receptor-like serine/threonine-protein kinase GSO2

C5Z2B4_SORBI TNP2-like protein

C5Z2B5_SORBI putative receptor-like protein kinase

C5Z2G3_SORBI unknown function

Table S5 Regions of genome-wide significance in reduction of heterozygosity relative to $S$. verticilliflorum and associated genes 


\begin{tabular}{|c|c|c|c|c|c|c|c|c|c|}
\hline chromosome & window & gene & a3 (bic 1765) & a5 (bic 1805) & a6 (bic 715) & a7 (bic 710) & a11 (du 1470) & a9 (du 505) & a10 (du 450) \\
\hline 7 & 59800000 & dw3 & 0.7169588 & 0.489916345 & 0.886234736 & 0.001029348 & 0.477686784 & 0.363034078 & 0.676461916 \\
\hline 9 & 57100000 & $d w 1$ & 0.430326598 & 0.305130691 & 0.00230527 & 0.368279324 & 0.180977448 & 0.341941378 & 0.395721262 \\
\hline 6 & 39400000 & $d w 2$ & 0.665201583 & 0.057426669 & 0.298814529 & 0.317679894 & 0.610788469 & 0.378785607 & 0.311719579 \\
\hline 1 & 12100000 & Sh1 & 0.001643632 & 0.297385872 & 0.028911337 & 0.000212513 & 0.354835471 & 0.07686203 & 0.06234129 \\
\hline 3 & 57300000 & Sh2 & 0.513833464 & 0.503304376 & 0.475469287 & 0.719246492 & 0.207224899 & 0.217029358 & 0.161350823 \\
\hline 4 & 6900000 & $\mathrm{Sh} 3 / \mathrm{Bt} 1$ & 0.525863822 & 0.220438392 & 0.553620438 & 0.001634715 & 0.067144308 & 0.070605796 & 0.081976552 \\
\hline 7 & 24600000 & Bt2 & 0.582609529 & 0.501609592 & 0.412557788 & 0.801374592 & 0.321041498 & 0.356407175 & 0.075252275 \\
\hline 1 & 12000000 & SbWRKY & 0.361395651 & 0.427090906 & 0.603085905 & 0.203227315 & 0.486529559 & 0.302235506 & 0.379554752 \\
\hline 4 & 51200000 & AE1 & 0.22551433 & 0.29453358 & 0.311256281 & 0.034073862 & 0.677054877 & 0.683438884 & 0.081427538 \\
\hline 3 & 730000 & cul4 & 0.701952197 & 0.604183218 & 0.578502305 & 0.926511526 & 0.672861455 & 0.403217476 & 0.440427355 \\
\hline 1 & 667000 & gt1 & 0.097794597 & 0.316054932 & 0.62376622 & 0.000168411 & 0.617927673 & 0.247660715 & 874132 \\
\hline 3 & 673000 & int1 & 0.24549123 & 0.384413387 & 0.494155025 & 0.004699184 & 0.127425119 & 0.01658232 & 0.062 \\
\hline 6 & 403000 & ma1 & 0.617705339 & 0.532350457 & 0.590362723 & 0.593731789 & 0.571373012 & 0.553418355 & 89672 \\
\hline 1 & 68000000 & ma3 & 0.246531398 & 0.434353232 & 0.517946331 & 0.037973221 & 0.833435067 & 0.489423682 & 0.412132698 \\
\hline 6 & 6800000 & ma6 & 0.15419183 & 0.357669236 & 0.101545909 & 0.555980974 & 0.807889865 & 0.583139814 & 0.679106223 \\
\hline 10 & 52300000 & Nud & 0.450228785 & 0.446656636 & 0.010462224 & 0.483913261 & 0.340556622 & 0.437064507 & 0.319686294 \\
\hline 6 & 5300000 & 02 & 0.013429001 & 0.089494808 & 0.000287218 & 0.003409689 & 0.237697548 & 0.010100032 & 0.002282872 \\
\hline 6 & 59800000 & $\mathrm{~Pa} 1$ & 0.198798653 & 0.422004202 & 0.50339961 & 0.769585741 & 0.180607303 & 0.49626172 & 0.482938499 \\
\hline 3 & 69600000 & SHP & 0.576035163 & 0.485634537 & 0.442796826 & 0.682561457 & 0.083018346 & 0.07321182 & 0.094031087 \\
\hline 3 & 71200000 & SPS1 & 0.785464458 & 0.797677336 & 0.857555457 & 0.903142979 & 0.765446871 & 0.662016811 & 0.777044825 \\
\hline 4 & 5700000 & SPS2 & 0.695212274 & 0.348024273 & 0.56633189 & 0.056854355 & 0.085577796 & 0.1669642 & 0.175319527 \\
\hline 5 & 13000000 & SPS3 & 0.611808756 & 0.569310494 & 0.870647378 & 0.756971064 & 0.741684177 & 0.773642816 & 0.841701362 \\
\hline 9 & 57500000 & SPS4 & 0.208514324 & 0.331713243 & 0.558643711 & 0.574416919 & 0.309467581 & 0.3428043 & 0.361862021 \\
\hline 10 & 54300000 & SPS5 & 0.63860949 & 0.21920424 & 0.000651432 & 0.348786362 & 0.179840872 & 0.081184781 & 0.058967394 \\
\hline 10 & 3800000 & sss1 & 0.375041814 & 0.55845213 & 0.684414407 & 0.597448311 & 0.473798407 & 0.525436039 & 0.587421989 \\
\hline 7 & 63400000 & & 0.691383152 & 0.335374091 & 0.899667869 & 0.000604092 & 0.683502612 & 0.283731511 & 0.464984252 \\
\hline 10 & 5800000 & suc1 & 0.589443244 & 0.637865314 & 0.62481392 & 0.406182939 & 0.732509736 & 0.6082817 & 0.711589757 \\
\hline 1 & 59600000 & SUS1 & 0.102857534 & 0.245293066 & 0.0583269 & 0.555907938 & 0.176826781 & 0.293207289 & 0.352236403 \\
\hline 4 & 67900000 & SUS2 & 0.458986562 & 0.576702496 & 0.163889482 & 0.417223531 & 0.34109847 & 0.40643326 & 0.369316348 \\
\hline 10 & 68700000 & SUS3 & 0.098485418 & 0.238211851 & 0.397000681 & 0.470113482 & 0.223766466 & 0.311699977 & 0.214376648 \\
\hline 1 & 68900000 & SUT1 & 0.566041623 & 0.531485138 & 0.655006916 & 0.394999175 & 0.54577088 & 0.394546242 & 0.451672203 \\
\hline 4 & 67600000 & SUT2 & 0.567902772 & 0.53458443 & 0.474764929 & 0.063559061 & 0.28588962 & 0.292630349 & 0.45073245 \\
\hline 1 & 28300000 & SUT3 & 0.218145354 & 0.201505373 & 0.351179354 & 0.744264086 & 0.482446235 & 0.325694104 & 0.535576405 \\
\hline 8 & 55400000 & SUT4 & 0.317691189 & 0.517536698 & 0.103511984 & 0.007573251 & 0.433216268 & 0.743111943 & 0.58091866 \\
\hline 1 & 9100000 & TB1 & 0.014057578 & 0.573426704 & 0.093823381 & 0.003083594 & 0.511843222 & 0.260897205 & 0.158842179 \\
\hline 7 & 61800000 & TGA1 & 0.470174403 & 0.656829436 & 0.857173271 & 2.03E-05 & 0.399043914 & 0.321679462 & 0.582541775 \\
\hline 2 & 71900000 & vrs1 & 0.474901762 & 0.266734382 & 0.395277557 & 0.307403979 & 0.366941678 & 0.433615896 & 0.337698283 \\
\hline 10 & 1900000 & Wx & 0.676418026 & 0.587602331 & 0.747884835 & 0.725536392 & 0.468105714 & 0.459480367 & 0.564016491 \\
\hline 2 & 14400000 & Wx_Chr2 & 0.73866598 & 0.67895781 & 0.66040409 & 0.570248694 & 0.348520009 & 0.502490469 & 0.536244356 \\
\hline
\end{tabular}

Table S6 $p$ values for reduction in heterozygosity in windows containing domestication loci observed in archaeological accessions relative to $S$. verticilliflorum. 


\begin{tabular}{|c|c|c|c|c|c|c|c|c|c|}
\hline chromosome & position & likelihood & start & end & Uniparc id & Uniparc id & Sb code & SORBI code & gene description \\
\hline \multirow{18}{*}{1} & \multirow{18}{*}{67625596} & \multirow{18}{*}{$186.9738 \mathrm{~s} 1$} & 67527437 & 67528255 & UPI0001A82EOA & UPI0001A82EOA & Sb01g044420 & C5WUS5_SORBI & unknown function \\
\hline & & & 67532193 & 67537252 & UP10001A8295D & UPI0001A8295D & Sb01g044430 & C5WUS6_SORBI & Pumilio RNA binding protein \\
\hline & & & 67538460 & 67540436 & UPI0001С80BA9;OI & UPIOOO1C80BA9 & Sb01g044440 & & ras-related protein $\mathrm{RABH} 1 \mathrm{~b}$-like \\
\hline & & & 67555746 & 67557224 & UPI0001A8295E & UPI0001A8295E & Sb01g044450 & C5WUS7_SORBI & WW domain protein \\
\hline & & & 67560187 & $67564611 \mathrm{C}$ & UPI0001A8295F & UPIO0001A8295F & Sb01g044460 & C5WUS8_SORBI & conserved oligomeric Golgi complex subunit 8 \\
\hline & & & 67568809 & 67573214 & UPI0001С80BAA;O| & UPIOOO1C8OBAA & Sb01g044470 & & mitochondrial adenine nucleotide transporter BTL3 \\
\hline & & & 67576601 & 67583786 & UPI0001A82960 & UPI0001A82960 & Sb01g044480 & C5WUS9_SORBI & calmodulin-binding transcription activator 1 isoform $\times 2$ \\
\hline & & & 67585849 & $67586537 \mathrm{C}$ & UPI0001А82ЕОВ & UPI0001А82ЕОВ & Sb01g044485 & CSWUTO_SORBI & reverse transcriptase \\
\hline & & & 67590805 & $67594920 \mathrm{C}$ & UPI0001A82961 & UPI0001A82961 & Sb01g044490 & CSWUT1_SORBI & unknown function \\
\hline & & & 67606065 & 67606893 & UPI0001A82962 & UPI0001A82962 & Sb01g044500 & CSWUT2_SORBI & trypsin like peptidase \\
\hline & & & 67612260 & $67612981 \mathrm{c}$ & UPI0001A82EOC & UPI0001A82EOC & Sb01g044505 & C5WUT3_SORBI & unknown function \\
\hline & & & 67623006 & 67629132 & UPI0001A82963 & UP10001A82963 & Sb01g044510 & C5WUT4_SORBI & unknown function \\
\hline & & & 67631156 & 67632142 & UPI0001A82964 & UPI0001A82964 & Sb01g044515 & CSWUTS_SORBI & $\mathrm{CCCH}$ domain zinc finger proetin \\
\hline & & & 67653779 & 67664222 & UP10001A82965 & UP10001A82965 & Sb01g044520 & CSWUT6_SORBI & trypsin like peptidase \\
\hline & & & 67666492 & 67670699 & UPI0001A829C6 & UPI0001A829C6 & Sb01g044530 & C5WUT7_SORBI & ubiquitin carboxyl-terminal hydrolase 3 \\
\hline & & & 67681955 & $67685954 \mathrm{C}$ & UPI0001A829C7 & UPI0001A829C7 & Sb01g044540 & C5WUT8_SORBI & LRR domain protein \\
\hline & & & 67687809 & 676900434 & UPI0001A829C8 & UPI0001A829C8 & Sb01g044550 & CSWUT9_SORBI & ras-related protein Rab11D \\
\hline & & & 67693174 & $67695434 \mathrm{C}$ & UPI0001A829C9 & UP10001A829C9 & Sb01g044560 & C5WUUO_SORBI & 2-carboxy-1,4-naphthoquinone phytyltransferase, chloroplastic \\
\hline & 54037240 & $284.8075 \mathrm{~s} 2$ & 53900589 & $53917120 \mathrm{C}$ & UP10001A83D58 & UP10001A83D58 & Sb02g021770 & C5X9S6_SORBI & nudix hydrolase 20 , chloroplastic \\
\hline & & & 53917736 & 539236824 & UP10001A83D59 & UP10001A83D59 & Sb02g021780 & C5X9S7_SORBI & UDP-glucose 4-epimerase \\
\hline & & & 53927463 & 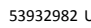 & UPI0001A83D5A & UPI0001A83D5A & Sb02g021790 & C5X9S8_SORBI & E3 ubiquitin-protein ligase \\
\hline & & & 53972111 & $53976091 \mathrm{u}$ & UPI0001C80E15;Or & r UPI0001C80E15 & Sb02g021800 & & receptor-like serine/threonine-protein kinase SD1-8 \\
\hline & & & 53991898 & $53993342 \mathrm{C}$ & UPI0001A838F8 & UPI0001A838F8 & Sb02g021810 & C5X9S9_SORBI & protein FAR-RED IMPAIRED RESPONSE 1-like \\
\hline & & & 53994545 & $54014672 \mathrm{U}$ & UPI0001A838F9 & UPI0001A838F9 & Sb02g021820 & C5X9TO_SORBI & protein FAR1-RELATED SEQUENCE 5-like \\
\hline & & & 54016136 & $54017327 \mathrm{C}$ & UPI0001A83D5B & UPI0001A83D5B & Sb02g021830 & C5X9T1_SORBI & unknown function \\
\hline & & & 54020593 & $54022973 \mathrm{C}$ & UP10001A83D5C & UP10001A83D5C & Sb02g021835 & C5X9T2_SORBI & unknown function \\
\hline & & & 54032811 & $54033740 \mathrm{C}$ & UPI0001A838FA & UPI0001A838FA & Sb02g021840 & C5X9T3__SORBI & Polynucleotidyl transferase ribonuclease $\mathrm{H}$-like superfamily protein \\
\hline & & & 54090301 & $54090747 \mathrm{U}$ & UPI0001A838FC & UP10001A838FC & Sb02g021850 & C5X9T5_SORBI & NBD sugar kinase HSP70 \\
\hline & & & 54156595 & $54156834 \mathrm{C}$ & UPI0001A83D5D & UP10001A83D5D & Sb02g021853 & C5X9T6_SORBI & unknown \\
\hline & & & 54169579 & $54170586 \mathrm{C}$ & UPI0001A83D5E & UPIO001A83D5E & Sb02g021856 & C5X9T7_SORBI & Polynucleotidyl transferase ribonuclease \\
\hline & & & 54173272 & $54173781 \mathrm{l}$ & UPI0001A83D5F & UPI0001A83D5F & Sb02g021860 & C5X9T8_SORBI & unknown \\
\hline & & & 54179475 & $54180150 \mathrm{C}$ & UP10001A83D60 & UP10001A83D60 & Sb02g021911 & C5X9T__SORBI & Anther Indehiscence 1 \\
\hline & 19095154 & $154.0901 \mathrm{~s} 3$ & 19004452 & $19005520 \mathrm{u}$ & UPI0001A845AF & UPI0001A845AF & Sb03g014221 & C5XJY4_SORBI & transposase \\
\hline & & & 19147217 & 19147932 U & UPIO0001A851BF & UPIO001A851BF & Sb03g014261 & C5XJY5_SORBI & transposase \\
\hline & & & 19148124 & 19148417 U & UPI0001A851C0 & UPI0001A851C0 & Sb03g014301 & C5XJY6_SORBI & transposase \\
\hline & & & 19151124 & $19159094 \mathrm{C}$ & UPI0001A851C1 & UPI0001A851C1 & Sb03g014340 & C5XJY7_SORBI & thiamine pyrophosphokinase 2 \\
\hline & & & 19161565 & $19162878 \mathrm{C}$ & UPI0001A851C2 & UP10001A851C2 & Sb03g014350 & C5XJY__SORBI & pollen-specific leucine-rich repeat extensin-like protein 1 \\
\hline & & & 19166935 & $19167843 \mathrm{C}$ & UPIO001A851C3 & UPI0001A851C3 & Sb03g014360 & CSXJYY_SORBI & rapid alkalinization factor \\
\hline & & & 19173459 & 19178759 u & UPI0001C80BB1;Or & IUPI0001C80BB1 & Sb03g01437 & & protein LOW PSII ACCUMULATION 1 \\
\hline & & & 19180099 & $19183534 \mathrm{U}$ & UPI0001A845BO & UPI0001A845BO & Sb03g014380 & CSXJZO_SORBI & $40 S$ ribosomal protein $\$ 4$ \\
\hline & & & 19185886 & 19193629 u & UPI0001A851C4 & UPI0001A851C4 & Sb03g014390 & C5XJZ1_SORBI & NB-LRR disease resistance protein \\
\hline & 36549186 & $197.3805 \mathrm{~s} 4$ & 36474476.3647 & 175344 & LOC110433364 & & & & ncRNA \\
\hline & & & 36469694.3647 & 170469 & LOC110433369 & & & & ncRNA \\
\hline & 50606510 & $428 \mathrm{~s} 5$ & 50633842 & $50666619 \mathrm{l}$ & UPI0001A864C6 & UPI0001A864C6 & Sb05g020710 & C5Y3T7_SORBI & reverse transcriptase \\
\hline & & & 50748352 & $50748630 \mathrm{C}$ & UP10001A8452A & UPIO001A8452A & Sb05g020712 & CSXMSO_SORBI & reverse transcriptase \\
\hline & & & 50773752 & 507739614 & UPI0001A864C7 & UPI0001A864C7 & Sb05g020715 & C5Y3T9_SORBI & unknown function - similar to cadmium induced protein \\
\hline & $7 \quad 25143622.2$ & $6.96 \mathrm{E}+02 \mathrm{~s} 6$ & 24438987 & 24439399 U & UPI0001A878AD & UPI0001A878AD & Sb07g012310 & C5YK24_SORBI & GDSL esterase/lipase \\
\hline & & & 24541299 & $24544032 \mathrm{U}$ & UPI0001A87D1D & UPI0001A87D1D & Sb07g012315 & C5YK25_SORBI & mucin-7-like \\
\hline & & & 24560864 & $24565790 *$ & *UPI000156629A & UPI000156629A & Sb07g012320 & A5Y409_SORBI & Bt2 \\
\hline & & & 25215441 & $25216665 \mathrm{U}$ & UPIO001A87D1E & UPIO0001A87D1E & Sb07g012421 & C5YK26_SORBI & unknown function \\
\hline & & & 25266157 & $25267821 \mathrm{U}$ & UPI0001A87D1F & UP10001A87D1F & Sb07g012520 & C5YK27_SORBI & transposase \\
\hline & & & 25696240 & $25700246 \mathrm{U}$ & UP10001A87D20 & UP10001A87D20 & Sb07g012720 & C5YK28_SORBI & pyrophosphate--fructose 6-phosphate 1-phosphotransferase subunit alpha-like \\
\hline & 728238132.2 & $5.77 \mathrm{E}+02 \mathrm{~s} 7$ & $28360196 . .2836$ & 63415 & LOC8069849 & & & & ncRNA \\
\hline & 741905551.1 & $3.44 E+02 s 8$ & 42079162 & $42081307 \mathrm{U}$ & UPI0001A87EOC & UPI0001A87EOC & Sb07g016970 & C5YKE7_SORBI & exopolygalacturonase \\
\hline & 745386874.8 & $8.52 \mathrm{E}+02 \mathrm{~s} 9$ & $44889340 . .4491$ & 19902 & LOC110436757 & & & & probable adenylate kinase 5 , chloroplastic \\
\hline & 746934129.7 & $5.98 \mathrm{E}+02 \mathrm{~s} 10$ & 47495562 & $47507543 \mathrm{U}$ & UPI0001A87E83 & UPI0001A87E83 & Sb07g018430 & C5YKG9_SORBI & alpha-soluble NSF attachment protein \\
\hline & 747836695.1 & $3.47 \mathrm{E}+02 \mathrm{~s} 11$ & 47799636 & & & & & & \\
\hline & & & 47800384 & $47800926 \mathrm{U}$ & UPIO001A879A7 & UP10001A879A7 & Sb07g018630 & C5YKH1_SORBI & unknown function \\
\hline & & & 47945333 & $47949221 \mathrm{U}$ & UP10001A879A8 & UP10001A879A8 & Sb07g018640 & C5YKH2_SORBI & TNP1-like \\
\hline
\end{tabular}

Table S7 Selective sweep regions identified with SweeD and associated genes

* indicates correspondance with the Mace et al (24) candidate domestication gene list 

$\begin{array}{lllllllllllllll}0.19812036 & 0.49355768 & 0.06093679 & 0.11687131 & 0.36637866 & 0.25147794 & 0.00394119 & 0.00363802 & 0.0209186 & 0.00257693 & 0.03744126 & 0.00257693\end{array}$ $\begin{array}{lllllllllllllll}0.08473549 & 0.11914507 & 0.29953009 & 0.22313173 & 0.37653479 & 0.1159618 & 0.16659087 & 0.29013188 & 0.06017887 & 0.47536759 & 0.07003183 & 0.47536759\end{array}$ $\begin{array}{lllllllllllllll}0.47097165 & 0.44808246 & 0.31256632 & 0.3089283 & 0.40003032 & 0.43140822 & 0.22298014 & 0.06336213 & 0.28149159 & 0.27269971 & 0.29498257 & 0.27269971\end{array}$ $\begin{array}{lllllllllllllll}0.42185842 & 0.43610732 & 0.48491739 & 0.31484008 & 0.4990147 & 0.34894649 & 0.32423829 & 0.41230863 & 0.30817038 & 0.23434895 & 0.19417917 & 0.23434895\end{array}$ $\begin{array}{lllllllllllllll}0.45778384 & 0.44444444 & 0.28740337 & 0.43353039 & 0.45005305 & 0.41761407 & 0.05638927 & 0.05926936 & 0.27724723 & 0.0883735 & 0.09989389 & 0.0883735\end{array}$ $\begin{array}{lllllllllllllll}0.48719115 & 0.34803699 & 0.37517053 & 0.11747764 & 0.1444596 & 0.2955889 & 0.29953009 & 0.1787176 & 0.03168107 & 0.12566318 & 0.0351675 & 0.12566318\end{array}$

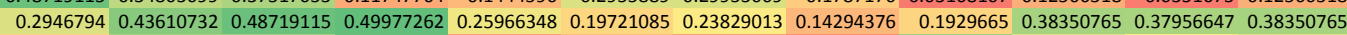
\begin{tabular}{ll|l|l|l|l|l|l|l|l|l|l|l|l|l|l|l|l|l|l|l|l}
0.18690314 & 0.38775201 & 0.39154161 & 0.49446718 & 0.09731696 & 0.14885554 & 0.104593 & 0.06790966 & 0.40427467 & 0.29210247 & 0.24465666 & 0.29210247
\end{tabular} $\begin{array}{lllllllllllllll}0.12657268 & 0.20645748 & 0.44217068 & 0.49446718 & 0.19114749 & 0.15810217 & 0.35622253 & 0.37683796 & 0.3659239 & 0.45990602 & 0.45793543 & 0.45990602\end{array}$ $\begin{array}{lllllllllllllll}0.23283311 & 0.16552979 & 0.21903896 & 0.17811126 & 0.45929968 & 0.10413824 & 0.22131272 & 0.07230559 & 0.30817038 & 0.39972715 & 0.32408671 & 0.39972715\end{array}$ $\begin{array}{lllllllllllllll}0.05714719 & 0.04259512 & 0.49446718 & 0.38623617 & 0.35015916 & 0.4780961 & 0.02940731 & 0.03061998 & 0.3659239 & 0.49598302 & 0.31711384 & 0.49598302\end{array}$ $\begin{array}{lllllllllllllll}0.1226315 & 0.12611793 & 0.47157799 & 0.3783538 & 0.45005305 & 0.38866151 & 0.01879642 & 0.02243444 & 0.40230408 & 0.04683947 & 0.04289829 & 0.04683947\end{array}$ $\begin{array}{llllllllllllllll}0.30695771 & 0.28103683 & 0.4780961 & 0.48613006 & 0.38032439 & 0.40958011 & 0.26026982 & 0.17371533 & 0.40230408 & 0.3022586 & 0.24465666 & 0.3022586\end{array}$ $\begin{array}{llllllllllllllll}0.31817493 & 0.22586024 & 0.07867212 & 0.19433076 & 0.22858875 & 0.10792785 & 0.03956344 & 0.1787176 & 0.05138699 & 0.26390784 & 0.08382598 & 0.26390784\end{array}$ $\begin{array}{llllllllllllllll}0.02667879 & 0.03440958 & 0.18326512 & 0.28452327 & 0.12869486 & 0.42595119 & 0.26421101 & 0.12066091 & 0.14749128 & 0.02213127 & 0.06684857 & 0.02213127\end{array}$ $\begin{array}{llllllllllllll}0.18523571 & 0.30013643 & 0.13475822 & 0.13172654 & 0.43171138 & 0.05623768 & 0.05381234 & 0.16689404 & 0.06169471 & 0.27269971 & 0.20190996 & 0.27269971\end{array}$ \begin{tabular}{ll|l|l|l|l|l|l|l|l|l|l|l|l}
0.29816583 & 0.48370471 & 0.31969077 & 0.44474761 & 0.26421101 & 0.17401849 & 0.42337426 & 0.06336213 & 0.17750493 & 0.25162953 & 0.31711384 & 0.25162953
\end{tabular} $\begin{array}{lllllllllllllll}0.45778384 & 0.2557223 & 0.42140367 & 0.23222677 & 0.1444596 & 0.28816129 & 0.03698651 & 0.23434895 & 0.44308019 & 0.17265424 & 0.20190996 & 0.17265424\end{array}$ \begin{tabular}{ll|l|l|l|l|l|l|l|l|l|l|l|l|l}
0.49310293 & 0.28952554 & 0.31332424 & 0.24511141 & 0.09519479 & 0.0779142 & 0.3745642 & 0.0551766 & 0.3659239 & 0.11005002 & 0.09110202 & 0.11005002
\end{tabular} $\begin{array}{llllllllllllllll}0.36243747 & 0.28952554 & 0.40791269 & 0.21145975 & 0.33121116 & 0.37501895 & 0.37350008 & 0.30726088 & 0.36774291 & 0.42837653 & 0.31711384 & 0.42837653\end{array}$ $\begin{array}{llllllllllllll}0.12323784 & 0.31772018 & 0.1435501 & 0.21934213 & 0.23162043 & 0.17614067 & 0.38153706 & 0.49840837 & 0.44308019 & 0.17598909 & 0.23601637 & 0.17598909\end{array}$ $\begin{array}{lllllllllllllll}0.03471275 & 0.01667425 & 0.1121722 & 0.23995756 & 0.29922692 & 0.41458239 & 0.35758678 & 0.48825224 & 0.04517205 & 0.16628771 & 0.14324693 & 0.16628771\end{array}$ \begin{tabular}{llllllllllllllll}
0.48279521 & 0.33909353 & 0.18887373 & 0.4144308 & 0.09458845 & 0.19220858 & 0.03956344 & 0.17371533 & 0.44308019 & 0.39972715 & 0.40093982 & 0.39972715 \\
\hline
\end{tabular} $\begin{array}{llllllllllllllll}0.00045475 & 0.00045475 & 0.2946794 & 0.42079733 & 0.40427467 & 0.23722904 & 0.47748977 & 0.18826739 & 0.44308019 & 0.31453691 & 0.39502804 & 0.31453691\end{array}$ $\begin{array}{llllllllllllllll}0.34227679 & 0.2557223 & 0.15597999 & 0.46127027 & 0.31484008 & 0.31362741 & 0.36198272 & 0.20221313 & 0.44308019 & 0.22343489 & 0.2176747 & 0.22343489\end{array}$ $\begin{array}{lllllllllllll}0.4600576 & 0.43610732 & 0.36167955 & 0.38987419 & 0.18887373 & 0.21494619 & 0.23025618 & 0.13430347 & 0.1606791 & 0.42686069 & 0.46869789 & 0.42686069\end{array}$ \begin{tabular}{ll|l|l|l|l|l|l|l|l|l|l|l|l|l}
0.04365621 & 0.01864484 & 0.47157799 & 0.4144308 & 0.1444596 & 0.1444596 & 0.4344399 & 0.473397 & 0.12141883 & 0.1502198 & 0.09004093 & 0.06533273
\end{tabular}

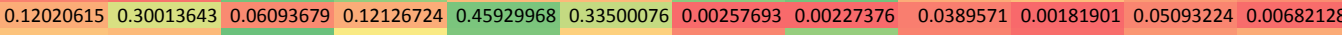
$\begin{array}{llllllllllllllll}0.16189177 & 0.14658178 & 0.48719115 & 0.24344399 & 0.45293315 & 0.18447779 & 0.05381234 & 0.41382447 & 0.04683947 & 0.00879188 & 0.0807943 & 0.11899348\end{array}$ $\begin{array}{lllllllllllllll}0.02986206 & 0.08033955 & 0.39093527 & 0.29134455 & 0.38032439 & 0.49886312 & 0.1188419 & 0.12763377 & 0.13839624 & 0.28058208 & 0.45793543 & 0.37486736\end{array}$ $\begin{array}{llllllllllllllll}0.13112021 & 0.15249356 & 0.49446718 & 0.38623617 & 0.35273609 & 0.22207064 & 0.10186448 & 0.07821737 & 0.30347127 & 0.49113233 & 0.35061392 & 0.3022586\end{array}$ $\begin{array}{lllllllllllllll}0.10125815 & 0.08033955 & 0.39533121 & 0.29134455 & 0.35273609 & 0.22586024 & 0.11565863 & 0.12763377 & 0.192057 & 0.19781719 & 0.32954373 & 0.3260573\end{array}$ $\begin{array}{lllllllllllllll}0.10792785 & 0.08594816 & 0.42837653 & 0.29877217 & 0.36107322 & 0.21812945 & 0.13854782 & 0.21585569 & 0.33348492 & 0.34439897 & 0.35061392 & 0.34940124\end{array}$ $\begin{array}{llllllllllllll}0.19887828 & 0.21327876 & 0.39154161 & 0.24602092 & 0.35485827 & 0.2955889 & 0.104593 & 0.39760497 & 0.40427467 & 0.47263908 & 0.03152948 & 0.03061998\end{array}$ $\begin{array}{llllllllllllllll}0.13354555 & 0.12157041 & 0.42837653 & 0.3089283 & 0.38153706 & 0.24207973 & 0.0627558 & 0.07230559 & 0.20782174 & 0.31256632 & 0.37956647 & 0.3260573\end{array}$ $\begin{array}{lllllllllllllll}0.13354555 & 0.12157041 & 0.4780961 & 0.31484008 & 0.45929968 & 0.25147794 & 0.05638927 & 0.13430347 & 0.27724723 & 0.49113233 & 0.16264969 & 0.12869486\end{array}$ $\begin{array}{llllllllllllllll}0.11702289 & 0.12157041 & 0.41397605 & 0.27724723 & 0.48810065 & 0.31165681 & 0.03501592 & 0.05017432 & 0.40427467 & 0.25420646 & 0.12081249 & 0.14703653\end{array}$ $\begin{array}{lllllllllllllll}0.30847355 & 0.31772018 & 0.03547067 & 0.15340306 & 0.33227224 & 0.02561771 & 0.03865393 & 0.25132636 & 0.40427467 & 0.06684857 & 0.18008186 & 0.04577838\end{array}$ $\begin{array}{llllllllllllllll}0.17280582 & 0.1226315 & 0.07260876 & 0.21312718 & 0.05775352 & 0.12445051 & 0.21464302 & 0.40381992 & 0.16416553 & 0.11095953 & 0.1891769 & 0.13339397\end{array}$ \begin{tabular}{l|l|l|l|l|l|l|l|l|l|l|l|l|l}
0.43686524 & 0.01394573 & 0.1255116 & 0.3089283 & 0.00257693 & 0.00106109 & 0.24359557 & 0.33894194 & 0.05214491 & 0.0389571 & 0.08215856 & 0.09261786
\end{tabular} $\begin{array}{lllllllllllllll}0.06230105 & 0.13490981 & 0.09519479 & 0.15340306 & 0.38790359 & 0.36774291 & 0.22298014 & 0.15294831 & 0.08958618 & 0.09246627 & 0.40093982 & 0.36728816\end{array}$ $\begin{array}{lllllllllllllll}0.24768834 & 0.17462483 & 0.21464302 & 0.2737608 & 0.13930575 & 0.44156435 & 0.32620888 & 0.12217675 & 0.16416553 & 0.45308474 & 0.18008186 & 0.30786721\end{array}$ $\begin{array}{llllllllllllllll}0.05487343 & 0.01167197 & 0.01106564 & 0.15340306 & 0.14491436 & 0.0209186 & 0.01212672 & 0.23434895 & 0.47991511 & 0.49113233 & 0.29361831 & 0.26178566\end{array}$ $\begin{array}{llllllllllllllll}0.35440352 & 0.38775201 & 0.19266333 & 0.02455662 & 0.18887373 & 0.03638017 & 0.18569047 & 0.04744581 & 0.25117478 & 0.34167046 & 0.44232227 & 0.27269971\end{array}$ \begin{tabular}{|l|l|l|l|l|l|l|l|l|l|l|l|l|l|l}
0.35440352 & 0.38775201 & 0.19266333 & 0.02455662 & 0.18887373 & 0.03638017 & 0.18569047 & 0.04744581 & 0.25117478 & 0.34167046 & 0.44232227 & 0.27269971 \\
0.22010005 & 0.31772018 & 0.4629377 & 0.14521752 & 0.28770653 & 0.31362741 & 0.30923147 & 0.34106412 & 0.09701379 & 0.123541 & 0.22495074 & 0.12566318 \\
\hline
\end{tabular} \begin{tabular}{|r|r|r|r|r|r|r|r|r|r|r|r|}
0.22010005 & 0.31772018 & 0.4629377 & 0.14521752 & 0.28770653 & 0.31362741 & 0.30923147 & 0.34106412 & 0.09701379 & 0.123541 & 0.22495074 & 0.12566318 \\
\hline 0.02395028 & 0.03031681 & 0.28179476 & 0.14688495 & 0.20554798 & 0.25375171 & 0.20024253 & 0.32272245 & 0.48324996 & 0.01303623 & 0.01909959 & 0.47536759 \\
\hline 0.1507
\end{tabular} $\begin{array}{llllllllllllllll}0.15507049 & 0.27269971 & 0.31332424 & 0.01182356 & 0.11656814 & 0.03835077 & 0.49082916 & 0.01682583 & 0.1302107 & 0.12884645 & 0.16037593 & 0.15673791\end{array}$ \begin{tabular}{llllllllllllllll}
0.07215401 & 0.13172654 & 0.24829468 & 0.13248446 & 0.08625133 & 0.43747158 & 0.18796423 & 0.15294831 & 0.0447173 & 0.0569956 & 0.1891769 & 0.05396392 \\
\hline
\end{tabular} \begin{tabular}{ll|l|l|l|l|l|l|l|l|l|l|l|l|l|l|l|l}
0.01015613 & 0.01167197 & 0.39533121 & 0.06639382 & 0.28361376 & 0.10944369 & 0.14067 & 0.18826739 & 0.1929665 & 0.37107776 & 0.32954373 & 0.42837653
\end{tabular} $\begin{array}{lllllllllllllll}0.26557526 & 0.47203274 & 0.25435804 & 0.34940124 & 0.28846445 & 0.11444596 & 0.39275428 & 0.12763377 & 0.30817038 & 0.37107776 & 0.34106412 & 0.36228589\end{array}$ $\begin{array}{lllllllllllllll}0.34227679 & 0.48370471 & 0.31332424 & 0.1996362 & 0.31756859 & 0.45172048 & 0.49492193 & 0.18826739 & 0.01682583 & 0.01364256 & 0.12975595 & 0.15673791\end{array}$ $\begin{array}{lllllllllllllll}0.44656662 & 0.48370471 & 0.34091254 & 0.44777929 & 0.47006215 & 0.31726542 & 0.21464302 & 0.46703047 & 0.04911323 & 0.05426709 & 0.22661816 & 0.34940124\end{array}$ $\begin{array}{lllllllllllllll}0.33181749 & 0.30013643 & 0.07867212 & 0.3783538 & 0.09231469 & 0.48446263 & 0.20691223 & 0.20903441 & 0.192057 & 0.37107776 & 0.14188267 & 0.27679248\end{array}$ $\begin{array}{lllllllllllllll}0.05259967 & 0.0598757 & 0.30680612 & 0.40927694 & 0.43171138 & 0.47203274 & 0.11020161 & 0.0551766 & 0.11050477 & 0.1083826 & 0.17068364 & 0.16628771\end{array}$ $\begin{array}{llllllllllllllll}0.08473549 & 0.11156586 & 0.18508413 & 0.18038502 & 0.11535546 & 0.10050023 & 0.12990753 & 0.11232378 & 0.08276489 & 0.04517205 & 0.0807943 & 0.06139154\end{array}$ $\begin{array}{lllllllllllllll}0.36243747 & 0.1862968 & 0.21464302 & 0.39396695 & 0.06593906 & 0.19433076 & 0.39987873 & 0.17341216 & 0.30347127 & 0.28058208 & 0.47112324 & 0.45990602\end{array}$ $\begin{array}{llllllllllllll}0.04107928 & 0.08594816 & 0.36046688 & 0.25678339 & 0.4990147 & 0.34894649 & 0.29998484 & 0.19539184 & 0.33469759 & 0.19781719 & 0.25162953 & 0.11141428\end{array}$ $\begin{array}{llllllllllllllll}0.49310293 & 0.09170835 & 0.04714264 & 0.1653782 & 0.15522207 & 0.0075792 & 0.05093224 & 0.28634228 & 0.25117478 & 0.23419736 & 0.1891769 & 0.17598909\end{array}$ \begin{tabular}{ll|l|l|l|l|l|l|l|l|l|l|l|l|l|l|l|l|l|l|l}
0.4600576 & 0.47203274 & 0.01273306 & 0.42079733 & 0.02031226 & 0.37441261 & 0.0113688 & 0.24859785 & 0.20782174 & 0.02137335 & 0.23601637 & 0.03304532
\end{tabular} $\begin{array}{llllllllllllll}0.12020615 & 0.16552979 & 0.10989844 & 0.31529483 & 0.06123996 & 0.43140822 & 0.09140518 & 0.29998484 & 0.40230408 & 0.47263908 & 0.12581476 & 0.09943914\end{array}$ $\begin{array}{lllllllllllllll}0.27239654 & 0.01000455 & 0.08018796 & 0.2147946 & 0.0009095 & 0.00697287 & 0.23025618 & 0.1482492 & 0.1691678 & 0.15006821 & 0.41503714 & 0.45990602\end{array}$ $\begin{array}{lllllllllllllll}0.42185842 & 0.43383356 & 0.19417917 & 0.36304381 & 0.10959527 & 0.16113385 & 0.14430802 & 0.1891769 & 0.27724723 & 0.18462938 & 0.46869789 & 0.45990602\end{array}$

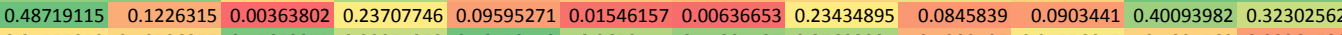
\begin{tabular}{ll|l|l|l|l|l|l|l|l|l|l|l|l}
0.21555252 & 0.19796877 & 0.45672275 & 0.32954373 & 0.48173412 & 0.3650144 & 0.41094437 & 0.37608004 & 0.1302107 & 0.24556617 & 0.1891769 & 0.09261786
\end{tabular} $\begin{array}{lllllllllllllll}0.14961346 & 0.28952554 & 0.0075792 & 0.0218281 & 0.00045475 & 0.00045475 & 0.4344399 & 0.38562983 & 0.05366075 & 0.1083826 & 0.25162953 & 0.02728513\end{array}$ $\begin{array}{lllllllllllllll}0.45778384 & 0.40215249 & 0.10959527 & 0.2034258 & 0.3118084 & 0.38290132 & 0.35622253 & 0.44368652 & 0.33348492 & 0.49113233 & 0.42943762 & 0.47536759\end{array}$ $\begin{array}{lllllllllllllll}0.45778384 & 0.44444444 & 0.1435501 & 0.27785357 & 0.28846445 & 0.38896468 & 0.35015916 & 0.39760497 & 0.05729877 & 0.15855692 & 0.05366075 & 0.17598909\end{array}$ \begin{tabular}{lllll|l|l|l|l|l|l|l|l|l|l|l}
0.34212521 & 0.29195089 & 0.39745339 & 0.23707746 & 0.48173412 & 0.29695316 & 0.47248749 & 0.25132636 & 0.1302107 & 0.17356374 & 0.16264969 & 0.21631044
\end{tabular}

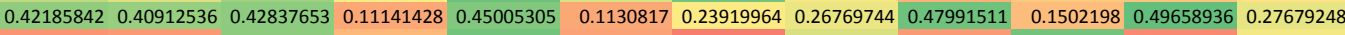
\begin{tabular}{ll|l|l|l|l|l|l|l|l|l|l|l|l|l|l}
0.07745945 & 0.08716083 & 0.42564802 & 0.1435501 & 0.47157799 & 0.10307716 & 0.03698651 & 0.29786266 & 0.08822192 & 0.47263908 & 0.05957253 & 0.25162953
\end{tabular} $\begin{array}{lllllllllllllll}0.18523571 & 0.17053206 & 0.06427164 & 0.10807943 & 0.08503865 & 0.10944369 & 0.28027891 & 0.25132636 & 0.03592542 & 0.12748219 & 0.03077156 & 0.08321965\end{array}$ $\begin{array}{lllllllllllllll}0.01455207 & 0.17462483 & 0.00424435 & 0.00939821 & 0.37153251 & 0.45596483 & 0.36228589 & 0.20221313 & 0.0560861 & 0.04532363 & 0.11444596 & 0.16674246\end{array}$ $\begin{array}{llllllllllllll}0.14612703 & 0.34803699 & 0.27315446 & 0.02880097 & 0.05532818 & 0.10944369 & 0.03319691 & 0.20221313 & 0.27724723 & 0.08700925 & 0.46869789 & 0.29119297\end{array}$ \begin{tabular}{ll|l|l|l|l|l|l|l|l|l|l|l|l|l}
0.21252084 & 0.23071093 & 0.4981052 & 0.24511141 & 0.45929968 & 0.28543277 & 0.38077914 & 0.42974079 & 0.192057 & 0.31256632 & 0.11050477 & 0.11899348
\end{tabular} $\begin{array}{llllllllllllllll}0.17356374 & 0.27269971 & 0.15446415 & 0.18038502 & 0.36107322 & 0.43140822 & 0.15507049 & 0.15385781 & 0.47991511 & 0.25420646 & 0.42943762 & 0.30786721\end{array}$ $\begin{array}{llllllllllllll}0.19251175 & 0.12157041 & 0.17841443 & 0.104593 & 0.47521601 & 0.2499621 & 0.38896468 & 0.39624072 & 0.20782174 & 0.12005457 & 0.32408671 & 0.20888283\end{array}$ 
chromosome position GERP score range highest lowest associated selection signal peaks

110600000

12100000

13000000

13200000

18800000

19000000

19500000

19900000

20400000

22700000

23900000

26000000

27300000

29000000

31200000

31400000

31500000

39600000

43600000

43900000

45000000

46600000

22700000

10400000

10500000

12800000

15800000

18500000

22000000

22900000

26300000

30300000

30400000

30800000

31000000

31100000

37500000

39200000

39900000

52000000

52700000

53800000

54300000

66900000

67800000

76700000

38100000

19500000

20500000

23200000

28200000

33400000

36300000

42000000

42500000

54900000

62100000

62200000

$4 \quad 13400000$

13900000

19000000

23900000

24000000

27500000
$0.18401937 \mathrm{M} 5 \quad \mathrm{M} 2$

0.818181818 A11 M2

0.666666667 A11 A10

0.27443609 A10 A3

0.524390244 A10 $\quad M 2$

0.22027972 A5 M2

$0.442307692 \mathrm{M} 2 \quad$ A10

0.214046823 A10 A6

0.380952381 Kew1 A11

$0.243445693 \mathrm{M} 6 \quad \mathrm{M} 2$

0.305555556 A10 M2

0.195488722 A3 M6

0.188034188 A11 A9

$0.236842105 \mathrm{M} 6 \quad \mathrm{M} 2$

0.209424084 A10 M6

0.186567164 M5 M6

0.188235294 A11 M6

0.962962963 A10 A5

$0.222698073 \mathrm{M} 5 \quad$ A10

0.605042017 A3 M2

0.5 Kew1 M2

$0.25382263 \mathrm{M} 6 \quad$ A5

0.169745958 Kew1 A10

0.37295082 M5 M2

$0.159751037 \mathrm{M} 6 \quad \mathrm{M} 2$

0.27173913 A3 $\quad M 2$

$0.16 \mathrm{~A} 10 \quad \mathrm{A3}$

$0.27027027 \mathrm{M} 2 \quad \mathrm{~A} 10$

0.517241379 Kew1 A5

$0.32238806 \mathrm{M} 6 \quad$ A9

0.467532468 A6 A11

0.386554622 A10 M2

0.222222222 A10 M2

0.262365591 A5 M2

0.265060241 A10 Kew1

0.242038217 A3 $\quad M 2$

$0.2734375 \mathrm{M} 6 \quad \mathrm{~A} 3$

0.28125 A11 A10

0.195652174 A3 $\quad M 2$

0.862222222 A3 M2

0.208510638 A7 $\quad M 2$

$0.2375 A 10 \quad A 11$

$0.418316832 \mathrm{M} 6 \quad \mathrm{M} 2$

$0.153846154 \mathrm{M} 5 \quad$ A9

0.153310105 A10 M2

0.466666667 A10 A7

$1.2 \mathrm{~A} 3 \quad \mathrm{~A} 10$

0.5 A11 A10

0.25 A11 A10

$0.208566108 \mathrm{M} 2 \quad$ A5

0.331818182 A3 A10

0.308539945 A6 $\quad M 2$

0.666666667 A10 M6

0.285714286 A10 M6

0.607260726 A9 M2

0.641025641 A7 $\quad$ M2

0.717948718 A11 A5

0.877005348 A3 $\quad$ A7

0.666666667 A10 A3

0.333333333 A3 $\quad$ A10

0.75 A10 A5

0.471177945 Kew1 M2

0.214477212 A3 M2

0.244897959 Kew1 M2
Sh1

pk4

pk5, s2

pk8 


\begin{tabular}{|c|c|c|c|c|}
\hline \multicolumn{2}{|c|}{27600000} & $0.210023866 \mathrm{M} 6$ & M2 & \\
\hline & 32300000 & 0.296296296 A10 & M6 & \\
\hline & 32700000 & 0.506849315 A3 & M2 & pk9 \\
\hline & 34200000 & 0.210663199 A10 & A7 & \\
\hline & 36100000 & 0.196721311 A3 & Kew1 & \\
\hline & 36900000 & 0.425396825 A11 & M2 & \\
\hline & 44100000 & $0.354330709 \mathrm{M} 6$ & A9 & \\
\hline & 47600000 & 0.189542484 A10 & A6 & \\
\hline & 57400000 & $1.125 \mathrm{~A} 10$ & Kew1 & \\
\hline & 58200000 & 0.376068376 A10 & A3 & \\
\hline 5 & 6000000 & 0.977777778 A5 & M2 & \\
\hline & 6100000 & 0.406015038 A10 & M2 & \\
\hline & 9100000 & 0.728323699 A6 & A11 & \\
\hline & 11900000 & $0.412280702 \mathrm{M} 6$ & A10 & \\
\hline & 12000000 & 0.438202247 A6 & A11 & \\
\hline & 14100000 & 0.308300395 A10 & M6 & \\
\hline & 17900000 & 0.37254902 A10 & M6 & \\
\hline & 22700000 & $0.277777778 \mathrm{M} 6$ & M2 & \\
\hline & 23800000 & $0.3 \mathrm{~A} 10$ & A7 & \\
\hline & 24900000 & 0.287356322 A10 & M2 & \\
\hline & 42000000 & 0.240469208 A3 & A10 & \\
\hline & 44800000 & 0.541176471 A3 & M2 & \\
\hline & 48500000 & $0.350553506 \mathrm{M} 6$ & A10 & \\
\hline & 49400000 & 0.737777778 Kew1 & M2 & \\
\hline & 50000000 & 0.448717949 A10 & M2 & \\
\hline & 50600000 & 0.350515464 A5 & M2 & s5 \\
\hline & 50700000 & $0.321782178 \mathrm{M} 6$ & M2 & \\
\hline & 51000000 & $0.234332425 \mathrm{M} 6$ & M2 & \\
\hline & 54000000 & $0.484018265 \mathrm{M} 5$ & A3 & \\
\hline & 55100000 & 1.1555555566 A9 & A10 & \\
\hline & 57200000 & $0.453333333 \mathrm{M} 5$ & Kew1 & \\
\hline 6 & 6700000 & $0.23015873 \mathrm{M} 2$ & A10 & \\
\hline & 6800000 & $1.04 \mathrm{~A} 11$ & A7 & \\
\hline & 7500000 & 0.168316832 Kew1 & A7 & \\
\hline & 9900000 & 0.213675214 A5 & A9 & \\
\hline & 10400000 & 0.157303371 A7 & M2 & \\
\hline & 14500000 & 0.171945701 A5 & M2 & \\
\hline & 15900000 & $0.289398281 \mathrm{M} 5$ & A10 & \\
\hline & 16000000 & 0.584269663 A3 & M2 & \\
\hline & 24000000 & 0.174863388 A3 & M2 & \\
\hline & 24300000 & 0.339047619 M5 & M2 & \\
\hline & 26600000 & 0.152671756 A3 & A10 & \\
\hline & 28600000 & $0.298181818 \mathrm{M} 5$ & M2 & pk17 \\
\hline & 32000000 & $0.2 \mathrm{~A} 9$ & M2 & \\
\hline & 33500000 & 0.319767442 A3 & M2 & \\
\hline & 34200000 & 0.239043825 M5 & M2 & \\
\hline & 38300000 & 0.178571429 A10 & A5 & \\
\hline 7 & 600000 & 0.384937238 A5 & A10 & \\
\hline & 7000000 & $0.8 \mathrm{~A} 10$ & Kew1 & \\
\hline & 9100000 & 0.20441989 Kew1 & A5 & \\
\hline & 10000000 & 0.377135348 A5 & M2 & \\
\hline & 15300000 & 0.18344519 M5 & A11 & \\
\hline & 15500000 & 0.261538462 M5 & A6 & \\
\hline & 17600000 & 0.224137931 A10 & M6 & \\
\hline & 17800000 & $0.5 \mathrm{~A} 3$ & M2 & \\
\hline & 24700000 & 0.215246637 A10 & A5 & Bt2 \\
\hline & 25100000 & 0.339285714 A10 & M6 & s6 \\
\hline & 25200000 & 0.231974922 Kew1 & M6 & \\
\hline & 25300000 & $0.5 \mathrm{~A} 10$ & M6 & \\
\hline & 26000000 & 0.198300283 A10 & M6 & \\
\hline & 28200000 & 0.189189189 A10 & A5 & s7 \\
\hline & 28700000 & $0.4375 \mathrm{~A} 10$ & A3 & \\
\hline & 38700000 & 0.256157635 Kew1 & A3 & \\
\hline & 39900000 & 0.208144796 A10 & Kew1 & \\
\hline & 47100000 & $0.38 \mathrm{~A} 10$ & A3 & \\
\hline & 47800000 & 0.295964126 A10 & A5 & s11 \\
\hline & 48000000 & 0.217741935 A10 & A3 & \\
\hline
\end{tabular}




\begin{tabular}{|c|c|c|c|}
\hline 48600000 & 0.302197802 A10 & A3 & \\
\hline 51200000 & $0.2 \mathrm{~A} 10$ & M2 & \\
\hline 53100000 & 0.202941176 A10 & M2 & \\
\hline 57600000 & 0.260869565 A10 & M2 & \\
\hline 58100000 & 0.649425287 A7 & Kew1 & \\
\hline 59800000 & 0.227272727 A10 & M6 & dw3 \\
\hline 61900000 & 0.239669421 A10 & A9 & TGA1 \\
\hline 63200000 & $0.237541528 \mathrm{M} 6$ & A3 & pk20 \\
\hline 64300000 & 0.404255319 A3 & Kew1 & \\
\hline 5500000 & 0.301754386 A5 & M2 & \\
\hline 6600000 & $0.625 \mathrm{~A} 10$ & A3 & \\
\hline 8500000 & 0.34893617 M5 & Kew1 & \\
\hline 39000000 & $0.595555556 \mathrm{M} 5$ & M2 & \\
\hline 40600000 & 1.157894737 A10 & M2 & pk24 \\
\hline 40800000 & 0.27076412 A10 & M2 & \\
\hline 45500000 & 0.5 A5 & A10 & \\
\hline 51800000 & 0.753623188 A11 & A5 & \\
\hline 54000000 & 0.575342466 A10 & Kew1 & \\
\hline 54500000 & 0.865384615 A10 & M2 & \\
\hline 54800000 & 1.368421053 A10 & A3 & \\
\hline 55100000 & 0.29787234 A3 & A10 & \\
\hline 900000 & 0.145762712 M5 & M2 & \\
\hline 4800000 & 0.181818182 A3 & A10 & \\
\hline 5100000 & $0.195744681 \mathrm{M} 2$ & A7 & \\
\hline 5200000 & 0.212598425 A11 & M2 & \\
\hline 7700000 & 0.117647059 A3 & A10 & \\
\hline 9800000 & 0.146443515 A7 & Kew1 & \\
\hline 10600000 & $0.375 \mathrm{~A} 10$ & M6 & \\
\hline 11800000 & 0.123966942 A10 & A3 & \\
\hline 12400000 & 0.202531646 M5 & A10 & \\
\hline 12500000 & $0.1625 \mathrm{M} 5$ & A7 & \\
\hline 12700000 & 0.44015444 M5 & M2 & \\
\hline 14200000 & $0.159509202 \mathrm{M} 6$ & A10 & \\
\hline 23800000 & 0.214511041 A3 & A7 & \\
\hline 24900000 & 0.396694215 A3 & M2 & \\
\hline 26700000 & 0.247619048 A10 & M6 & \\
\hline 34300000 & 0.117647059 A5 & A3 & \\
\hline 36900000 & 0.222222222 A3 & M2 & \\
\hline 37900000 & 0.185661765 A5 & A11 & \\
\hline 38100000 & 0.18522602 A11 & A7 & \\
\hline 41300000 & 0.158878505 A10 & A5 & \\
\hline 42000000 & 0.270967742 A10 & A5 & pk26 \\
\hline 42900000 & 0.17989418 A3 & Kew1 & \\
\hline 44300000 & 0.191616766 A10 & M2 & \\
\hline 45900000 & $0.140540541 \mathrm{M} 5$ & M2 & \\
\hline 47100000 & $0.236686391 \mathrm{~A} 10$ & M2 & \\
\hline 6100000 & 0.888888889 АЗ & A10 & \\
\hline 6200000 & 0.363636364 A10 & A5 & \\
\hline 11600000 & 0.621848739 A3 & M6 & \\
\hline 12900000 & 0.232142857 A9 & M6 & \\
\hline 14100000 & 0.502617801 A11 & M2 & \\
\hline 15000000 & $1.333333333 \mathrm{~A} 10$ & A3 & \\
\hline 16700000 & 0.213675214 A6 & A10 & \\
\hline 20400000 & 0.456410256 A3 & A11 & \\
\hline 21500000 & 0.21978022 A5 & A7 & pk28 \\
\hline 24600000 & 0.259136213 A11 & M6 & \\
\hline 26700000 & 0.238636364 A3 & A5 & \\
\hline 36700000 & 0.583892617 A10 & A5 & \\
\hline 39100000 & 0.264285714 A10 & A5 & \\
\hline 49100000 & 0.410958904 M5 & M2 & \\
\hline 49500000 & 0.242105263 A6 & A3 & \\
\hline
\end{tabular}

Table S9 Regions of GERP score deviation between genomes $>2$ standard deviations 


\begin{tabular}{|c|c|c|c|c|}
\hline gene & window & tree number & phylogenetic incongruence & potential donor \\
\hline dw3 & 479000000 & 704 bicolor $\mathrm{A} 3-\mathrm{A} 5, \mathrm{~A} 7$, durra $\mathrm{A} 10$ & no & no \\
\hline dw1 & 596200000 & 876 bicolor $A 6$ & yes & durra A11 \\
\hline$d w 2$ & 396300000 & 582 bicolor A3-A5 & no & no \\
\hline su & 482600000 & 709 bicolor A3-A5,A7 & yes & durra A11 \\
\hline SPS2 & 232100000 & 341 bicolor A3-A5,A6-A7 & no & no \\
\hline SUS1 & 59600000 & 87 bicolor A3-A5, A5-A6 & yes & durra $\mathrm{A} 11, \mathrm{~A} 9$ \\
\hline SPS5 & 653100000 & 960 bicolor A3-A5 & no & no \\
\hline Sh3/Bt1 & 233300000 & 342 bicolor A7 & yes & no \\
\hline TB1 & 9100000 & 13 bicolor A5-A6,A7 & no & no \\
\hline $\mathrm{O} 2$ & 362200000 & 532 bicolor $A 6, A 7$ & yes & durra $\mathrm{A} 11, \mathrm{~A} 10$ \\
\hline SPS3 & 307500000 & 452 bicolor $A 6-A 7$ & yes & durra $\mathrm{A} 10$ \\
\hline Sh1 & 12100000 & 17 bicolor $\mathrm{A} 3$ & no & no \\
\hline Ae1 & 277600000 & 408 bicolor wild-A3, A9-A10 & no & no \\
\hline int1 & 219200000 & 322 bicolor wild-A3,A7 & yes & no \\
\hline gt1 & 66700000 & 98 durra $\mathrm{A} 11-\mathrm{A} 9$, bicolor $\mathrm{A} 7$ & yes & durra A11 \\
\hline SUT4 & 539000000 & 792 durra $A 9-A 10, A 7$ & yes & no \\
\hline TGA1 & 481000000 & 707 bicolor A7 & yes & durra A9, A10 \\
\hline ma3 & 68000000 & 99 durra A11-A9 & yes & bicolor A3,A5 \\
\hline ma6 & 363700000 & 534 durra A11-A9 & yes & bicolor A5 \\
\hline pk1 & 44900000 & 66 durra $\mathrm{A} 10$ & no & no \\
\hline pk2 & 84900000 & 124 bicolor A5 & no & no \\
\hline pk3 & 117800000 & 173 bicolor $\mathrm{A} 3$ & no & no \\
\hline pk4 & 127600000 & 187 bicolor $A 6$ & yes & no \\
\hline pk5 & 128100000 & 188 bicolor $\mathrm{A} 3, \mathrm{~A} 5-\mathrm{A} 6, \mathrm{~A} 7$ durra $\mathrm{A} 11$ & yes & bicolor A3 \\
\hline pk6 & 184600000 & 271 bicolor $\mathrm{A} 3$ & no & no \\
\hline pk7 & 244500000 & 359 bicolor A5 & yes & durra A9 \\
\hline pk8 & 253900000 & 373 durra $A 9, \mathrm{~A} 10$ & yes & bicolor A6 \\
\hline pk9 & 259200000 & 381 durra A11 & no & no \\
\hline pk10 & 263700000 & 387 bicolor $\mathrm{A} 3$ & no & no \\
\hline pk11 & 309400000 & 454 bicolor $\mathrm{A} 3$ & yes & no \\
\hline pk12 & 322400000 & 473 durra A11 & no & no \\
\hline pk13 & 337800000 & 496 bicolor $\mathrm{A} 3$ & no & no \\
\hline pk14 & 354000000 & 520 bicolor $A 7$ & yes & no \\
\hline pk15 & 355600000 & 522 bicolor wild-A3,A5,A6,A7 & yes & no \\
\hline pk16 & 379500000 & 557 bicolor $A 6$ & no & no \\
\hline pk17 & 385500000 & 566 durra A11 & yes & no \\
\hline pk18 & 469900000 & 690 durra A11 & no & no \\
\hline pk19 & 482300000 & 709 bicolor wild-A3, A7 & yes & no \\
\hline pk20 & 495900000 & 729 bicolor $A 6$ & yes & no \\
\hline pk21 & 513100000 & 754 bicolor A7 & no & no \\
\hline pk22 & 515000000 & 757 bicolor $A 5, A 6$ & yes & no \\
\hline pk23 & 516500000 & 759 durra $\mathrm{A} 11, \mathrm{~A} 9, \mathrm{~A} 10$ bicolor $\mathrm{A} 7$ & no & no \\
\hline pk24 & 524200000 & 770 bicolor $\mathrm{A5}$ & no & no \\
\hline pk25 & 536500000 & 788 bicolor $\mathrm{A} 3$ & no & no \\
\hline pk26 & 581100000 & 854 bicolor A5, durra A11-A9 & yes & bicolor A5 \\
\hline pk27 & 616500000 & 906 bicolor $A 6$ & no & no \\
\hline pk28 & 620300000 & 911 bicolor A7 & no & no \\
\hline pk29 & 635300000 & 933 durra $\mathrm{A} 11, \mathrm{~A} 10$ & yes & bicolor A6 \\
\hline pk30 & 625800000 & 920 bicolor A7 & yes & no \\
\hline
\end{tabular}

Table S10 Phylogenetic congruence of regions containing significant reductions in heterozygosity 

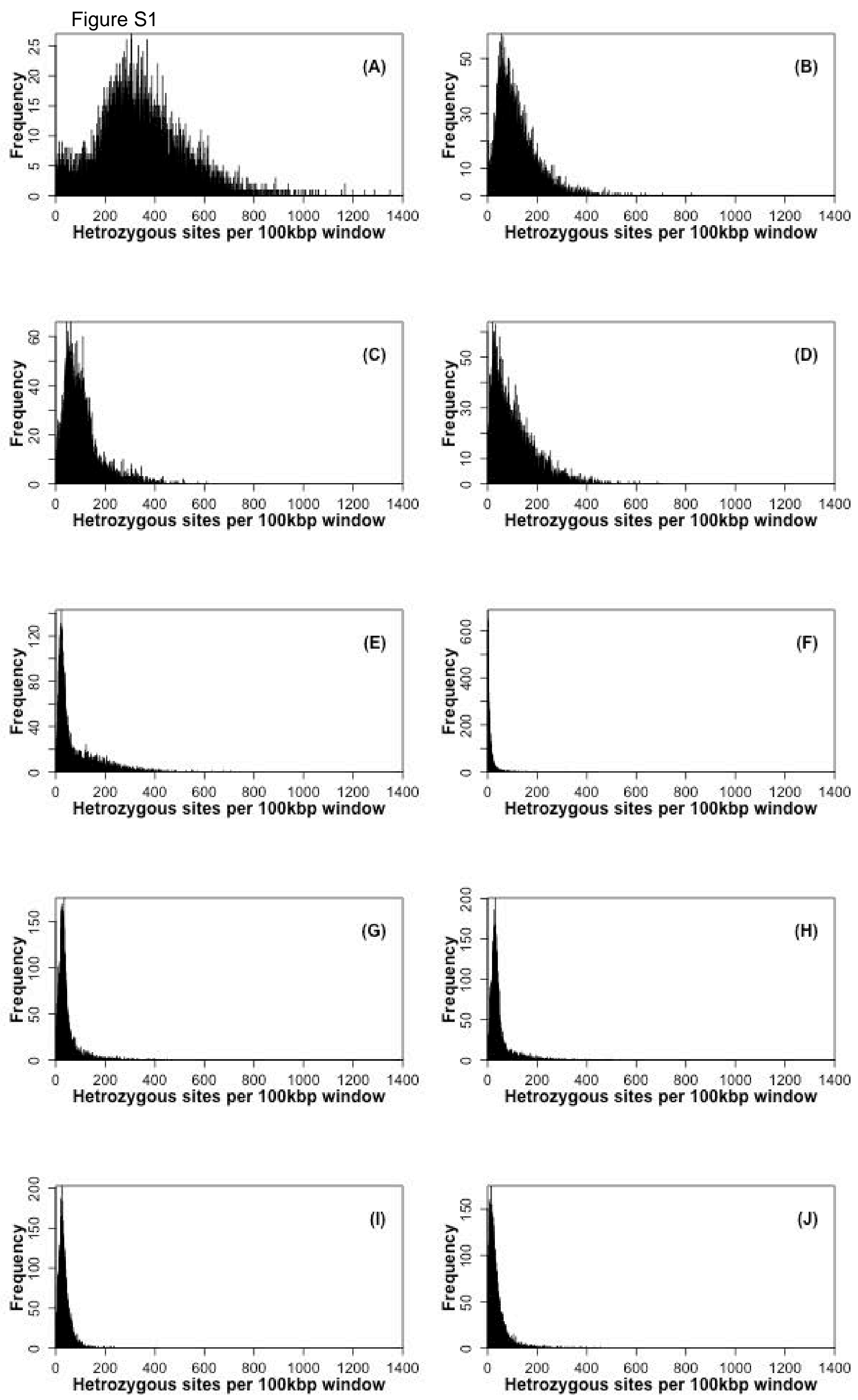


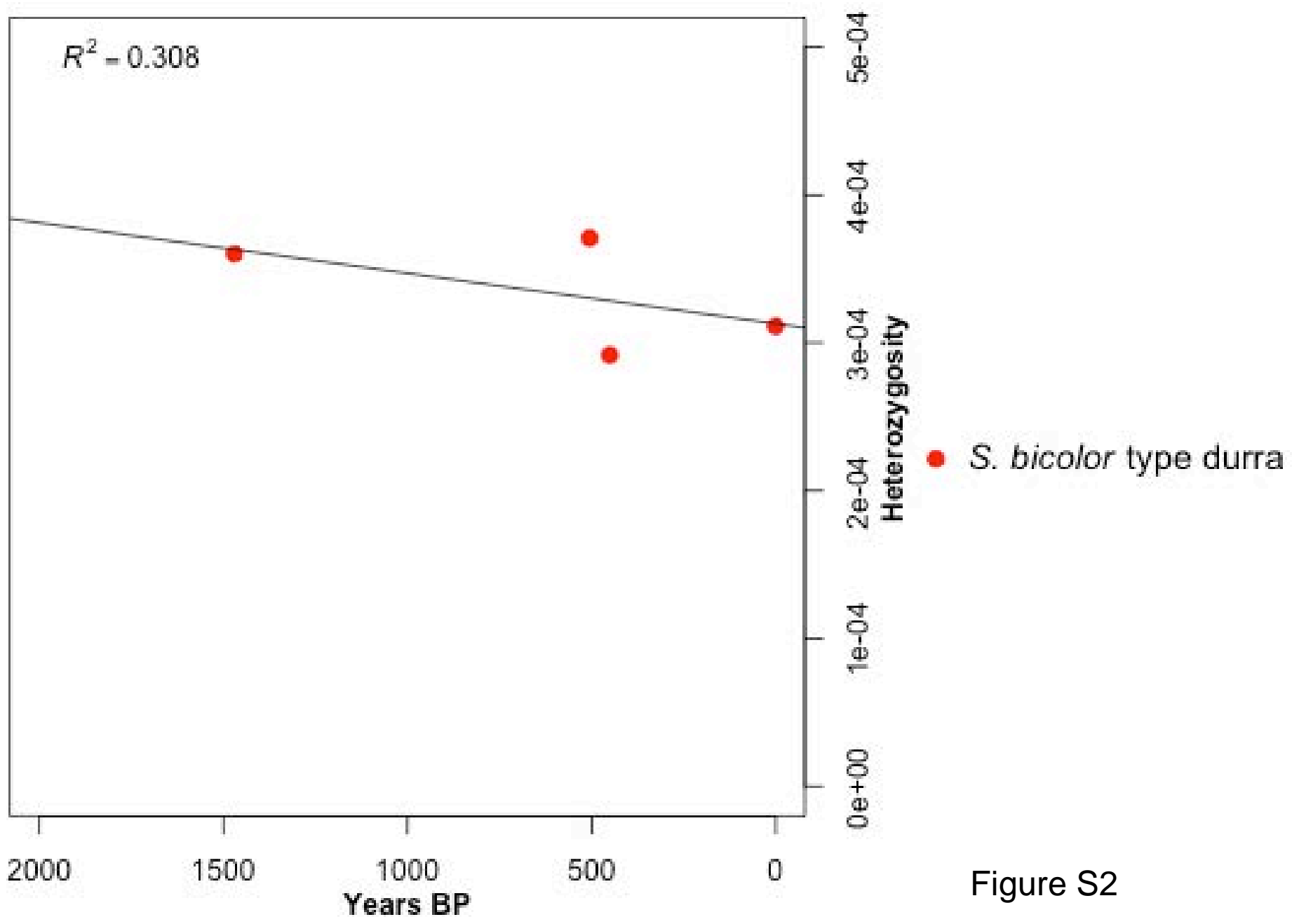



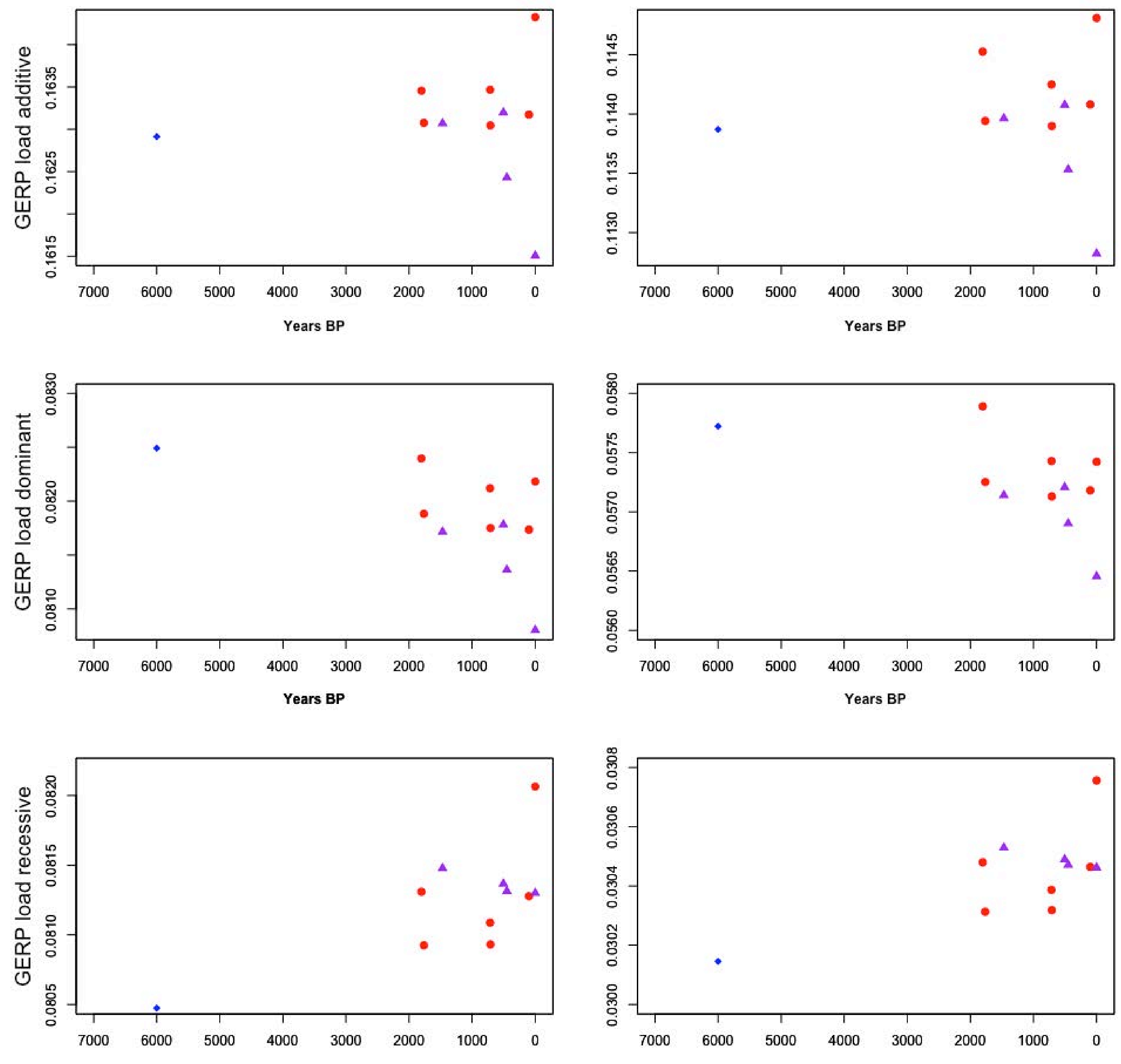

Years BP

Years BP

Figure S3

- Wild sorghum

- S. bicolor type bicolor $\Delta$ S. bicolor type durra 


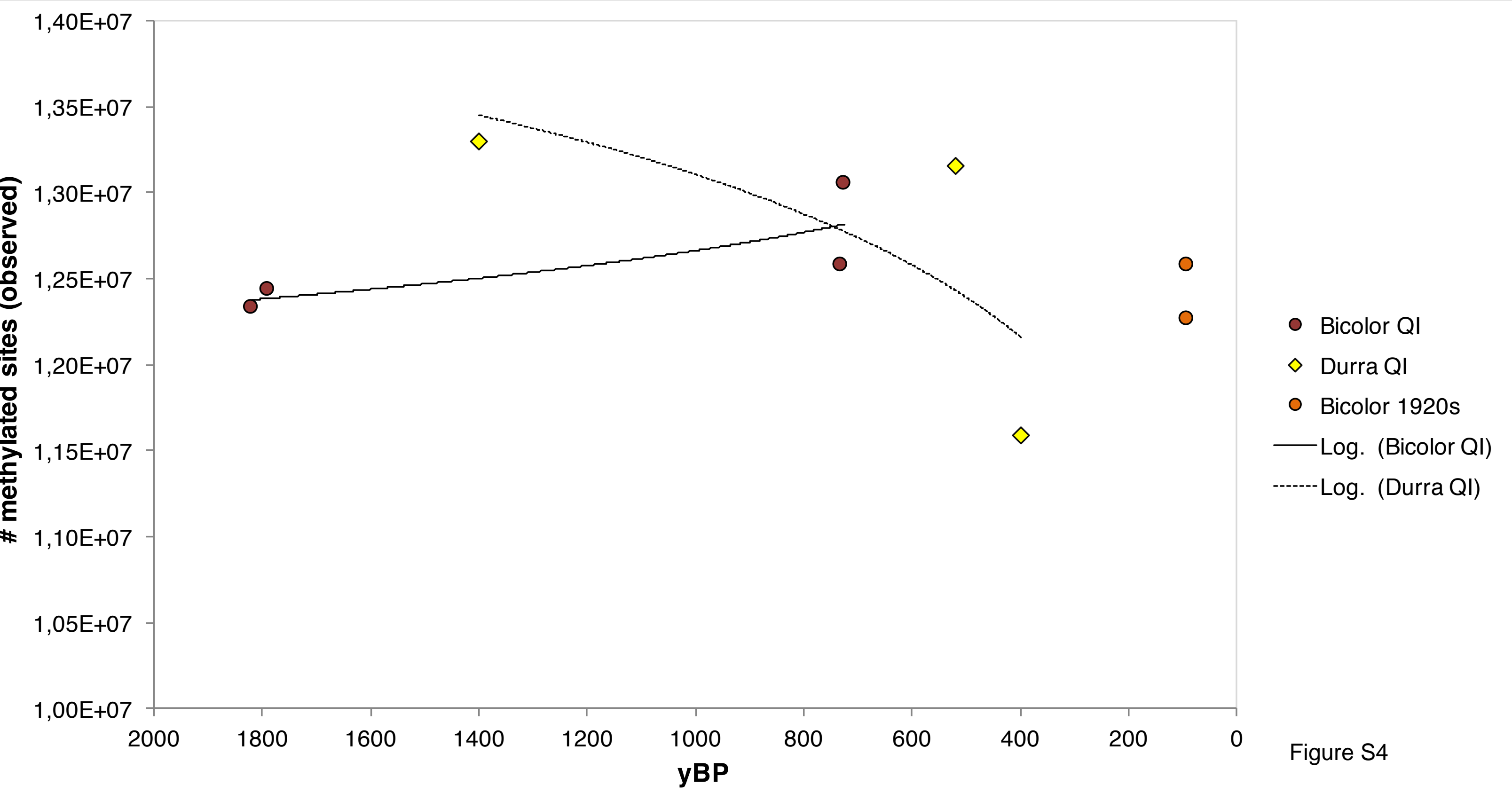




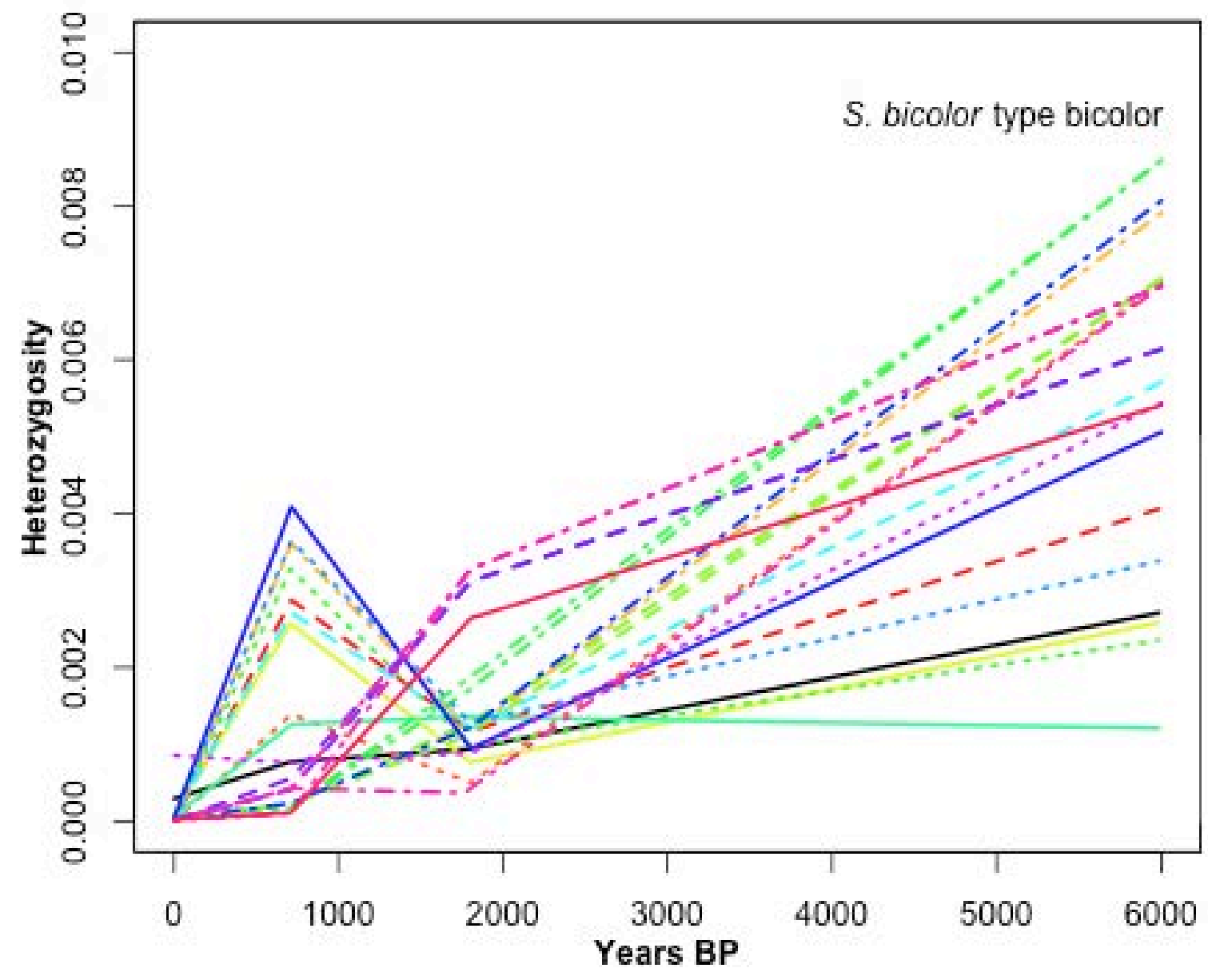
- Genome - SPS2
-- dw3 .... SPS3
dw2 ... SPS5
Sh3/Bt1- su
Bt2 - SUS1
AE1 ....
cul4 ... TB1
int1 - TGA1
SPS1

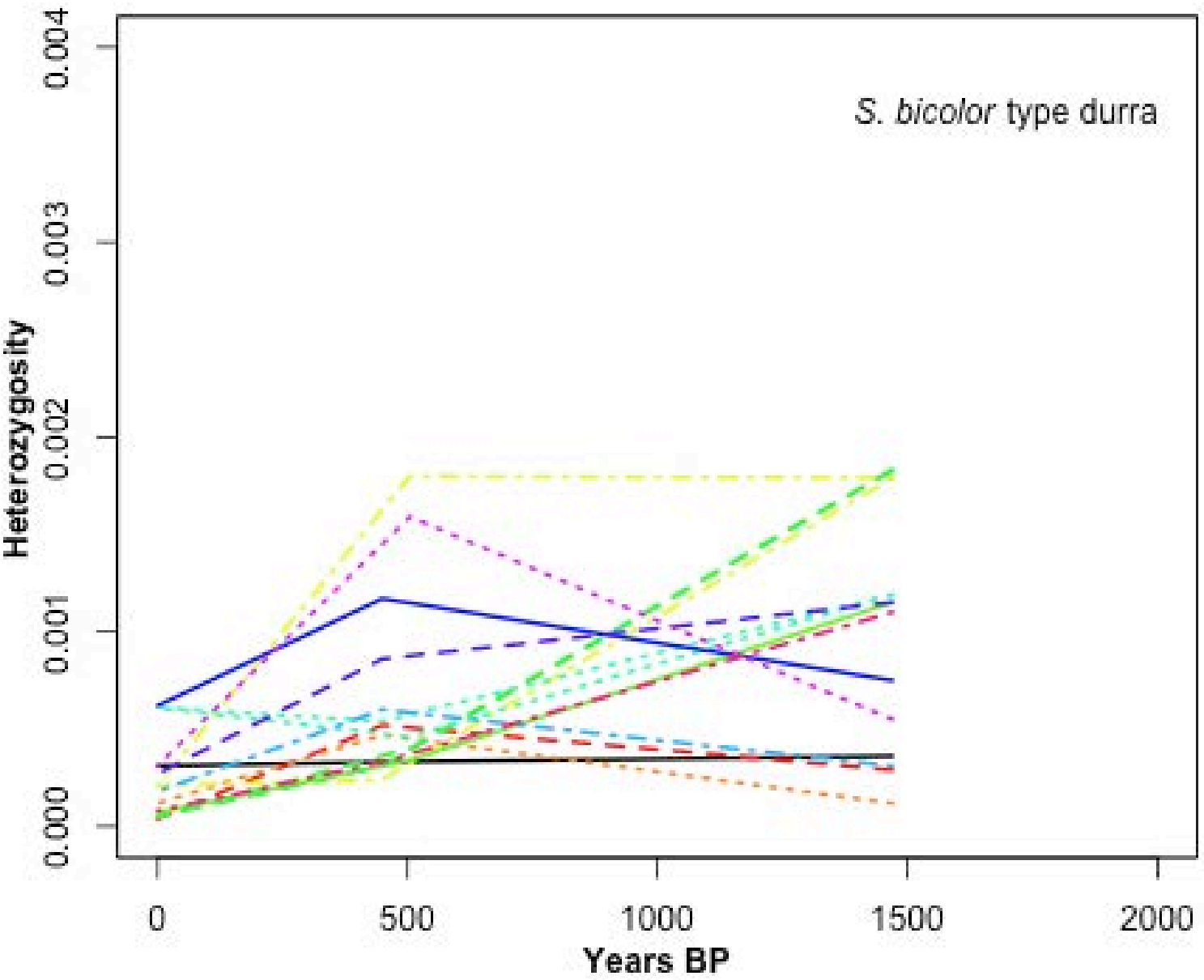

- Genome … ma6

- dw3 -.. Pa1

$\mathrm{dw} 2-\mathrm{SPS} 3$

AE1 - - SUS1

gt1

SUT4

ma3

TB1

Figure S5 


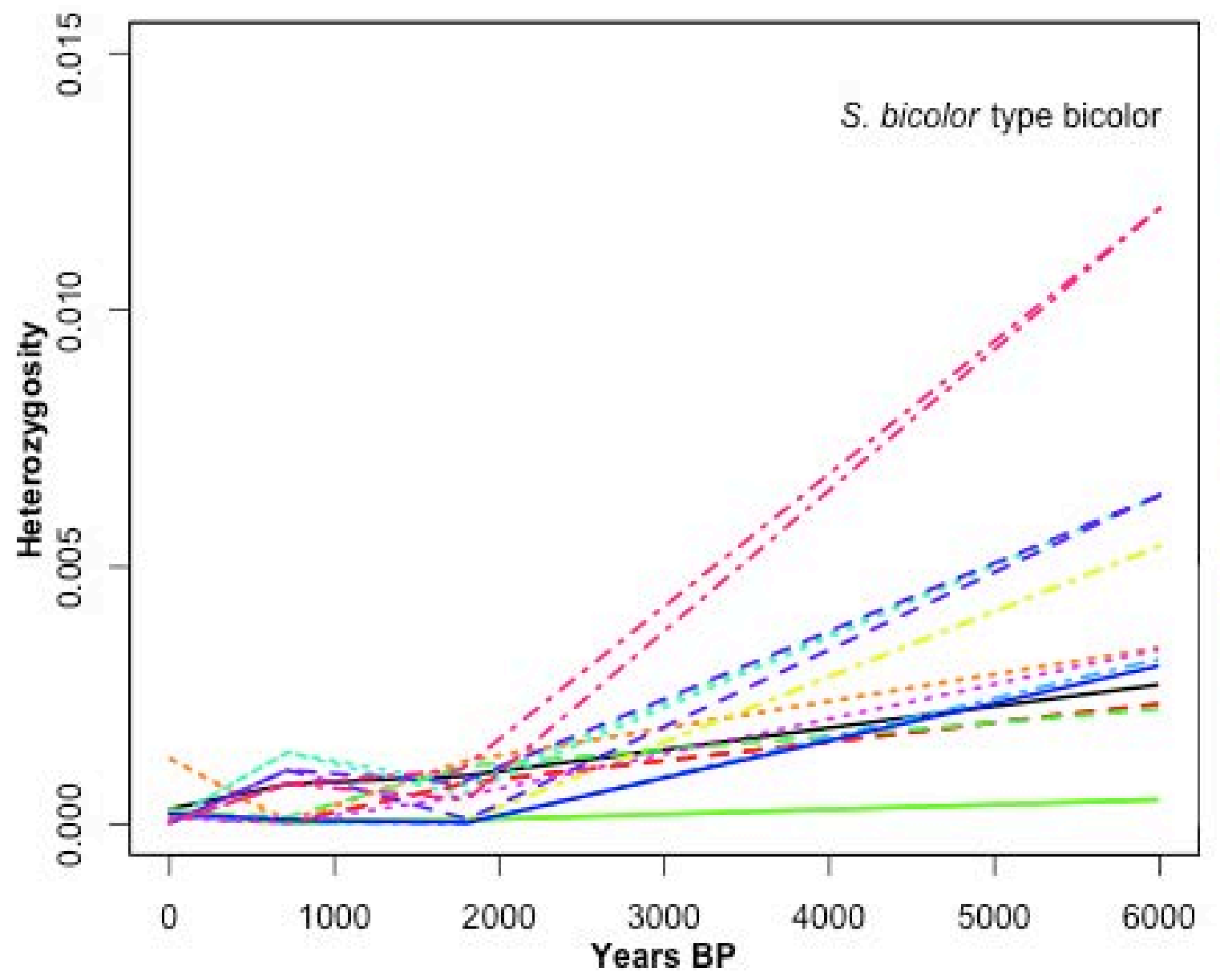

$\begin{aligned} \text { - } & \text { Genome } \\ \ldots & \text { pk4 } \\ & \text { pk5 } \\ & \text { pk15 } \\ & \text { pk16 } \\ \ldots & \text { pk18 } \\ & \text { pk19 } \\ \ldots & \text { pk22 } \\ \ldots & \text { pk24 } \\ \ldots & \text { pk26 } \\ \ldots & \text { pk27 } \\ \ldots & \text { pk28 }\end{aligned}$

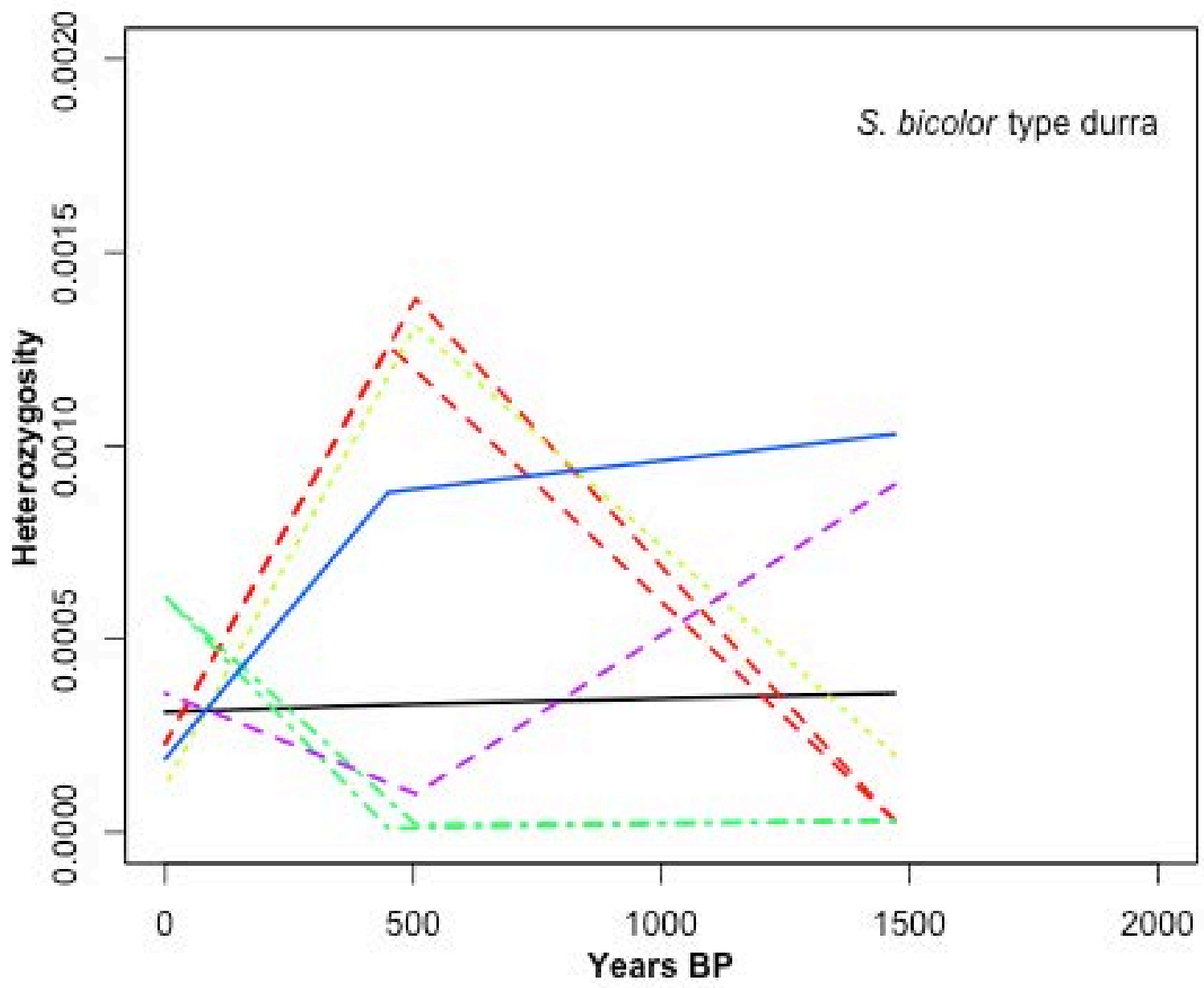



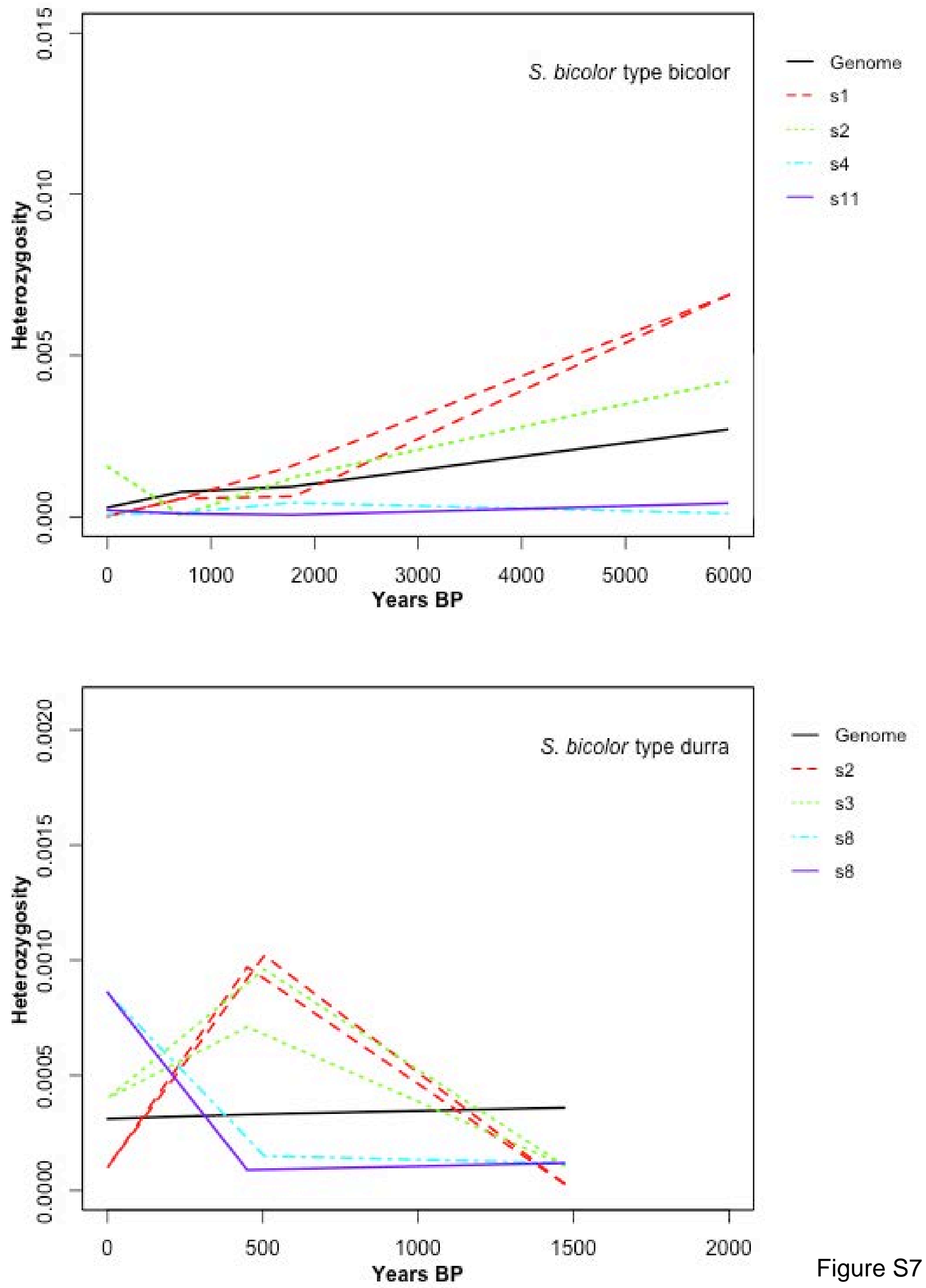


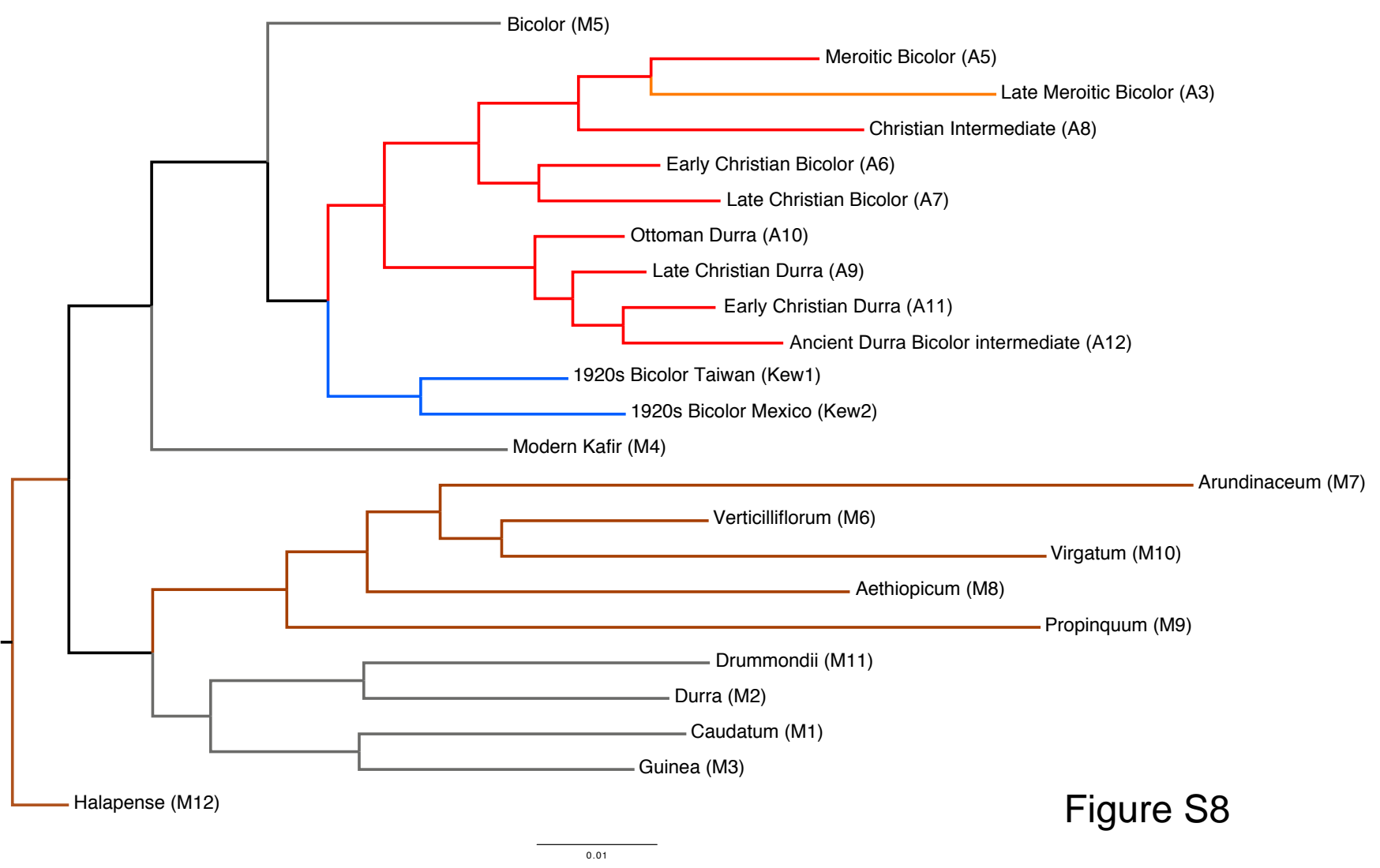


Introgression study - D(BTX_623, Diff.Varieties, A3, S.halapense)
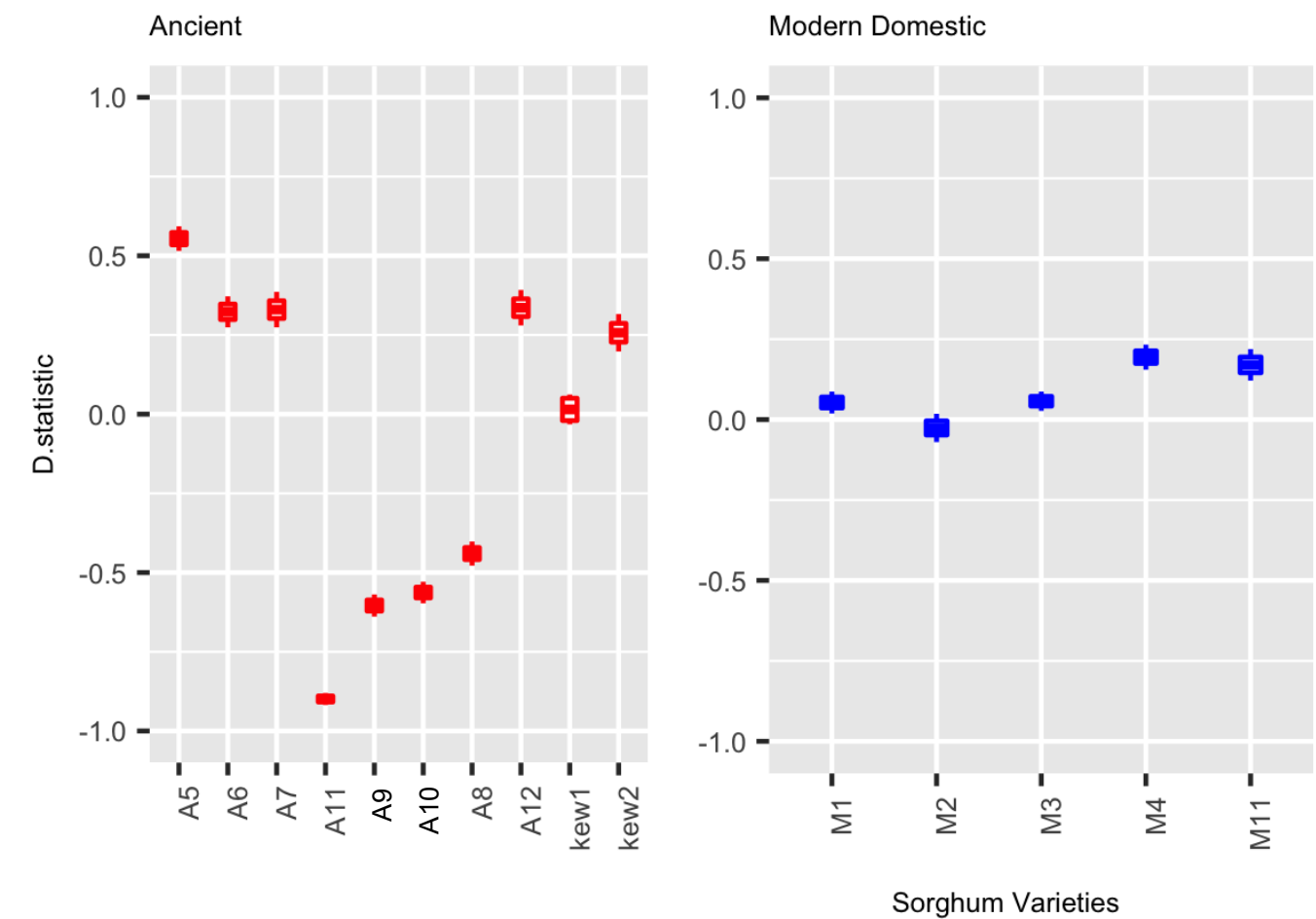

Modern Wild

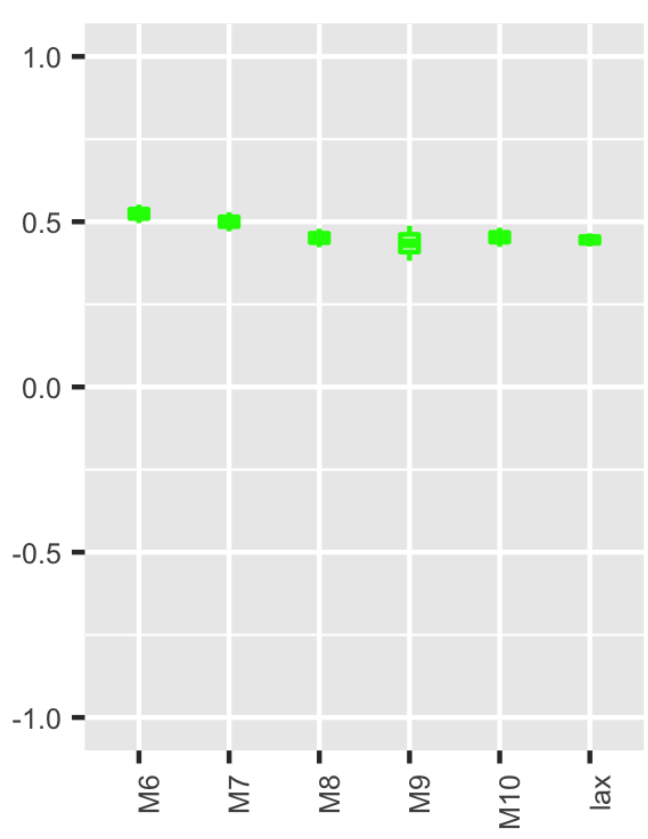

Figure 59 


\section{Figure S10}

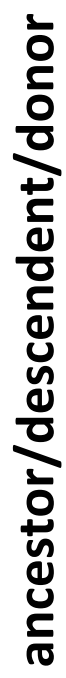

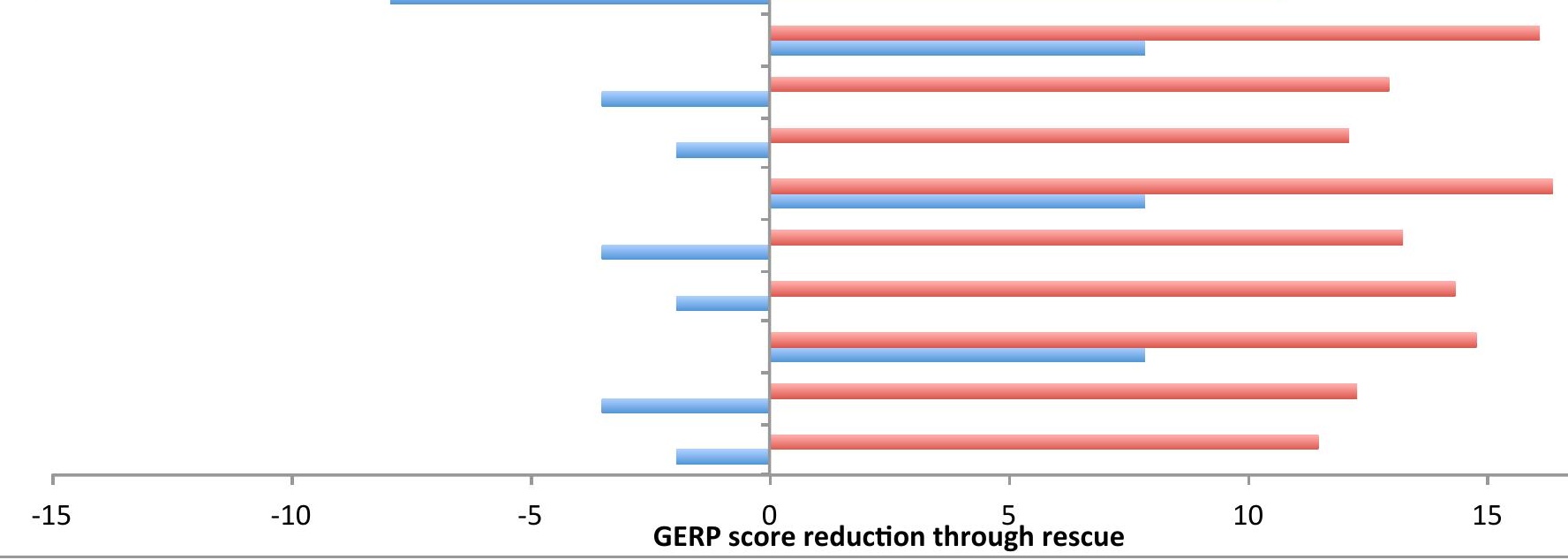

A9/A10/A7

A9/A10/A6

A9/A10/A5

A9/A10/A3

A11/A10/A7

A11/A10/A6

A11/A10/A5

A11/A10/A3

A11/A9/A7

A11/A9/A6

A11/A9/A5

A11/A9/A3

A6/A7/A10

A6/A7/A9

A6/A7/A11 on target rescue

A5/A7/A10

A5/A7/A9

A5/A7/A11

A5/A6/A10

A5/A6/A9

A5/A6/A11

A3/A7/A10

A3/A7/A9

A3/A7/A11

A3/A6/A10

A3/A6/A9

A3/A6/A11

A3/A5/A10

A3/A5/A9

A3/A5/A11 


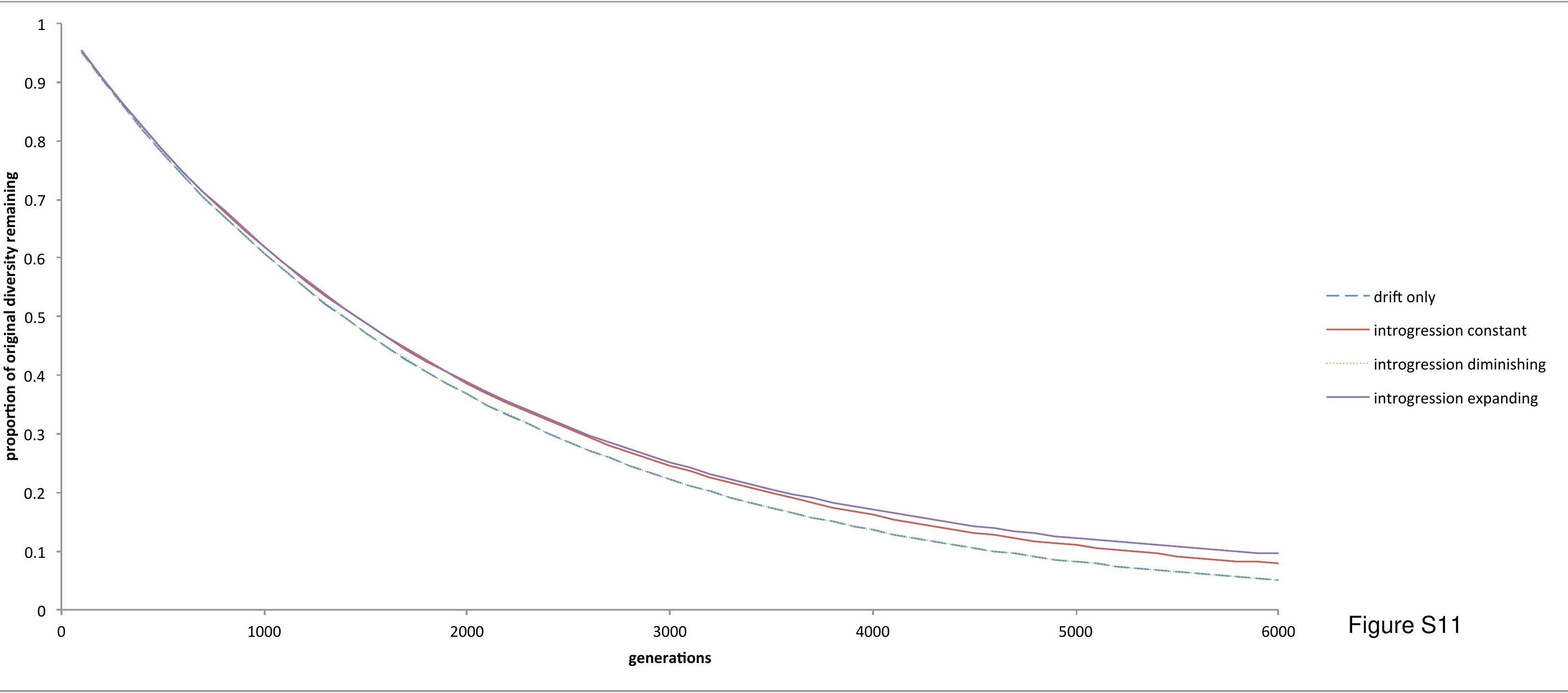




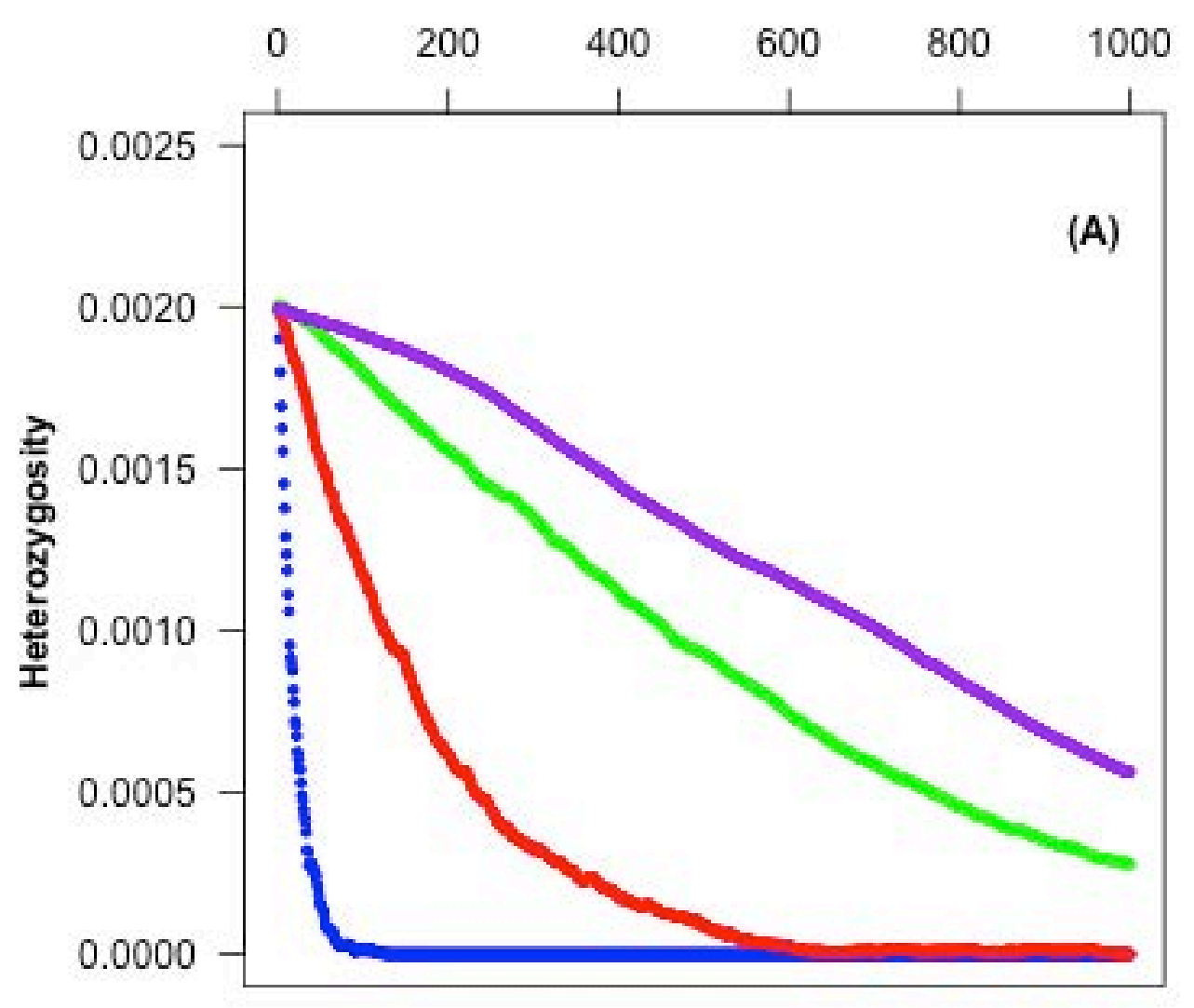

Generations

- $100 \cdot 1000 \cdot 10000 \cdot 100000$

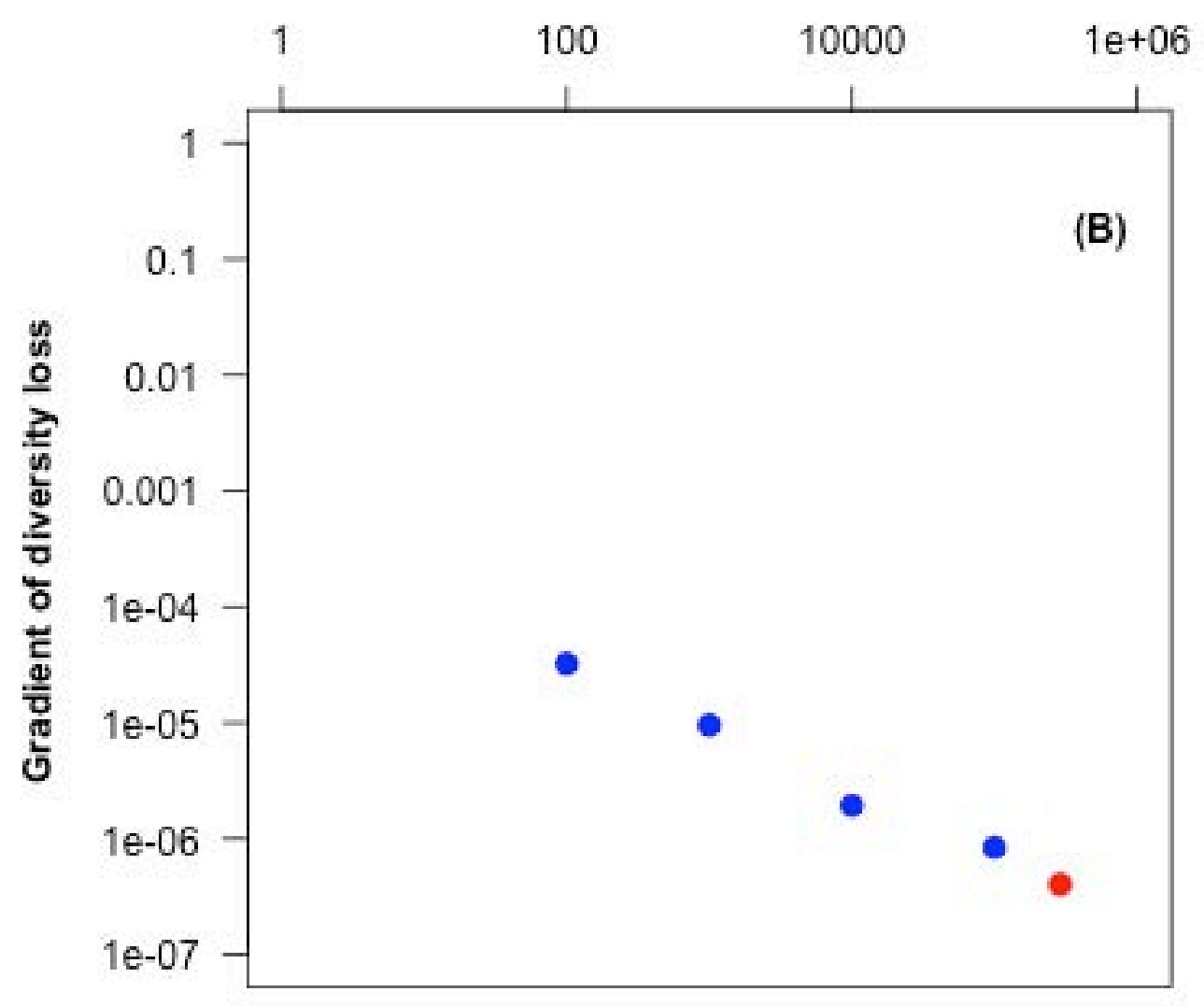

Population size $\mathrm{N}$

Figure S12 • Model Gradient • Sorghum Gradient 